\title{
Penetration of Antibacterial Agents into Pulmonary Epithelial Lining Fluid: An Update
}

\author{
Emily N. Drwiega ${ }^{1} \cdot$ Keith A. Rodvold ${ }^{1,2}$ (D) \\ Accepted: 18 July 2021 / Published online: 15 October 2021 \\ (C) The Author(s), under exclusive licence to Springer Nature Switzerland AG 2021
}

\begin{abstract}
A comprehensive review of drug penetration into pulmonary epithelial lining fluid (ELF) was previously published in 2011. Since then, an extensive number of studies comparing plasma and ELF concentrations of antibacterial agents have been published and are summarized in this review. The majority of the studies included in this review determined ELF concentrations of antibacterial agents using bronchoscopy and bronchoalveolar lavage, and this review focuses on intrapulmonary penetration ratios determined with area under the concentration-time curve from healthy human adult studies or pharmacokinetic modeling of various antibacterial agents. If available, pharmacokinetic/pharmacodynamic parameters determined from preclinical murine infection models that evaluated ELF concentrations are also provided. There are also a limited number of recently published investigations of intrapulmonary penetration in critically ill patients with lower respiratory tract infections, where greater variability in ELF concentrations may exist. The significance of these changes may impact the intrapulmonary penetration in the setting of infection, and further studies relating ELF concentrations to clinical response are needed. Phase I drug development programs now include assessment of initial pharmacodynamic target values for pertinent organisms in animal models, followed by evaluation of antibacterial penetration into the human lung to assist in dosage selection for clinical trials in infected patients. The recent focus has been on $\beta$-lactam agents, including those in combination with $\beta$-lactamase inhibitors, particularly due to the rise of multidrug-resistant infections. This manifests as a large portion of the review focusing on cephalosporins and carbapenems, with or without $\beta$-lactamase inhibitors, in both healthy adult subjects and critically ill patients with lower respiratory tract infections. Further studies are warranted in critically ill patients with lower respiratory tract infections to evaluate the relationship between intrapulmonary penetration and clinical and microbiological outcomes. Our clinical research experience with these studies, along with this literature review, has allowed us to outline key steps in developing and evaluating dosage regimens to treat extracellular bacteria in lower respiratory tract infections.
\end{abstract}

\section{Introduction}

In 2011, two reviews were published in this journal regarding the penetration of anti-infective agents into pulmonary epithelial lining fluid (ELF) [1,2]. A significant number of studies have arisen during the past decade since the determination of ELF concentrations of new antibiotics has become an integral part of phase I drug development programs.

Keith A. Rodvold

kar@uic.edu

1 College of Pharmacy, University of Illinois Chicago, m/c 886, 833 South Wood Street, Room \# 164, Chicago, IL 60612, USA

2 College of Medicine, University of Illinois Chicago, Chicago, IL, USA
Consequently, intrapulmonary penetration studies are often conducted once single and multiple ascending dose studies are completed. This, in combination with initial pharmacodynamic (PD) target values determined from animal models, assists in providing a basis for dosage selection in the treatment of bacterial pneumonia (Fig. 1) [3, 4]. The aims of these studies in healthy adult subjects are to characterize the antibiotic penetration to pulmonary effect sites and provide support for dose selection of future clinical trials in patients with community- or hospital-acquired bacterial pneumonia.

Historically, investigator-initiated studies evaluating intrapulmonary penetration in infected patients frequently involved antibacterial agents that had regulatory approval, been marketed for over a decade, and commonly used in the intensive care unit [3-5]. More recently, manufacturerinitiated intrapulmonary pharmacokinetic (PK) studies are being conducted in critically ill patients as part of phase III 


\section{Key Points}

Intrapulmonary penetration studies in healthy adult subjects are commonly conducted as a phase I clinical trial to assess plasma and epithelial lining fluid concentrations of new antibacterial drug candidates.

In recent years, a significant number of intrapulmonary penetration studies have been conducted with $\beta$-lactam agents, with or without $\beta$-lactamase inhibitors.

The number of intrapulmonary penetration studies of newer agents in critically ill patients are limited, however they have demonstrated greater variability in extent and consistency in epithelial lining fluid penetration compared with healthy subjects.

Pharmacokinetic/pharmacodynamic analysis of plasma and intrapulmonary concentration-time data from preclinical animal models, healthy subjects, and critically ill patients has provided support for evaluating optimal dosing of antibacterial agents for the treatment of pneumonia.

drug development programs [6-8]. These studies are allowing assessment of the wide variability observed in plasma and ELF concentrations in critically ill patients. Such PK studies are likely to have an impact on dose selection, target PD parameters, and susceptibility breakpoints.

Bronchoscopy and bronchoalveolar lavage (BAL) are commonly used methodologies for determining concentrations of antibacterial agents in ELF. These methods have been previously described [1]. In the previous 2011 reviews, ELF to plasma penetration ratio was frequently reported for each sampling time. However, to account for hysteresis and to minimize the issues with single sampling time, changes in penetration ratio over time should be considered [3]. In more recent studies, the ELF to plasma penetration ratio is determined by the ratio of the area under the concentrationtime curve (AUC) values, often determined from the mean site concentration for each sampling time or by population PK analysis of all available plasma and ELF concentrations. In addition, the penetration ratios were calculated assuming no protein binding in ELF (i.e., unbound ELF) and either unbound or total plasma (i.e., dependent on whether plasma protein binding was determined or assumed from previous studies). This methodology does inherently have limitations, including small sample of studies, sampling location with respect to infection site, and determining an AUC based on sampling from different patients. These limitations have been previously described [1,3]. This review presents intrapulmonary penetration ratios in this way except where specified.

The aim of this review was to provide a comprehensive update of the previous assessment of the concentrations of antibacterial agents in ELF and the extent of their intrapulmonary penetration [1]. Literature for this review was obtained through a comprehensive search of MEDLINE from 2011 to 2021 for the drugs included in this review. Product packaging information was also used. Our focus is on human studies that compared ELF with plasma concentrations and determined intrapulmonary penetration ratios from AUC or PK modeling methods. A brief commentary is provided if murine or other animal infection models have quantified ELF concentrations and assisted in determining best $\mathrm{PK} / \mathrm{PD}$ parameters. A discussion is also included regarding recent investigations assessing the penetration of selected antibacterial agents into ELF of critically ill patients with lower respiratory tract infections.
Fig. 1 Preclinical and human pharmacokinetic/pharmacodynamic methods to support dosage selection of antibacterial agents for the treatment of pneumonia. Reprinted with permission from Rizk et al. [4]. $P K$ pharmacokinetic, $P D$ pharmacodynamic, $E L F$ epithelial lining fluid

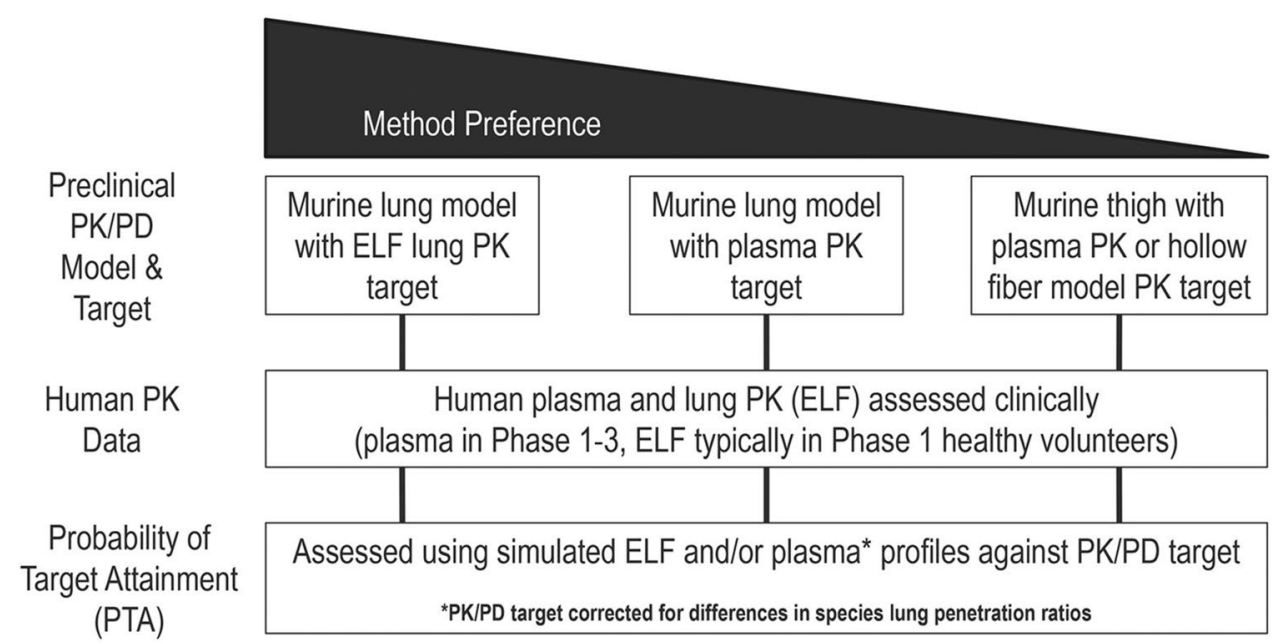




\section{$2 \beta$-Lactam Agents With and Without $\beta$-Lactamase Inhibitors}

In the past 10 years, a significant number of intrapulmonary penetration studies have been conducted with $\beta$-lactam agents. Antibiotic development programs during this time focused on cephalosporins and carbapenems, including combinations with $\beta$-lactamase inhibitors, for the treatment of multidrug-resistant infections. The following sections will review the ELF penetration studies involving $\beta$-lactam agents and the $\beta$-lactamase inhibitor component. The discussion has been separated into investigations involving healthy adult subjects and those evaluating critically ill patients with lower respiratory tract infections. Monte Carlo simulations were also included when population PK analysis and target indexes (e.g., time of unbound drug concentrations are above the minimum inhibitory concentration $[f \mathrm{~T}>\mathrm{MIC}]$ in plasma and ELF for $\beta$-lactams and the duration of time for a fixed concentration for $\beta$-lactamase inhibitors) were incorporated.

\subsection{Healthy Subjects}

Plasma and ELF concentrations in healthy adult subjects for $\beta$-lactams and $\beta$-lactam $/ \beta$-lactamase inhibitor combinations are displayed in Tables 1 and 2, respectively. Penetration ratios were based on values for AUC in ELF (assuming no protein binding) and plasma (accounting for the percentage of plasma protein binding when available).

\subsubsection{Ceftaroline}

Ceftaroline is a broad-spectrum cephalosporin with in vitro activity against both Gram-positive and Gram-negative organisms, including methicillin-resistant Staphylococcus aureus (MRSA) [9]. Ceftaroline fosamil is the prodrug that is converted to the active form, ceftaroline, and is approved in the US for the treatment of acute bacterial skin and skin structure infections and community-acquired bacterial pneumonia [10]. A study comparing ELF and plasma concentrations of ceftaroline was conducted in 50 healthy adult subjects [11]. Ceftaroline fosamil $600 \mathrm{mg}$ was administered as a 1-h intravenous infusion. Half of the subjects were dosed every $12 \mathrm{~h}$ for seven total doses and the other half of the subjects were dosed every $8 \mathrm{~h}$ for 10 total doses. The penetration ratios of ELF to unbound plasma based on ceftaroline AUC were 0.23 and 0.24 in the 12 -h and 8-h dosing groups, respectively, accounting for $20 \%$ protein binding of ceftaroline in plasma (Table 1). In both groups, ceftaroline concentrations in ELF were observed to exceed $1 \mu \mathrm{g} / \mathrm{mL}$ (e.g., US FDA-approved MIC breakpoint of ceftaroline for S. aureus) only 1 and $2 \mathrm{~h}$ after the infusion.
PK data from these 50 subjects were included in a population PK analysis, and the penetration ratio of ELF to unbound plasma concentrations was reported as 0.25 . Simulations were used to assess the achievement of $f \mathrm{~T}>\mathrm{MIC}$ in plasma and ELF. At an MIC of $1 \mu \mathrm{g} / \mathrm{mL}$ for $S$. aureus, approximately $14 \%$ and $53 \%$ of patients receiving ceftaroline fosamil $600 \mathrm{mg}$ every $12 \mathrm{~h}$ and every $8 \mathrm{~h}$, respectively, were predicted to achieve $42 \% f \mathrm{~T}>\mathrm{MIC}$ in ELF. The PK/PD targets used in this target attainment analysis of ceftaroline were derived in a neutropenic murine lung infection model [12]. The required $f \mathrm{~T}>\mathrm{MIC}$ target to produce stasis and a $1-\log$ reduction in colony forming units were $16 \%$ and $41 \%$, respectively, for $S$. aureus isolates with MIC values ranging from 0.5 to $4 \mu \mathrm{g} / \mathrm{mL}$. Ceftaroline concentrations in serum and ELF were similar in magnitude at each sampling time, and no differences in these concentrations were observed in infected and uninfected mice.

\subsubsection{Cefiderocol}

Cefiderocol is a novel siderophore cephalosporin available as an intravenous formulation and is approved in the US for the treatment of adult patients with complicated urinary tract infections, hospital-acquired bacterial pneumonia, and ventilator-associated bacterial pneumonia [13, 14]. A study has assessed plasma and ELF concentrations in 20 healthy adult males after receiving a single dose of cefiderocol $2000 \mathrm{mg}$ as a 1-h intravenous infusion [15]. Samples of BAL were collected at $1,2,4$, and $6 \mathrm{~h}$ after the start of the infusion (Table 1). The concentration-time profile of ELF and plasma concentrations of cefiderocol tended to decrease in a parallel pattern. The intrapulmonary penetration ratio of ELF to total cefiderocol plasma based on $\mathrm{AUC}_{6}$ was 0.101 . When accounting for plasma protein binding of $57.8 \%$, the penetration ratio was 0.24 . The cefiderocol AUC ratios of alveolar macrophage (AM) to plasma were 0.02 and 0.04 based on total drug in plasma and unbound drug in plasma, respectively. These findings lend further support for the continued evaluation of cefiderocol for the treatment of lower respiratory tract infections.

\subsubsection{Doripenem}

Doripenem is a carbapenem available for intravenous administration and is approved by the FDA for the treatment of complicated intra-abdominal infections and complicated urinary tract infections $[16,17]$. A study has assessed plasma and intrapulmonary concentrations in 40 healthy adults after receiving doripenem 500 or $1000 \mathrm{mg}$ every $8 \mathrm{~h}$ as a 4-h intravenous infusion for a total of three doses [18]. Samples of BAL were collected at 3, 4.5, 6, or $8 \mathrm{~h}$. Mean ELF to total 
Table 1 Plasma and epithelial lining fluid concentrations of $\beta$-lactam agents in healthy subjects

\begin{tabular}{|c|c|c|c|c|c|c|c|}
\hline Antibacterial agent & Dosage regimen & Subjects $[n]$ & $\begin{array}{l}\text { Sampling } \\
\text { time }[\mathrm{h}]^{\mathrm{a}}\end{array}$ & $\begin{array}{l}\text { ELF to plasma } \\
\text { ratio based on } \\
\text { AUC }\end{array}$ & $\begin{array}{l}\text { Plasma concentra- } \\
\text { tion }[\mu \mathrm{g} / \mathrm{mL}]^{\mathrm{b}}\end{array}$ & $\begin{array}{l}\text { ELF concentration } \\
{[\mu \mathrm{g} / \mathrm{mL}]^{\mathrm{b}}}\end{array}$ & References \\
\hline \multirow[t]{10}{*}{ Ceftaroline } & \multirow{5}{*}{$\begin{array}{l}600 \mathrm{mg} \text { IV q12h } \times 7 \\
\text { doses }\end{array}$} & 5 & 1 & \multirow[t]{5}{*}{$0.23^{\mathrm{c}}$} & $18.73(14.8,25.7)^{\mathrm{d}}$ & $3.38(2.08,7.63)$ & \multirow[t]{10}{*}[11]{} \\
\hline & & 5 & 2 & & $8.47(5.49,11.4)^{\mathrm{d}}$ & $1.60(1.08,3.45)$ & \\
\hline & & 5 & 4 & & $3.27(2.2,4.9)^{\mathrm{d}}$ & $0.54(0.36,1.26)$ & \\
\hline & & 5 & 8 & & $0.90(0.4,1.2)^{\mathrm{d}}$ & $0.18(0.00,0.22)^{\mathrm{e}}$ & \\
\hline & & 5 & 12 & & $0.27(0.11,0.43)^{\mathrm{d}}$ & $0.00(0.00,0.00)^{\mathrm{f}}$ & \\
\hline & \multirow{5}{*}{$\begin{array}{l}600 \mathrm{mg} \text { IV q8h } \times 10 \\
\text { doses }\end{array}$} & 5 & 1 & \multirow[t]{5}{*}{$0.24^{\mathrm{g}}$} & $21.31(16.7,28.9)^{\mathrm{d}}$ & $3.56(2.69,5.07)$ & \\
\hline & & 5 & 2 & & $9.46(7.85,12.0)^{\mathrm{d}}$ & $2.57(0.61,3.2)$ & \\
\hline & & 5 & 4 & & $3.56(2.85,5.49)^{\mathrm{d}}$ & $0.58(0.39,0.98)$ & \\
\hline & & 5 & 6 & & $1.74(1.28,3.29)^{\mathrm{d}}$ & $0.27(0.17,0.52)$ & \\
\hline & & 5 & 8 & & $0.99(0.20,1.74)^{\mathrm{d}}$ & $0.26(0.00,0.7)^{\mathrm{e}}$ & \\
\hline \multirow[t]{4}{*}{ Cefiderocol } & \multirow[t]{4}{*}{$2000 \mathrm{mg} \mathrm{IV} \times 1$ dose } & 5 & 1 & \multirow[t]{4}{*}{$0.24^{\mathrm{h}}$} & \multirow[t]{4}{*}{$\mathrm{NR}$} & $13.8(26.9)^{\mathrm{i}}$ & \multirow[t]{4}{*}[15]{} \\
\hline & & 5 & 2 & & & $6.69(23.1)^{\mathrm{i}}$ & \\
\hline & & 5 & 4 & & & $2.78(37.2)^{\mathrm{i}}$ & \\
\hline & & 5 & 6 & & & $1.38(11.8)^{\mathrm{i}}$ & \\
\hline \multirow[t]{8}{*}{ Doripenem } & \multirow{4}{*}{$\begin{array}{l}500 \mathrm{mg} \text { IV q8h over } \\
4 \mathrm{~h} \times 3 \text { doses }\end{array}$} & 5 & 3 & \multirow[t]{4}{*}{$0.30^{\mathrm{j}}$} & $7.14 \pm 0.53$ & $2.14 \pm 0.51$ & \multirow[t]{8}{*}{ [18] } \\
\hline & & 5 & 4.5 & & $4.89 \pm 1.51$ & $1.67 \pm 0.55$ & \\
\hline & & 5 & 6 & & $1.63 \pm 0.38$ & $0.93 \pm 0.36$ & \\
\hline & & 5 & 8 & & $0.49 \pm 0.24$ & $0.32 \pm 0.18^{\mathrm{k}}$ & \\
\hline & \multirow{4}{*}{$\begin{array}{l}1000 \mathrm{mg} \text { IV q8h over } \\
4 \mathrm{~h} \times 3 \text { doses }\end{array}$} & 5 & 3 & \multirow[t]{4}{*}{$0.28^{\mathrm{j}}$} & $13.85 \pm 1.26$ & $3.80 \pm 0.66$ & \\
\hline & & 5 & 4.5 & & $10.92 \pm 1.81$ & $3.50 \pm 0.78$ & \\
\hline & & 5 & 6 & & $3.57 \pm 0.31$ & $1.73 \pm 0.51$ & \\
\hline & & 5 & 8 & & $1.06 \pm 0.26$ & $0.53 \pm 0.38$ & \\
\hline
\end{tabular}

$E L F$ epithelial lining fluid, $A U C$ area under the concentration-time curve, $I V$ intravenously, $N R$ not reported, $q x h$ every $x$ hours, $S D$ standard deviation, $C V \%$ percentage coefficient of variation

${ }^{\text {a }}$ Sampling time after the last dose

${ }^{\mathrm{b}}$ Total plasma and ELF concentrations expressed as mean \pm SD or median (minimum, maximum)

${ }^{\mathrm{c}}$ Based on the ratio of $\mathrm{AUC}_{12}$ in $\mathrm{ELF}$ to $\mathrm{AUC}_{12}$ in unbound plasma, assuming $20 \%$ protein binding in plasma

${ }^{\mathrm{d}}$ Median value based on 25 total plasma samples at each sampling time

${ }^{\mathrm{e}}$ Four of five subjects had measurable ceftaroline concentrations at the 8-h sampling time

${ }^{\mathrm{f}}$ No subjects $(n=5)$ had measurable ceftaroline concentrations at the 12-h sampling time

${ }^{g}$ Based on the ratio of $\mathrm{AUC}_{8}$ in ELF to $\mathrm{AUC}_{8}$ in unbound plasma, assuming $20 \%$ protein binding in plasma

${ }^{\mathrm{h}}$ Based on the ratio of $\mathrm{AUC}_{6}$ in $\mathrm{ELF}$ to $\mathrm{AUC}_{6}$ in unbound plasma, assuming $57.8 \%$ protein binding in plasma

${ }^{\mathrm{i}}$ Values expressed as geometric mean (CV\% geometric mean)

${ }^{\mathrm{j}}$ Based on the ratio of $\mathrm{AUC}_{8}$ in $\mathrm{ELF}$ to $\mathrm{AUC}_{8}$ in total plasma

${ }^{\mathrm{k}}$ Four of five subjects had measurable doripenem concentrations at the 8-h sampling time

plasma ratios ranged from 0.30 to 0.62 and 0.28 to 0.53 for patients receiving 500 and $1000 \mathrm{mg}$ doses, respectively (Table 1). The penetration ratio of ELF to total doripenem based on $\mathrm{AUC}_{8}$ were similar ( 0.30 and 0.28 , respectively) for each dosing level. Intrapulmonary penetration into ELF with doripenem is similar to previously reported intrapulmonary penetration with other carbapenem antibiotics [1]. Doripenem concentrations in AM were reported below the quantitative limit of detection.

\subsubsection{Piperacillin/Tazobactam}

Plasma and ELF concentrations of piperacillin/tazobactam and ceftolozane/tazobactam were compared in healthy adult subjects [19]. Twenty-five subjects were assigned to receive three doses of piperacillin/tazobactam $4.5 \mathrm{~g}$ every $6 \mathrm{~h}$ as a 2-h intravenous infusion. The ELF to total plasma ratio based on $\mathrm{AUC}_{6}$ for piperacillin and tazobactam was 0.26 and 0.54 , respectively (Table 2). After accounting for plasma 
protein binding of $30 \%$ for piperacillin, the ELF to unbound plasma penetration ratio was 0.38 . These results were subsequently added to a population PK model and compared with critically ill patients receiving piperacillin/tazobactam, further described below.

\subsubsection{Ceftolozane/Tazobactam}

Ceftolozane is a parenteral cephalosporin with in vitro activity against many Gram-negative organisms, including multidrug-resistant Pseudomonas aeruginosa [20]. The addition of tazobactam improves the antibacterial coverage of ceftolozane against selected Enterobacterales in the presence of selected extended-spectrum $\beta$-lactamases (e.g., TEM-, SHV- and CTX-M-type extended-spectrum $\beta$-lactamases). Ceftolozane/tazobactam has three FDAapproved indications, including complicated urinary tract infections and complicated intra-abdominal infections, at a recommended dosage of $1.5 \mathrm{~g}$ every $8 \mathrm{~h}$ as a 1 -h intravenous infusion, and, more recently, for the treatment of

Table 2 Plasma and epithelial lining fluid concentrations of $\beta$-lactam/ $\beta$-lactamase inhibitor combination products in healthy subjects

\begin{tabular}{|c|c|c|c|c|c|c|c|}
\hline Antibacterial agent & Dosage regimen & Subjects $[n]$ & $\begin{array}{l}\text { Sampling } \\
\text { time }[\mathrm{h}]^{\mathrm{a}}\end{array}$ & $\begin{array}{l}\text { Ratio of ELF to } \\
\text { plasma based on } \\
\text { AUC }\end{array}$ & $\begin{array}{l}\text { Plasma } \\
\text { concentration } \\
{[\mu \mathrm{g} / \mathrm{mL}]^{\mathrm{b}}}\end{array}$ & $\begin{array}{l}\text { ELF concentration } \\
{[\mu \mathrm{g} / \mathrm{mL}]^{\mathrm{b}}}\end{array}$ & References \\
\hline \multirow{10}{*}{$\begin{array}{l}\text { Piperacillin/ } \\
\text { tazobactam }\end{array}$} & \multirow{5}{*}{$\begin{array}{l}\text { Piperacillin } 4 \mathrm{~g} \text { IV } \\
\text { q6h } \times 3 \text { doses }\end{array}$} & 5 & 0.5 & \multirow[t]{5}{*}{$0.26^{\mathrm{c}}$} & $263 \pm 45$ & $58.8 \pm 12.5$ & \multirow[t]{20}{*}{ [19] } \\
\hline & & 5 & 1 & & $152 \pm 24$ & $31.0 \pm 10.9$ & \\
\hline & & 5 & 2 & & $69.5 \pm 19.8$ & $19.7 \pm 9.5$ & \\
\hline & & 5 & 4 & & $14.8 \pm 6.0$ & $6.4 \pm 4.5$ & \\
\hline & & 5 & 6 & & $3.4 \pm 1.1$ & $3.0 \pm 1.0$ & \\
\hline & \multirow{5}{*}{$\begin{array}{l}\text { Tazobactam } 0.5 \mathrm{~g} \text { IV } \\
\text { q6h } \times 3 \text { doses }\end{array}$} & 5 & 0.5 & \multirow[t]{5}{*}{$0.54^{\mathrm{c}}$} & $29.9 \pm 6.1$ & $15.3 \pm 7.8$ & \\
\hline & & 5 & 1 & & $19.0 \pm 2.6$ & $7.2 \pm 2.8$ & \\
\hline & & 5 & 2 & & $9.6 \pm 2.4$ & $5.2 \pm 3.2$ & \\
\hline & & 5 & 4 & & $1.9 \pm 2.4$ & $1.8 \pm 1.2$ & \\
\hline & & 5 & 6 & & $0.7 \pm 0.2$ & $1.0 \pm 1.0$ & \\
\hline \multirow{10}{*}{$\begin{array}{l}\text { Ceftolozane/ } \\
\text { tazobactam }\end{array}$} & \multirow{5}{*}{$\begin{array}{l}\text { Ceftolozane } 1 \mathrm{~g} \mathrm{IV} \\
\mathrm{q} 8 \mathrm{~h} \times 3 \text { doses }\end{array}$} & 5 & 1 & \multirow[t]{5}{*}{$0.48^{\mathrm{d}}$} & $58.5 \pm 7.8$ & $21.8 \pm 6.4$ & \\
\hline & & 5 & 2 & & $34.0 \pm 3.8$ & $14.9 \pm 3.0$ & \\
\hline & & 5 & 4 & & $14.3 \pm 2.4$ & $9.3 \pm 6.0$ & \\
\hline & & 5 & 6 & & $5.5 \pm 1.6$ & $4.9 \pm 2.4$ & \\
\hline & & 5 & 8 & & $3.9 \pm 1.4$ & $4.2 \pm 2.5$ & \\
\hline & \multirow{5}{*}{$\begin{array}{l}\text { Tazobactam } 0.5 \mathrm{~g} \text { IV } \\
\mathrm{q} 8 \mathrm{~h} \times 3 \text { doses }\end{array}$} & 5 & 1 & \multirow[t]{5}{*}{$0.44^{\mathrm{d}}$} & $15.2 \pm 1.9$ & $4.5 \pm 1.1$ & \\
\hline & & 5 & 2 & & $3.9 \pm 0.7$ & $1.7 \pm 0.6$ & \\
\hline & & 5 & 4 & & $0.7 \pm 0.1$ & $0.5 \pm 0.2$ & \\
\hline & & 5 & 6 & & $0.2 \pm 0^{\mathrm{e}}$ & $0.2 \pm 0.1^{\mathrm{f}}$ & \\
\hline & & 5 & 8 & & $B Q L^{g}$ & $0.3 \pm 0.1^{\mathrm{e}}$ & \\
\hline \multirow{16}{*}{$\begin{array}{l}\text { Ceftazidime/ } \\
\text { avibactam }\end{array}$} & \multirow{4}{*}{$\begin{array}{l}\text { Ceftazidime } 2000 \\
\text { mg IV q8h } \times 9 \\
\text { doses }\end{array}$} & 22 & 2 & \multirow[t]{4}{*}{$0.31^{\mathrm{d}}$} & \multirow[t]{4}{*}{ NR } & \multirow[t]{4}{*}{ NR } & \multirow[t]{16}{*}[24]{} \\
\hline & & & 4 & & & & \\
\hline & & & 6 & & & & \\
\hline & & & 8 & & & & \\
\hline & \multirow{4}{*}{$\begin{array}{l}\text { Ceftazidime } 3000 \\
\text { mg IV q8h } \times 9 \\
\text { doses }\end{array}$} & 21 & 2 & \multirow[t]{4}{*}{$0.32^{\mathrm{d}}$} & \multirow[t]{4}{*}{ NR } & \multirow[t]{4}{*}{ NR } & \\
\hline & & & 4 & & & & \\
\hline & & & 6 & & & & \\
\hline & & & 8 & & & & \\
\hline & \multirow{4}{*}{$\begin{array}{r}\text { Avibactam } 500 \mathrm{mg} \\
\text { IV q8h } \times 9 \text { doses }\end{array}$} & 22 & 2 & \multirow[t]{4}{*}{$0.35^{\mathrm{d}}$} & \multirow[t]{4}{*}{ NR } & \multirow[t]{4}{*}{ NR } & \\
\hline & & & 4 & & & & \\
\hline & & & 6 & & & & \\
\hline & & & 8 & & & & \\
\hline & \multirow{4}{*}{$\begin{array}{l}\text { Avibactam } 1000 \mathrm{mg} \\
\text { IV q8h } \times 9 \text { doses }\end{array}$} & 21 & 2 & \multirow[t]{4}{*}{$0.32^{\mathrm{d}}$} & NR & NR & \\
\hline & & & 4 & & & & \\
\hline & & & 6 & & & & \\
\hline & & & 8 & & & & \\
\hline
\end{tabular}


Table 2 (continued)

\begin{tabular}{|c|c|c|c|c|c|c|c|}
\hline Antibacterial agent & Dosage regimen & Subjects $[n]$ & $\begin{array}{l}\text { Sampling } \\
\text { time }[\mathrm{h}]^{\mathrm{a}}\end{array}$ & $\begin{array}{l}\text { Ratio of ELF to } \\
\text { plasma based on } \\
\text { AUC }\end{array}$ & $\begin{array}{l}\text { Plasma } \\
\text { concentration } \\
{[\mu \mathrm{g} / \mathrm{mL}]^{\mathrm{b}}}\end{array}$ & $\begin{array}{l}\text { ELF concentration } \\
{[\mu \mathrm{g} / \mathrm{mL}]^{\mathrm{b}}}\end{array}$ & References \\
\hline \multirow{12}{*}{$\begin{array}{l}\text { Cefepime/ } \\
\text { zidebactam }\end{array}$} & \multirow{6}{*}{$\begin{array}{l}\text { Cefepime } 2 \text { g IV q8h } \\
\times 7 \text { doses }\end{array}$} & 6 & 0.5 & \multirow[t]{6}{*}{$0.39^{\mathrm{d}}$} & $84.06 \pm 17.94$ & $26.31 \pm 9.89$ & \multirow[t]{12}{*}[30]{} \\
\hline & & 5 & 1.25 & & $107.0 \pm 11.03$ & $35.24 \pm 3.89$ & \\
\hline & & 6 & 3 & & $45.97 \pm 6.16$ & $19.77 \pm 3.71$ & \\
\hline & & 6 & 6 & & $14.43 \pm 4.76$ & $7.62 \pm 4.56$ & \\
\hline & & 6 & 8 & & $8.50 \pm 4.34$ & $4.62 \pm 1.63$ & \\
\hline & & 6 & 10 & & $3.73 \pm 2.24$ & $2.18 \pm 0.84$ & \\
\hline & \multirow{6}{*}{$\begin{array}{l}\text { Zidebactam } 1 \text { g IV } \\
\mathrm{q} 8 \mathrm{~h} \times 7 \text { doses }\end{array}$} & 6 & 0.5 & \multirow[t]{6}{*}{$0.38^{\mathrm{d}}$} & $36.03 \pm 6.94$ & $11.41 \pm 4.46$ & \\
\hline & & 5 & 1.25 & & $45.80 \pm 3.29$ & $14.61 \pm 1.87$ & \\
\hline & & 6 & 3 & & $19.65 \pm 3.22$ & $7.59 \pm 1.77$ & \\
\hline & & 6 & 6 & & $5.89 \pm 1.89$ & $2.77 \pm 1.54$ & \\
\hline & & 6 & 8 & & $3.30 \pm 1.65$ & $2.80 \pm 3.27$ & \\
\hline & & 6 & 10 & & $1.55 \pm 0.90$ & $0.74 \pm 0.33$ & \\
\hline \multirow{8}{*}{$\begin{array}{l}\text { Cefepime/ } \\
\text { enmetazobactam }\end{array}$} & \multirow{4}{*}{$\begin{array}{c}\text { Cefepime } 2 \mathrm{~g} \text { IV over } \\
2 \mathrm{~h} \mathrm{q} 8 \mathrm{~h} \times 9 \text { doses }\end{array}$} & 19 & 2 & \multirow[t]{4}{*}{$0.61^{\mathrm{h}}$} & \multirow[t]{4}{*}{ NR } & \multirow[t]{4}{*}{ NR } & \multirow[t]{8}{*}[35]{} \\
\hline & & & 4 & & & & \\
\hline & & & 6 & & & & \\
\hline & & & 8 & & & & \\
\hline & \multirow{4}{*}{$\begin{array}{l}\text { Enmetazobactam } 1 \mathrm{~g} \\
\text { IV over } 2 \mathrm{~h} \mathrm{q} 8 \mathrm{~h} \times \\
9 \text { doses }\end{array}$} & 19 & 2 & \multirow[t]{4}{*}{$0.53^{\mathrm{h}}$} & \multirow[t]{4}{*}{ NR } & \multirow[t]{4}{*}{ NR } & \\
\hline & & & 4 & & & & \\
\hline & & & 6 & & & & \\
\hline & & & 8 & & & & \\
\hline \multirow{10}{*}{$\begin{array}{l}\text { Meropenem/ } \\
\text { vaborbactam }\end{array}$} & \multirow{5}{*}{$\begin{array}{c}\text { Meropenem } 2 \mathrm{~g} \text { IV } \\
\mathrm{q} 8 \mathrm{~h} \times 3 \text { doses }\end{array}$} & 5 & 1.5 & \multirow[t]{5}{*}{$0.63^{\mathrm{d}} / 0.65^{\mathrm{i}}$} & $41.2 \pm 5.02$ & $21.4 \pm 3.96$ & \multirow[t]{10}{*}{ [39] } \\
\hline & & 5 & 3.25 & & $47.7 \pm 7.28$ & $28.3 \pm 6.69$ & \\
\hline & & 5 & 4 & & $23.8 \pm 4.30$ & $16.1 \pm 4.77$ & \\
\hline & & 5 & 6 & & $7.24 \pm 2.79$ & $7.51 \pm 5.29$ & \\
\hline & & 5 & 8 & & $1.36 \pm 0.51$ & $2.51 \pm 1.13$ & \\
\hline & \multirow{5}{*}{$\begin{array}{l}\text { Vaborbactam } 2 \text { g IV } \\
\mathrm{q} 8 \mathrm{~h} \times 3 \text { doses }\end{array}$} & 5 & 1.5 & \multirow[t]{5}{*}{$0.53^{\mathrm{d}} / 0.79^{\mathrm{j}}$} & $42.1 \pm 5.00$ & $18.6 \pm 3.76$ & \\
\hline & & 5 & 3.25 & & $51.1 \pm 6.78$ & $26.1 \pm 7.12$ & \\
\hline & & 5 & 4 & & $28.2 \pm 5.32$ & $15.7 \pm 3.36$ & \\
\hline & & 5 & 6 & & $10.8 \pm 2.82$ & $8.04 \pm 5.81$ & \\
\hline & & 5 & 8 & & $2.74 \pm 1.12$ & $2.61 \pm 1.35$ & \\
\hline \multirow[t]{8}{*}{$\begin{array}{l}\text { Imipenem/ } \\
\text { relebactam }\end{array}$} & \multirow[t]{4}{*}{$\begin{array}{l}\text { Imipenem } 500 \mathrm{mg} \text { IV } \\
\mathrm{q} 6 \mathrm{~h} \times 5 \text { doses }\end{array}$} & 4 & 0.5 & \multirow[t]{4}{*}{$0.44^{\mathrm{k}} / 0.55^{1}$} & \multirow[t]{4}{*}{$\mathrm{NR}$} & $\begin{array}{l}32.09(21.26 \\
48.44)^{\mathrm{m}}\end{array}$ & {$[40]$} \\
\hline & & 4 & 1.0 & & & $\begin{array}{l}20.27(13.43 \\
30.59)^{\mathrm{m}}\end{array}$ & \\
\hline & & 4 & 1.5 & & & $\begin{array}{l}16.47(10.92 \\
24.87)^{\mathrm{m}}\end{array}$ & \\
\hline & & 4 & 3.0 & & & $5.99(3.97,9.04)^{\mathrm{m}}$ & \\
\hline & Relebactam $250 \mathrm{mg}$ & 4 & 0.5 & $0.43^{\mathrm{k}} / 0.54^{\mathrm{l}}$ & NR & $14.93(9.89,22.53)^{\mathrm{m}}$ & \\
\hline & IV q6h × 5 doses & 4 & 1.0 & & & $10.93(7.24,16.50)^{\mathrm{m}}$ & \\
\hline & & 4 & 1.5 & & & $9.49(6.29,14.32)^{\mathrm{m}}$ & \\
\hline & & 4 & 3.0 & & & $4.27(2.83,6.45)^{\mathrm{m}}$ & \\
\hline
\end{tabular}


Table 2 (continued)

\begin{tabular}{|c|c|c|c|c|c|c|c|}
\hline Antibacterial agent & Dosage regimen & Subjects $[n]$ & $\begin{array}{l}\text { Sampling } \\
\text { time }[\mathrm{h}]^{\mathrm{a}}\end{array}$ & $\begin{array}{l}\text { Ratio of ELF to } \\
\text { plasma based on } \\
\text { AUC }\end{array}$ & $\begin{array}{l}\text { Plasma } \\
\text { concentration } \\
{[\mu \mathrm{g} / \mathrm{mL}]^{\mathrm{b}}}\end{array}$ & $\begin{array}{l}\text { ELF concentration } \\
{[\mu \mathrm{g} / \mathrm{mL}]^{\mathrm{b}}}\end{array}$ & References \\
\hline \multirow{10}{*}{$\begin{array}{l}\text { Sulbactam/ } \\
\text { durlobactam }\end{array}$} & \multirow{5}{*}{$\begin{array}{l}\text { Sulbactam } 1 \mathrm{~g} \mathrm{IV} \\
\mathrm{q} 6 \mathrm{~h} \times 3 \text { doses }\end{array}$} & 6 & 1 & \multirow[t]{5}{*}{$0.50^{\mathrm{c}} / 0.81^{\mathrm{n}}$} & $17.28 \pm 2.97$ & $9.22 \pm 2.25$ & \multirow[t]{10}{*}[46]{} \\
\hline & & 6 & 2.5 & & $21.42 \pm 3.31$ & $10.25 \pm 2.29$ & \\
\hline & & 6 & 3.25 & & $12.03 \pm 2.66$ & $5.67 \pm 1.74$ & \\
\hline & & 6 & 4 & & $8.58 \pm 1.90$ & $4.64 \pm 1.56$ & \\
\hline & & 6 & 6 & & $2.24 \pm 1.01$ & $1.27 \pm 0.49$ & \\
\hline & \multirow{5}{*}{$\begin{array}{l}\text { Durlobactam } 1 \mathrm{~g} \mathrm{IV} \\
\mathrm{q} 6 \mathrm{~h} \times 3 \text { doses }\end{array}$} & 6 & 1 & \multirow[t]{5}{*}{$0.37^{\mathrm{c}} / 0.41^{\mathrm{o}}$} & $24.33 \pm 3.35$ & $9.14 \pm 1.51$ & \\
\hline & & 6 & 2.5 & & $31.23 \pm 3.80$ & $10.47 \pm 1.70$ & \\
\hline & & 6 & 3.25 & & $20.78 \pm 4.54$ & $7.14 \pm 1.66$ & \\
\hline & & 6 & 4 & & $15.10 \pm 2.68$ & $6.03 \pm 1.88$ & \\
\hline & & 6 & 6 & & $5.33 \pm 1.80$ & $2.15 \pm 0.78$ & \\
\hline
\end{tabular}

$E L F$ epithelial lining fluid, $A U C$ area under the concentration-time curve, $I V$ intravenously, $B Q L$ below quantitative limit of detection, $N R$ not reported, $S D$ standard deviation, $q x h$ every $x$ hours

${ }^{\text {a }}$ Sampling time after the last dose

${ }^{\mathrm{b}}$ Total plasma and ELF concentrations reported as mean $\pm \mathrm{SD}$

${ }^{\mathrm{c}}$ Based on the ratio of $\mathrm{AUC}_{6}$ in $\mathrm{ELF}$ to $\mathrm{AUC}_{6}$ in total plasma

${ }^{\mathrm{d}}$ Based on the ratio of $\mathrm{AUC}_{8}$ in $\mathrm{ELF}$ to $\mathrm{AUC}_{8}$ in total plasma

${ }^{\mathrm{e}}$ Two of five subjects had concentrations equal to or above the quantitative limit of detection of $0.1 \mu \mathrm{g} / \mathrm{mL}$

${ }^{\mathrm{f}}$ Five of five subjects had concentrations BQL of $0.1 \mu \mathrm{g} / \mathrm{mL}$

${ }^{\mathrm{g}}$ Three of five subjects had concentrations equal to or above the quantitative limit of detection of $1.0 \mathrm{ng} / \mathrm{mL}$

${ }^{\mathrm{h}} \mathrm{Based}$ on the ratio of $\mathrm{AUC}_{24}$ in $\mathrm{ELF}$ to $\mathrm{AUC}_{24}$ in total plasma (calculated from Bayesian posterior estimates)

${ }^{\mathrm{i}}$ Based on the ratio of $\mathrm{AUC}_{8}$ in $\mathrm{ELF}$ to $\mathrm{AUC}_{8}$ in unbound plasma, assuming $2 \%$ protein binding in plasma

${ }^{\mathrm{j}} \mathrm{Based}$ on the ratio of $\mathrm{AUC}_{8}$ in ELF to $\mathrm{AUC}_{8}$ in unbound plasma, assuming 33\% protein binding in plasma

${ }^{\mathrm{k}}$ Based on the ratio of $\mathrm{AUC}_{\infty}$ in ELF to $\mathrm{AUC}_{\infty}$ in total plasma

${ }^{1}$ Based on the ratio of $\mathrm{AUC}_{\infty}$ in ELF to $\mathrm{AUC}_{\infty}$ in unbound plasma, assuming $20 \%$ protein binding in plasma

${ }^{\mathrm{m}}$ Geometric mean (95\% confidence interval) reported in units of $\mu \mathrm{M}$

${ }^{\mathrm{n}}$ Based on the ratio of $\mathrm{AUC}_{6}$ in $\mathrm{ELF}$ to $\mathrm{AUC}_{6}$ in unbound plasma, assuming $38 \%$ protein binding in plasma

${ }^{\circ} \mathrm{Based}$ on the ratio of $\mathrm{AUC}_{6}$ in $\mathrm{ELF}$ to $\mathrm{AUC}_{6}$ in unbound plasma, assuming $10 \%$ protein binding in plasma

hospital-acquired and ventilator-associated bacterial pneumonia at an intravenous dosage of $3.0 \mathrm{~g}$ every $8 \mathrm{~h}$ infused over $1 \mathrm{~h}$. Intrapulmonary penetration of ceftolozane/tazobactam was evaluated in mice [21]. Following an $8 \mathrm{mg} / \mathrm{kg}$ dose of ceftolozane and tazobactam, the ELF to total plasma ratio based on AUC was 0.32 for ceftolozane and 0.45 for tazobactam. In mice, there were no significant differences between ceftolozane and tazobactam PK alone compared with combined administration.

Plasma and ELF concentrations of ceftolozane and tazobactam have been reported for 25 healthy adult subjects assigned to receive three doses of ceftolozane/tazobactam $1.5 \mathrm{~g}$ every $8 \mathrm{~h}$ as a $1-\mathrm{h}$ intravenous infusion [19]. The ELF to total plasma ratio based on $\mathrm{AUC}_{8}$ for ceftolozane and tazobactam was 0.48 and 0.44 , respectively (Table 2 ). After accounting for a plasma protein binding of $20 \%$ for ceftolozane, the ELF to unbound plasma ratio was 0.59 . The observed difference in tazobactam concentrations between piperacillin/tazobactam and ceftolozane/tazobactam was most likely due to differences in measurable concentrations and dosing frequency (i.e., every $6 \mathrm{~h}$ vs. every $8 \mathrm{~h}$ ).

Xiao and colleagues developed a population PK model using this same plasma and ELF data of ceftolozane and tazobactam [22]. The calculated penetration ratios, based on parametric intracompartment clearance parameters, were $52 \%$ for ceftolozane and $46 \%$ for tazobactam. Monte Carlo simulated concentration-time profiles and the probability of target attainment were determined in plasma and ELF for dosage regimens of 1.5 and $3 \mathrm{~g}$ administered as a 1-h intravenous infusion every $8 \mathrm{~h}$. For Enterobacterales and $P$. aeruginosa with MIC values of up to $8 \mu \mathrm{g} / \mathrm{mL}$, the probability of achieving a target attainment of $40 \% f \mathrm{~T}>\mathrm{MIC}$ in ELF was $75 \%$ for the $1.5 \mathrm{~g}$ dose and $95.6 \%$ for the $3 \mathrm{~g}$ dose. These consistent and higher probability of target attainment of the 
$3 \mathrm{~g}$ dose lend support for the dose that was evaluated in the pivotal phase III clinical trial and ultimately recommended for the treatment of hospital-acquired and ventilator-associated bacterial pneumonia in adult patients with a creatinine clearance $>50 \mathrm{~mL} / \mathrm{min}$.

\subsubsection{Ceftazidime/Avibactam}

Ceftazidime/avibactam is the combination of ceftazidime, a third-generation, antipseudomonal cephalosporin, and avibactam, a non- $\beta$-lactam $\beta$-lactamase inhibitor. Multidrugresistant Enterobacterales are an important cause of nosocomial pneumonia. Avibactam restores ceftazidime activity to bacteria producing Ambler class $\mathrm{A}$ and $\mathrm{C} \beta$-lactamases, including extended-spectrum $\beta$-lactamases, and carbapenemases, such as Klebsiella pneumoniae carbapenemases (KPCs) [23]. In a study assessing the interaction between pulmonary surfactant and ceftazidime/avibactam, pulmonary surfactant did not inhibit the in vitro activity of ceftazidime, with or without avibactam, supporting continued investigation for ceftazidime/avibactam for the treatment of pneumonia [23]. A PK study evaluating the penetration of two different doses of ceftazidime/avibactam into ELF was conducted in 42 healthy adults [24]. Subjects received either ceftazidime $2000 \mathrm{mg}$ with avibactam $500 \mathrm{mg}$ or ceftazidime $3000 \mathrm{mg}$ with avibactam $1000 \mathrm{mg}$ administered every $8 \mathrm{~h}$ as a 2-h intravenous infusion for nine doses. In both plasma and ELF, the mean AUC of ceftazidime was approximately 1.5-fold greater in the higher dosing regimen. The intrapulmonary penetration ratio of ceftazidime based on noncompartmental $\mathrm{AUC}_{8}$ calculations for the two doses were similar at 0.31 and 0.32 (Table 2). The mean $\mathrm{AUC}_{8}$ values of avibactam in plasma and ELF, respectively, were 1.98 and 1.81 times higher with the $1000 \mathrm{mg}$ dose compared with the $500 \mathrm{mg}$ dose. The ELF to plasma ratio based on similar AUC calculations for avibactam $500 \mathrm{mg}$ and $1000 \mathrm{mg}$ were 0.35 and 0.32 , respectively. The ratio of ELF to plasma in human subjects was higher than in the murine infection model (i.e., the mean intrapulmonary penetration based on AUC for ceftazidime and avibactam was 0.24 and 0.22 , respectively) [25]. Ceftazidime/avibactam has been approved for hospitalacquired and ventilator-associated bacterial pneumonia for the ceftazidime $2000 \mathrm{mg}$ with avibactam $500 \mathrm{mg}$ dose [26]. The higher dosing regimen of ceftazidime $3000 \mathrm{mg}$ with avibactam $1000 \mathrm{mg}$ was not pursued for approval of use in patients with lower respiratory tract infections.

Subsequently, Dimelow and colleagues used the healthy subject data for ceftazidime and avibactam to develop several population PK models to evaluate non-linear relationships between plasma and ELF concentrations [27]. Different direct response models were used to evaluate ELF penetration, including an effect site equilibration method and a plasma-ELF link function that incorporated proportional, power, or saturable models. Concentration-time profiles were simulated for 1000 subjects receiving ceftazidime 2000 $\mathrm{mg}$ and avibactam $500 \mathrm{mg}$ administered every $8 \mathrm{~h}$ as a 2-h intravenous infusion. A saturable Michaelis-Menten model provided the best description of the non-linear plasma-ELF relationship for ceftazidime (i.e., ELF penetration was higher at low plasma concentrations, but saturable at plasma concentrations $>250 \mu \mathrm{g} / \mathrm{mL}$ ), whereas avibactam was best described with a power model (i.e., lesser degree of a nonlinear plasma-ELF relationship). Overall, the ELF penetration ratio was 0.52 at clinically relevant ELF and plasma concentrations of $8 \mu \mathrm{g} / \mathrm{mL}$ and $15.2 \mu \mathrm{g} / \mathrm{mL}$, respectively. For avibactam, the penetration ratio was 0.47 at ELF and plasma concentrations of $1 \mu \mathrm{g} / \mathrm{mL}$ and $2.4 \mu \mathrm{g} / \mathrm{mL}$, respectively. The ELF concentration-time simulations supported plasma PK/ PD targets of $8 \mu \mathrm{g} / \mathrm{mL}$ and $1 \mu \mathrm{g} / \mathrm{mL}$ for ceftazidime and avibactam, respectively, and the median simulated ELF concentrations were $14.7 \mu \mathrm{g} / \mathrm{mL}$ and $1.4 \mu \mathrm{g} / \mathrm{mL}$.

\subsubsection{Cefepime/Zidebactam}

WCK 5222 is a combination of a cephalosporin, cefepime, and $\beta$-lactam enhancer, zidebactam (formerly known as WCK 5107). Zidebactam is a novel non- $\beta$-lactam bicycloacyl hydrazide that inhibits penicillin-binding protein 2 and $\beta$-lactamases. Cefepime/zidebactam is being studied for the treatment of multidrug resistant Gram-negative infections [28, 29]. Plasma and ELF concentrations of cefepime and zidebactam were compared in adult subjects who received seven doses of WCK 5222 (cefepime $2 \mathrm{~g}$ and zidebactam 1 g) every $8 \mathrm{~h}$ as an intravenous infusion over $1 \mathrm{~h} \mathrm{[30].} \mathrm{Table} 2$ displays the plasma and ELF concentrations for both components. The ratio of ELF to total plasma based on $\mathrm{AUC}_{8}$ values calculated from the mean concentration of cefepime at each BAL sampling time was 0.39. A similar ratio value (0.38) was observed for zidebactam. Cefepime ELF penetration ratios have previously been reported as ranging from 0.99 to 1.12 , however this was in critically ill patients with nosocomial pneumonia receiving continuous infusion cefepime [31]. Concentrations of cefepime and zidebactam in AM were also evaluated. The ratios of AM to total plasma based on $\mathrm{AUC}_{8}$ values for cefepime and zidebactam were 0.27 and 0.10 , respectively. The ratio of ELF to total plasma in human subjects was lower than concentrations in a neutropenic murine lung infection model (i.e., the mean intrapulmonary penetration for cefepime and zidebactam was 0.50 and 0.70 , respectively) [32]. The respective target $\% f \mathrm{~T}>\mathrm{MIC}$ for cefepime when co-administered with zidebactam was $18 \%$, and $31 \%$ for stasis and $1-\log _{10}$ bactericidal activity against metallo- $\beta$-lactamase producing Enterobacterales. A second study using a similar murine lung infection model demonstrated $1-\log _{10}$ to $2-\log _{10}$ bactericidal activity against multidrug resistant $P$. aeruginos with an $\mathrm{MIC} \leq 16 \mu \mathrm{g} / \mathrm{mL}$, 
when ELF concentrations were matched to those observed in healthy subjects [33]. These data support further evaluations of WCK 5999 for the treatment of nosocomial pneumonia caused by multidrug resistant Gram-negative microorganisms.

\subsubsection{Cefepime/Enmetazobactam}

Cefepime/enmetazobactam is a $\beta$-lactam/ $\beta$-lactamase inhibitor combination undergoing clinical investigation for a variety of infections, including nosocomial pneumonia [34]. Enmetazobactam (formerly known as AAI101) is a novel $\beta$-lactamase inhibitor, restoring activity of cefepime against Enterobacterales expressing extended-spectrum $\beta$-lactamases, OXA-48, and AmpC enzymes. While intrapulmonary penetration of cefepime has been previously described, this study represented the first evaluation of enmetazobactam concentrations in ELF from 19 healthy adult subjects [35]. Participants received cefepime $2 \mathrm{~g}$ and enmetazobactam $1 \mathrm{~g}$ simultaneously, every $8 \mathrm{~h}$, as an intravenous infusion over $2 \mathrm{~h}$ for nine doses. A three-compartment population PK model was developed, and Bayesian posterior parameter estimates of each subject were used to determine steady-state $\mathrm{AUC}_{24}$ values. The mean ratios of ELF to total plasma based on these $\mathrm{AUC}_{24}$ values were 0.61 and 0.53 for cefepime and enmetazobactam, respectively (Table 2). A strong correlation $(r=0.916, p<0.001)$ was observed between cefepime and enmetazobactam AUC values in ELF. A slightly higher ratio (i.e., $\mathrm{AUC}_{8}$ ELF to $\mathrm{AUC}_{8}$ total plasma of 0.734 and 0.615 for cefepime and enmetazobactam, respectively) was observed in a neutropenic murine lung infection model using population PK modeling [36]. Additionally, PD targets in ELF were identified and associated with $a \geq 2-\log _{10}$ decline in bacterial burden when $f \mathrm{~T}>\mathrm{MIC}$ for cefepime and $f \mathrm{~T}>2 \mu \mathrm{g} / \mathrm{mL}$ for enmetazobactam were $20 \%$. Monte Carlo simulations for 1000 subjects, using a dosage regimen of cefepime $2 \mathrm{~g}$ and enmetazobactam 1 g every $8 \mathrm{~h}$ and the dual PD targets in ELF, were found to have a $94.4 \%$ and $78.1 \%$ probability of target attainment at MIC values of $8 \mu \mathrm{g} / \mathrm{mL}$ and $16 \mu \mathrm{g} / \mathrm{mL}$, respectively. These results support further development of the combination of cefepime and enmetazobactam for the treatment of nosocomial pneumonia.

\subsubsection{Meropenem/Vaborbactam}

Meropenem is a carbapenem antibiotic with activity against a broad spectrum of aerobic and anaerobic Gram-positive and Gram-negative organisms and is used for a wide variety of severe infections. Vaborbactam (formerly known as RPX7009) is a non- $\beta$-lactam, cyclic boronic acid-based $\beta$-lactamase inhibitor, currently approved in the US as a fixed-dose combination with meropenem for the treatment of complicated urinary tract infections. Vaborbactam has inhibitory activity against serine $\beta$-lactamases belonging to Amber classes A and C, including KPC-producing Enterobacterales [37]. The in vitro antibacterial potency of meropenem and meropenem/vaborbactam was not affected by bovine pulmonary surfactant [38].

Wenzler and colleagues compared the plasma, ELF, and AM concentrations of the combination product meropenem/ vaborbactam [39]. Healthy adults received three doses of meropenem $2 \mathrm{~g}$ in fixed-dose combination with vaborbactam $2 \mathrm{~g}$ every $8 \mathrm{~h}$ as a 3 -h intravenous infusion. Plasma and ELF concentrations of meropenem and vaborbactam are reported in Table 2. The $\mathrm{AUC}_{8}$ (based on mean concentrations at the BAL sampling times) of meropenem in ELF was $111.7 \mu \mathrm{g} \cdot \mathrm{h} /$ $\mathrm{mL}$ and the $\mathrm{AUC}_{8}$ ratio of ELF to total plasma was 0.63. The mean ratios of ELF to unbound plasma concentrations at the BAL sampling times of meropenem ranged from 0.525 to 2.13. The $\mathrm{AUC}_{8}$ of vaborbactam in ELF was $105.1 \mu \mathrm{g} \cdot \mathrm{h} / \mathrm{mL}$, and the $\mathrm{AUC}_{8}$ ratio of ELF to total plasma for vaborbactam was 0.53 . When accounting for $33 \%$ protein binding, this ratio increased to 0.79 . The range for mean ratios of vaborbactam ELF concentrations to unbound plasma concentrations at the BAL sampling times was 0.45-1.01.

The AM concentrations of meropenem and vaborbactam were also evaluated in this study [39]. The median AM concentrations of vaborbactam at BAL sampling times ranged from 2.28 to $6.94 \mu \mathrm{g} / \mathrm{mL}$, while the mean ratios of vaborbactam AM to plasma concentrations ranged from 0.06 to 2.58. However, the AM concentrations for meropenem were below the lower limit of quantification at all sampling times. Given that meropenem AM concentrations were unable to be detected, the clinical significance of the AM concentrations of the $\beta$-lactamase inhibitor vaborbactam are unknown.

\subsubsection{Imipenem/Relebactam}

Imipenem is a carbapenem antibiotic co-formulated at a 1:1 ratio with cilastatin, an inhibitor of renal dipeptidase. Imipenem has broad spectrum activity against aerobic and anaerobic Gram-positive and Gram-negative bacteria and is used for serious hospital-acquired infections. Relebactam (formerly known as MK-7655) is a non- $\beta$-lactam, bicyclic diazabicyclooctane $\beta$-lactamase inhibitor and exhibits activity against Ambler Class A and C $\beta$-lactamase enzymes produced by Gram-negative bacilli [37]. Imipenem/cilastatin/ relebactam has three FDA-approved indications, including treatment of complicated urinary tract infections, complicated intra-abdominal infections, and hospital-acquired and ventilator-associated bacterial pneumonia. The recommended dosage is $1.25 \mathrm{~g}$ (imipenem $500 \mathrm{mg}$, cilastatin 500 $\mathrm{mg}$, relebactam $250 \mathrm{mg}$ ) every $6 \mathrm{~h}$ as a 30-min intravenous infusion. 
Plasma and ELF concentrations for imipenem and relebactam were evaluated in a phase I study of 16 healthy adult subjects receiving imipenem/cilastatin $(500 \mathrm{mg}$ of each component) in combination with relebactam $250 \mathrm{mg}$ every $6 \mathrm{~h}$ as an intravenous infusion over $30 \mathrm{~min}$ [40]. Participants received five doses and BAL collection period was limited to $3 \mathrm{~h}$ after the last dose (Table 2). Like other carbapenems, imipenem concentrations in ELF were lower than concurrent plasma concentrations at each sampling time. The imipenem and relebactam penetration ratios for ELF to unbound plasma based on $\mathrm{AUC}_{\infty}$ were 0.55 and 0.54 , respectively. In addition, a population PK model using unbound plasma concentrations and a time-invariant partition coefficient value of 0.55 best fit the ELF data, consistent with penetration ratios. Van Hasselt and colleagues have previously reported a pooled population PK model to quantify total plasma concentrations and ELF penetration of imipenem [41]. Penetration of imipenem and relebactam into AM was lower than observed for ELF. Most of the AM concentrations for imipenem were below the lower limit of detection and were therefore not reported. Geometric mean ratios for AM to plasma concentrations of relebactam ranged from 0.14 to 0.51 and increased over the sampling times of $0.5-3 \mathrm{~h}$. The relebactam penetration ratio of AM to unbound plasma based on $\mathrm{AUC}_{\infty}$ was 0.36 . These data provided support for the dosage regimens of imipenem/cilastatin/relebactam using the phase III clinical trial for the treatment of bacterial pneumonia $[42,43]$.

\subsubsection{Sulbactam/Durlobactam (Formerly ETX2514SUL)}

Sulbactam is a $\beta$-lactamase inhibitor with intrinsic activity against Acinetobacter baumannii, and has been approved for use in the US as a combination product with ampicillin. Durlobactam (formerly known as ETX2514) is a novel $\beta$-lactamase inhibitor with broad spectrum in vitro activity against Ambler class A, C, and D $\beta$-lactamase enzymes [44]. $\beta$-lactamase inhibition accomplished by durlobactam restores sulbactam activity against carbapenem-resistant $A$. baumannii [45]. Intrapulmonary concentrations of sulbactam and durlobactam were compared in 30 adult healthy subjects who received three doses of concurrent administration of sulbactam $1 \mathrm{~g}$ and durlobactam $1 \mathrm{~g}$ every $6 \mathrm{~h}$ as a 3-h intravenous infusion [46]. Plasma (total) and ELF concentrations for both components are shown in Table 2. The $\mathrm{AUC}_{6}$ values of plasma and ELF based on mean sulbactam concentrations at the BAL sampling times were $67.89 \mu \mathrm{g} \cdot \mathrm{h} /$ $\mathrm{mL}$ and $34.7 \mu \mathrm{g} \cdot \mathrm{h} / \mathrm{mL}$, respectively. The penetration ratio for ELF to total plasma based on these $\mathrm{AUC}_{6}$ values was 0.5 . This ratio increases to 0.81 when unbound plasma concentrations of sulbactam are used. For durlobactam, $\mathrm{AUC}_{6}$ values of total plasma and ELF concentrations were 109.05 $\mu \mathrm{g} \cdot \mathrm{h} / \mathrm{mL}$ and $40.1 \mu \mathrm{g} \cdot \mathrm{h} / \mathrm{mL}$, respectively. The ratio of ELF to total plasma based on $\mathrm{AUC}_{6}$ values was 0.37 . Durlobactam is not significantly protein bound (approximately $10 \%$ ), therefore the ratio of ELF to unbound durlobactam in plasma increased to 0.41 . These findings support the further exploration of sulbactam/durlobactam for the treatment of lower respiratory tract infections caused by $\beta$-lactamase-producing A. baumannii. While AM concentrations were evaluated in this study for both sulbactam and durlobactam, the AUC ratios were not presented as concentrations were low and were generally consistent across the 6-h interval.

\subsection{Critically III Patients}

Concerns continue to exist on whether intrapulmonary penetration studies in healthy subjects are reflective of the time course, pattern, and/or magnitude of ELF concentrations in serious ill patients with lower respiratory tract infections [3]. During the past 10 years, several PK studies and data analyses have attempted to provide further insight into the differences in ELF concentration-time profiles between healthy subjects and critically ill patients with pulmonary infections. This section reviews the plasma and ELF concentrations in critically ill patients for the most commonly studied antibiotics, $\beta$-lactams, and $\beta$-lactam $\beta$-lactamase inhibitor combinations.

\subsubsection{Piperacillin/Tazobactam}

Steady-state plasma and ELF concentrations of piperacillin and tazobactam in critically ill patients with nosocomial pneumonia have previously been reviewed [1]. Since then, Felton and colleagues assessed steady-state piperacillin/ tazobactam PK in 17 critically ill patients [47]. Intubated patients with pneumonia received piperacillin $4 \mathrm{~g}$ combined with tazobactam $0.5 \mathrm{~g}$ every 8 or $12 \mathrm{~h}$ based on renal function. A population PK analysis was conducted based on 128 plasma and 31 ELF samples. Bayesian posterior parameter estimates were used to determine AUC in plasma and ELF for each patient. The median penetration ratios $\left(\mathrm{AUC}_{\mathrm{ELF}} /\right.$ $\mathrm{AUC}_{\text {unbound plasma }}$ ) for piperacillin and tazobactam were 0.49 (range 0.02-5.16) and 1.21 (range 0.11-3.91), respectively (Table 3 ). The observed high variability could not be explained by relationships of pulmonary permeability and antibiotic concentrations in plasma or ELF. The probability of achieving PD targets to treat an organism with an MIC of $1 \mu \mathrm{g} / \mathrm{mL}$ and $16 \mu \mathrm{g} / \mathrm{mL}$ were estimated using a 5000-subject Monte Carlo simulation. For empirical administration of a piperacillin dosage regimen of $4 \mathrm{~g}$ every $8 \mathrm{~h}$ infused intravenously over $30 \mathrm{~min}$, both unbound plasma and ELF concentrations would achieve $50 \%$ and $100 \% \mathrm{~T}>\mathrm{MIC}$ in an estimated $96 \%$ and $77 \%$ of patients, respectively. However, suppression of the emergence of resistance (based on $C_{\min } / \mathrm{MIC}>3.4$, where $C_{\min }$ is the minimum concentration) 
occurred in only $38-41 \%$ of patients. The probability of achieving 50\% and $100 \% \mathrm{~T}>\mathrm{MIC}$, when the MIC is $16 \mu \mathrm{g} /$ $\mathrm{mL}$, was $54 \%$ and $20 \%$, respectively. $C_{\min } / \mathrm{MIC}>3.4$ only occurred in $6 \%$ of patients. Individualization of dosage regimens for piperacillin/tazobactam may be required in order to optimize plasma and ELF concentrations in critically ill patients.

A population PK analysis was conducted using previously published serum and ELF concentrations of piperacillin to determine and compare intrapulmonary penetration of 25 healthy adult subjects and 53 critically ill patients [48]. The piperacillin dose studied in healthy subjects was $4 \mathrm{~g}$ every $6 \mathrm{~h}$ for three doses, whereas critically ill patients received 4 $\mathrm{g}$ every $8 \mathrm{~h}$ as a 5 - or 30-min infusion, or $12-16 \mathrm{~g} /$ day as a continuous intravenous infusion. Although all participants had received the combination product piperacillin/tazobactam, only data for piperacillin were included in this analysis. The critically ill patients had higher median serum (304.2 vs. $238.4 \mu \mathrm{g} \bullet \mathrm{h} / \mathrm{mL}$ ) and ELF (173.5 vs. $78.8 \mu \mathrm{g} \bullet \mathrm{h} / \mathrm{mL}$ ) AUC values than the healthy subjects, with the respective interquartile ranges (IQR) being six times $(331.7 \mu \mathrm{g} \bullet \mathrm{h} / \mathrm{mL}$ vs. $48.3 \mu \mathrm{g} \bullet \mathrm{h} / \mathrm{mL})$ and four times $(218.7 \mu \mathrm{g} \bullet \mathrm{h} / \mathrm{mL}$ vs. 51.3 $\mu \mathrm{g} \bullet \mathrm{h} / \mathrm{mL}$ ) greater in patients. When a 5000 -subject Monte Carlo simulation was conducted based on the PK data, the median (IQR) intrapulmonary penetration ratios based on AUC from 18 to $24 \mathrm{~h}\left(\mathrm{AUC}_{18-24}\right)$ were 0.33 (0.18) and 0.54 (0.51) for healthy subjects and critically ill patients, respectively. Assessment of target attainment for a dosage regimen of $4 \mathrm{~g}$ of piperacillin every $8 \mathrm{~h}$ as a 30-min intravenous infusion predicted $>95 \%$ of healthy subjects and patients had adequate exposure in both serum and ELF to treat organisms with an MIC of $1 \mu \mathrm{g} / \mathrm{mL}$. Approximately $50 \%$ of critically ill patients had appropriate serum and ELF concentrations of piperacillin to treat an organism with a MIC value of 16 $\mu \mathrm{g} / \mathrm{mL}$. However, predicted piperacillin concentrations in healthy subjects would result in an inadequate exposure at this MIC value. While the median penetration ratio in critically ill patients was considerably greater than in healthy subjects, the marked variability of serum and lung concentrations in critically ill patients must be considered when designing dosage regimens based on PK and penetration data from healthy subjects.

\subsubsection{Ceftazidime}

The intrapulmonary penetration and ELF concentrations of ceftazidime in critically ill patients have been previously reviewed [1, 49]. Prior studies administered ceftazidime as either a single intramuscular injection or by continuous intravenous infusion. Cousson and colleagues compared plasma and ELF concentrations of ceftazidime in 34 mechanically ventilated patients with pneumonia [50]. Patients were randomized to receive ceftazidime as either a
$20 \mathrm{mg} / \mathrm{kg}$ intravenous bolus over $30 \mathrm{~min}$ followed by a continuous intravenous infusion of $60 \mathrm{mg} / \mathrm{kg} /$ day or intermittent intravenous infusions of $20 \mathrm{mg} / \mathrm{kg}$ over $30 \mathrm{~min}$ every $8 \mathrm{~h}$. Serial plasma concentrations of ceftazidime were collected over the first $48 \mathrm{~h}$ of therapy and a single BAL was performed at $44 \mathrm{~h}$ after the start of ceftazidime administration. The median $\mathrm{AUC}_{48}$ for total plasma was $1348 \mu \mathrm{g} \cdot \mathrm{h} / \mathrm{mL}$ and $1361 \mu \mathrm{g} \cdot \mathrm{h} / \mathrm{mL}$ in the continuous infusion and intermittent infusion groups, respectively. The respective median ELF concentration and ELF to total plasma penetration ratio were $12 \mu \mathrm{g} / \mathrm{mL}$ and 0.42 in the continuous infusion group and 6 $\mu \mathrm{g} / \mathrm{mL}$ and 0.44 in the intermittent infusion group (Table 3). These results suggest higher intrapulmonary exposure when ceftazidime is administered by continuous infusion. In addition, the dosage regimen evaluated in this study resulted in higher intrapulmonary ceftazidime exposures than previously reported (e.g., mean ELF concentration of $8.2 \mu \mathrm{g} /$ $\mathrm{mL}$ and intrapulmonary penetration of 0.206 ) in critically ill adult patients receiving ceftazidime $4 \mathrm{~g}$ /day for the treatment of severe bacterial pneumonia [51].

\subsubsection{Cefiderocol}

The ELF penetration of cefiderocol was evaluated in seven mechanically ventilated patients with pneumonia. Adult patients were administered cefiderocol $2 \mathrm{~g}$ (or $1.5 \mathrm{~g}$ if renally impaired) every $8 \mathrm{~h}$ as a 3 -h intravenous infusion (or every $6 \mathrm{~h}$ if the patient had augmented renal function [estimated creatinine clearance $>120 \mathrm{~mL} / \mathrm{min}$ ]) [52]. Total plasma and ELF concentrations of cefiderocol after the start of the infusion are reported in Table 3. The geometric mean (range) for ELF to unbound plasma concentration ratios at $3 \mathrm{~h}(n=4)$ and $5 \mathrm{~h}(n=3)$ were $0.211(0.090-0.422)$ and $0.547(0.443-0.822)$. These ratios were approximately twoto fourfold higher than observed in healthy subjects receiving a single $2 \mathrm{~g}$ dose of cefiderocol infused intravenously over $1 \mathrm{~h}$ [15]. These results suggest higher ELF exposures of cefiderocol in patients with pneumonia compared with healthy subjects.

\subsubsection{Ceftolozane/Tazobactam}

Plasma and ELF penetration was evaluated in 26 ventilated critically ill patients receiving ceftolozane/tazobactam [53]. Participants received four to six doses of ceftolozane/ tazobactam 3 g every $8 \mathrm{~h}$ administered as a 1 -h intravenous infusion. A reduced dose was administered in patients with creatinine clearance $<50 \mathrm{~mL} / \mathrm{min}$ or $<30 \mathrm{~mL} / \mathrm{min}$, respectively (Table 3). The penetration ratios for ELF to unbound plasma (i.e., $21 \%$ and $30 \%$ plasma protein binding assumed for ceftolozane and tazobactam, respectively) were 0.50 for ceftolozane and 0.62 for tazobactam, based on $\mathrm{AUC}_{8}$ values calculated from the geometric means of ELF concentrations 
Table 3 Plasma and epithelial lining fluid concentrations of $\beta$-lactams in critically ill patients

\begin{tabular}{|c|c|c|c|c|c|c|c|}
\hline $\begin{array}{l}\text { Antibacterial } \\
\text { agent }\end{array}$ & Dosage regimen & Patients $[n]$ & $\begin{array}{l}\text { Sampling time } \\
{[h]^{\mathrm{a}}}\end{array}$ & $\begin{array}{l}\text { ELF to plasma } \\
\text { ratio based on } \\
\text { AUC }\end{array}$ & $\begin{array}{l}\text { Plasma concentra- } \\
\text { tion }[\mu \mathrm{g} / \mathrm{mL}]^{\mathrm{b}}\end{array}$ & $\begin{array}{l}\text { ELF concentra- } \\
\text { tion }[\mu \mathrm{g} / \mathrm{mL}]^{\mathrm{b}}\end{array}$ & References \\
\hline \multirow[t]{2}{*}{$\begin{array}{l}\text { Piperacillin/ } \\
\text { tazobactam }\end{array}$} & $\begin{array}{l}\text { Piperacillin } 4 \mathrm{~g} \mathrm{IV} \\
\text { over } 30 \mathrm{~min} \mathrm{q} 8 \mathrm{~h} \\
\left(\mathrm{q} 12 \mathrm{~h} \text { if } \mathrm{CL}_{\mathrm{CR}}\right. \\
<20 \mathrm{~mL} / \mathrm{min})\end{array}$ & 16 & $\begin{array}{l}\text { Between } 7.88 \text { and } \\
148.33^{c}\end{array}$ & $0.49^{\mathrm{d}}$ & $\begin{array}{l}\text { Range: } 5.26- \\
241.62\end{array}$ & $\begin{array}{l}\text { Range: } 0.14- \\
295.43\end{array}$ & [47] \\
\hline & $\begin{array}{l}\text { Tazobactam } 0.5 \mathrm{~g} \\
\text { IV over } 30 \mathrm{~min} \\
\mathrm{q} 8 \mathrm{~h}(\mathrm{q} 12 \mathrm{~h} \text { if } \\
\mathrm{CL}_{\mathrm{CR}}<20 \mathrm{~mL} / \\
\text { min) }\end{array}$ & 16 & $\begin{array}{l}\text { Between } 7.88 \text { and } \\
148.33^{\mathrm{c}}\end{array}$ & $1.21^{\mathrm{d}}$ & $\begin{array}{l}\text { Range: } 3.24- \\
33.90\end{array}$ & $\begin{array}{l}\text { Range: } 0.62- \\
\quad 62.48\end{array}$ & \\
\hline \multirow[t]{2}{*}{ Ceftazidime } & $\begin{array}{l}\text { Intermittent infu- } \\
\text { sion: } 20 \mathrm{mg} / \mathrm{kg} \\
\text { IV over } 30 \mathrm{~min} \\
\text { q8h }\end{array}$ & 17 & $44^{e}$ & ND & 95 and $6^{f}$ & 6.0 & {$[50]$} \\
\hline & $\begin{array}{l}\text { CI: } 20 \mathrm{mg} / \mathrm{kg} \text { IV } \\
\text { over } 30 \mathrm{~min} \\
\text { loading dose, } \\
\text { followed by } \\
60 \mathrm{mg} / \mathrm{kg} / \text { day } \\
\text { IV CI }\end{array}$ & 17 & $44^{\mathrm{e}}$ & ND & 27.0 & 12.0 & \\
\hline \multirow[t]{4}{*}{ Cefiderocol } & \multirow{4}{*}{$\begin{array}{l}2 \mathrm{~g} \mathrm{IV}(1.5 \\
\mathrm{g} \text { if renally } \\
\text { impaired) over } \\
3 \mathrm{~h} \text { q8h }(\mathrm{q} 6 \mathrm{~h} \text { if } \\
\mathrm{CL}_{\mathrm{CR}}>120 \mathrm{~mL} / \\
\text { min) for } 6-9 \\
\text { doses }\end{array}$} & 7 & 1 & ND & $60.3^{\mathrm{g}}$ & $\mathrm{NC}$ & [52] \\
\hline & & 7 & 3 & & $80.8^{\mathrm{g}}$ & $7.63^{\mathrm{g}, \mathrm{h}}$ & \\
\hline & & 7 & 5 & & $56.3^{\mathrm{g}}$ & $10.4^{\mathrm{g}, \mathrm{i}}$ & \\
\hline & & 7 & 7 & & $44.6^{\mathrm{g}}$ & $\mathrm{NC}$ & \\
\hline \multirow{10}{*}{$\begin{array}{r}\text { Ceftolozane/ } \\
\text { tazobactam }\end{array}$} & \multirow{5}{*}{$\begin{array}{l}\text { Ceftolozane } 2 \mathrm{~g} \\
\mathrm{IV} \text { over } 1 \mathrm{~h} \mathrm{q} 8 \mathrm{~h} \\
\text { if } \mathrm{CL}_{\mathrm{CR}}>50 \\
\mathrm{~mL} / \mathrm{min}(1 \mathrm{~g} \\
\mathrm{IV} \text { over } 1 \mathrm{~h} \mathrm{q} 8 \mathrm{~h} \\
\text { if } \mathrm{CL}_{\mathrm{CR}} 30-50 \\
\mathrm{~mL} / \mathrm{min} ; 500 \\
\mathrm{mg} \mathrm{IV} \text { over } 1 \mathrm{~h} \\
\mathrm{q} 8 \mathrm{~h} \text { if } \mathrm{CL}_{\mathrm{CR}} \\
15-29 \mathrm{~mL} / \mathrm{min}) \\
\text { for } 4-6 \text { doses }\end{array}$} & 5 & 1 & $0.50^{\mathrm{j}}$ & NR & NR & {$[53]$} \\
\hline & & 5 & 2 & & NR & NR & \\
\hline & & 5 & 4 & & NR & NR & \\
\hline & & 4 & 6 & & NR & NR & \\
\hline & & 3 & 8 & & NR & NR & \\
\hline & \multirow{5}{*}{$\begin{array}{l}\text { Tazobactam } 1 \mathrm{~g} \\
\text { IV over } 1 \mathrm{~h} \mathrm{q} 8 \mathrm{~h} \\
\text { if } \mathrm{CL}_{\mathrm{CR}}>50 \\
\mathrm{~mL} / \mathrm{min}(500 \\
\mathrm{mg} \mathrm{IV} \mathrm{over} 1 \mathrm{~h} \\
\mathrm{q} 8 \mathrm{~h} \text { if } \mathrm{CL}_{\mathrm{CR}} \\
30-50 \mathrm{~mL} / \mathrm{min} \text {; } \\
250 \mathrm{mg} \mathrm{IV} \mathrm{over} \\
1 \mathrm{~h} \mathrm{q} 8 \mathrm{~h} \text { if } \mathrm{CL}_{\mathrm{CR}} \\
15-29 \mathrm{~mL} / \mathrm{min}) \\
\text { for } 4-6 \text { doses }\end{array}$} & 5 & 1 & $0.62^{\mathrm{k}}$ & NR & NR & \\
\hline & & 5 & 2 & & NR & NR & \\
\hline & & 5 & 4 & & NR & NR & \\
\hline & & 4 & 6 & & NR & NR & \\
\hline & & 3 & 8 & & NR & NR & \\
\hline Meropenem & $\begin{array}{l}2 \mathrm{~g} \text { or } 500 \mathrm{mg} \mathrm{IV} \\
\text { over } 3 \text {-h infu- } \\
\text { sion } \mathrm{q} 8 \mathrm{~h} \text { or } 1 \mathrm{~g} \\
\text { IV over } 30 \mathrm{~min} \\
\text { q8h }\end{array}$ & 17 & NR & $0.25^{1}$ & NR & NR & {$[55]$} \\
\hline
\end{tabular}


Table 3 (continued)

\begin{tabular}{|c|c|c|c|c|c|c|c|}
\hline $\begin{array}{l}\text { Antibacterial } \\
\text { agent }\end{array}$ & Dosage regimen & Patients $[n]$ & $\begin{array}{l}\text { Sampling time } \\
{[h]^{\mathrm{a}}}\end{array}$ & $\begin{array}{l}\text { ELF to plasma } \\
\text { ratio based on } \\
\text { AUC }\end{array}$ & $\begin{array}{l}\text { Plasma concentra- } \\
\text { tion }[\mu \mathrm{g} / \mathrm{mL}]^{\mathrm{b}}\end{array}$ & $\begin{array}{l}\text { ELF concentra- } \\
\text { tion }[\mu \mathrm{g} / \mathrm{mL}]^{\mathrm{b}}\end{array}$ & References \\
\hline \multirow[t]{11}{*}{ Meropenem } & \multirow{6}{*}{$\begin{array}{l}1 \mathrm{~g} \mathrm{IV} \text { over } \\
30 \mathrm{~min} \mathrm{q} 8 \mathrm{~h}\end{array}$} & 5 & 0 & \multirow[t]{6}{*}{$0.20^{\mathrm{m}}$} & NR & NR & \multirow[t]{11}{*}[56]{} \\
\hline & & 5 & 0.5 & & NR & NR & \\
\hline & & 5 & 1 & & NR & NR & \\
\hline & & 5 & 3 & & NR & NR & \\
\hline & & 5 & 4 & & NR & NR & \\
\hline & & 5 & 6 & & NR & NR & \\
\hline & \multirow{5}{*}{$\begin{array}{l}1 \mathrm{~g} \mathrm{IV} \text { over } 3 \mathrm{~h} \\
\mathrm{q} 8 \mathrm{~h}\end{array}$} & 5 & 0 & \multirow[t]{5}{*}{$0.29^{\mathrm{m}}$} & NR & NR & \\
\hline & & 5 & 1 & & NR & NR & \\
\hline & & 5 & 3 & & NR & NR & \\
\hline & & 5 & 4 & & NR & NR & \\
\hline & & 5 & 6 & & NR & NR & \\
\hline \multirow[t]{10}{*}{ Meropenem } & \multirow{5}{*}{$\begin{array}{l}\text { Loading dose } \\
\text { of } 2 \mathrm{~g} \mathrm{IV} \text { over } \\
15 \mathrm{~min} \text { followed } \\
\text { by } 3 \mathrm{~g} / \text { day } \mathrm{CI}\end{array}$} & 15 & 0 & \multirow[t]{5}{*}{$0.32^{\mathrm{m}}$} & 12.9 & $\mathrm{NC}$ & \multirow[t]{10}{*}[57]{} \\
\hline & & 15 & 1.5 & & 13.4 & $\mathrm{NC}$ & \\
\hline & & 15 & 3 & & 13.3 & $\mathrm{NC}$ & \\
\hline & & 15 & 6 & & 11.7 & 3.9 & \\
\hline & & 15 & 8 & & 12.3 & $\mathrm{NC}$ & \\
\hline & \multirow{5}{*}{$\begin{array}{l}\text { Loading dose } \\
\text { of } 2 \mathrm{~g} \text { IV over } \\
15 \mathrm{~min} \text { followed } \\
\text { by } 6 \mathrm{~g} / \text { day IV CI }\end{array}$} & 15 & 0 & \multirow[t]{5}{*}{$0.36^{\mathrm{m}}$} & 23.0 & $\mathrm{NC}$ & \\
\hline & & 15 & 1.5 & & 23.9 & $\mathrm{NC}$ & \\
\hline & & 15 & 3 & & 21.4 & $\mathrm{NC}$ & \\
\hline & & 15 & 6 & & 22.4 & 6.6 & \\
\hline & & 15 & 8 & & 18.9 & $\mathrm{NC}$ & \\
\hline \multirow[t]{8}{*}{ Doripenem } & \multirow{4}{*}{$\begin{array}{l}500 \mathrm{mg} \text { IV over } \\
1 \mathrm{~h}\end{array}$} & 2 & 0 & \multirow[t]{4}{*}{0.29} & NR & NR & \multirow[t]{8}{*}[58]{} \\
\hline & & 2 & 2 & & NR & NR & \\
\hline & & 2 & 4 & & NR & NR & \\
\hline & & 2 & 6 & & NR & NR & \\
\hline & \multirow{4}{*}{$\begin{array}{l}500 \mathrm{mg} \text { IV over } \\
4 \mathrm{~h}\end{array}$} & 2 & 0 & \multirow[t]{4}{*}{0.21} & NR & NR & \\
\hline & & 2 & 2 & & NR & NR & \\
\hline & & 2 & 4 & & NR & NR & \\
\hline & & 2 & 6 & & NR & NR & \\
\hline
\end{tabular}

$E L F$ epithelial lining fluid, $A U C$ area under the concentration-time curve, $I V$ intravenously, $C L_{C R}$ creatinine clearance, $C I$ continuous intravenous infusion, $N D$ not determined, $N C$ no samples collected at this time, $N R$ not reported, $q x h$ every $x$ hours

${ }^{a}$ Sampling time after the last dose

${ }^{\text {b } V a l u e s ~ e x p r e s s e d ~ a s ~ m e d i a n ~}$

${ }^{\mathrm{c}}$ Sample collection occurred throughout therapy

${ }^{\mathrm{d}}$ Median value for the ratio of AUC in ELF to AUC in unbound plasma, assuming 30\% protein binding in plasma

${ }^{\mathrm{e}}$ Sampling time was at steady-state (44 $\mathrm{h}$ after starting therapy)

${ }^{\mathrm{f}}$ Maximum and minimum ceftazidime concentration, respectively

${ }^{g}$ Values expressed as geometric mean

${ }^{\mathrm{h}}$ Four patients had an ELF concentration at $3 \mathrm{~h}$

${ }^{\mathrm{i}}$ Three patients had an ELF concentration at $5 \mathrm{~h}$

${ }^{\mathrm{j}}$ Based on the ratio of $\mathrm{AUC}_{8}$ in ELF to $\mathrm{AUC}_{8}$ in unbound plasma, assuming $21 \%$ protein binding in plasma

${ }^{\mathrm{k}} \mathrm{Based}$ on the ratio of $\mathrm{AUC}_{8}$ in $\mathrm{ELF}$ to $\mathrm{AUC}_{8}$ in unbound plasma, assuming $30 \%$ protein binding in plasma

${ }^{1}$ Median value for the ratio of AUC in ELF to AUC in total plasma

${ }^{\mathrm{m}}$ Based on the ratio of $\mathrm{AUC}_{24}$ in ELF to $\mathrm{AUC}_{24}$ in total plasma

${ }^{\mathrm{n}}$ Calculated from the reported values of $\mathrm{AUC}_{8}$ in $\mathrm{ELF}$ and total plasma 
at each BAL sampling time. These findings were comparable with previously reported intrapulmonary penetration ratios in healthy adult subjects [19]. However, the plasma and ELF concentration-time profiles in critically ill patients had higher interpatient variability and a delay in the time to maximum ELF concentration (i.e., geometric mean of $6 \mathrm{~h}$ for ceftolozane and $2 \mathrm{~h}$ for tazobactam). These observations were further explored and confirmed by Zhang and colleagues, who developed a population PK model that incorporated 16 clinical trials, including the intrapulmonary penetration studies of healthy subjects and critically ill patients and the plasma concentrations obtained in the pivotal phase III study in patients with hospital-acquired and ventilator-associated bacterial pneumonia [54]. By using a hypothetical link compartment model, the respective disposition rate constants to describe ceftolozane and tazobactam distribution between plasma and ELF and ELF elimination were shown to be $97 \%$ and $52 \%$ lower in patients with pneumonia compared with healthy subjects. These results provide further elaboration on the delayed distribution, large interindividual variability, and sustained ELF exposure of ceftolozane and tazobactam in critically ill patients.

\subsubsection{Meropenem}

In addition to the previously reported intrapulmonary penetration of meropenem in healthy subjects, multiple studies have evaluated the ELF concentrations of meropenem in patients with nosocomial pneumonia. Lodise and colleagues described the plasma and ELF PK of meropenem in 39 intubated patients with hospital-acquired pneumonia [55]. Population PK modeling was conducted from a total of 269 plasma concentrations and 17 ELF concentrations. The derived pulmonary penetration ratios based on AUC values in ELF and total plasma included 0.30 when calculated from the mean parameter vector of the population model, a median value of 0.264 when determined with Bayesian parameter estimates for the 17 patients with an ELF sample, and a median value of 0.254 when estimated from a 9999-subject Monte Carlo simulation. However, the mean ( \pm standard deviation $[\mathrm{SD}])$ penetration ratio in the Monte Carlo simulation was 0.816 ( \pm 2.542 ), with the 10th and 90th percentiles being 0.037 and 1.78 , respectively. This study confirms that ELF penetration of meropenem has a wide range of variability in critically ill patients with hospital-acquired pneumonia.

In a study evaluating 55 adult patients with severe nosocomial pneumonia, meropenem $1 \mathrm{~g}$ every $8 \mathrm{~h}$ was administered as an intravenous infusion, either over $30 \mathrm{~min}$ or $3 \mathrm{~h}$ (Table 3 ) [56]. Noncompartmental PK estimates based on mean values of plasma and ELF concentrations at each sampling time demonstrated a higher $\mathrm{AUC}_{24}$ in plasma $(502 \mu \mathrm{g} \bullet \mathrm{h} / \mathrm{mL}$ vs. 422 $\mu \mathrm{g} \bullet \mathrm{h} / \mathrm{mL}, p=0.082)$ and ELF $(150 \mu \mathrm{g} \bullet \mathrm{h} / \mathrm{mL}$ vs. $80.3 \mu \mathrm{g} \bullet \mathrm{h} /$ $\mathrm{mL}, p=0.010$ ) for the 3 -h versus 30 -min infusion groups.
The penetration ratio of meropenem ELF to plasma based on $\mathrm{AUC}_{24}$ was 0.20 for the 30-min infusion group and 0.29 for the 3-h extended infusion group. Population PK modeling and Monte Carlo simulations were used to provided support of an empiric dose of meropenem for the treatment of severe nosocomial pneumonia. The dosage regimen of $2 \mathrm{~g}$ every $8 \mathrm{~h}$ as a 3-h extended intravenous infusion was predicted to achieve PD target values of $40-100 \% f \mathrm{~T}>\mathrm{MIC}$ for susceptibility breakpoint ranges of $2-8 \mu \mathrm{g} / \mathrm{mL}$ in plasma and $0.06-1.0$ $\mu \mathrm{g} / \mathrm{mL}$ in ELF.

A PK study comparing two dosage regimens of meropenem administered by continuous infusion was conducted in 31 intensive care unit patients with nosocomial pneumonia [57]. Participants received a $2 \mathrm{~g}$ loading dose of meropenem administered as a $15 \mathrm{~min}$ IV infusion and were randomly assigned to receive either a $3 \mathrm{~g} /$ day or $6 \mathrm{~g} /$ day continuous intravenous infusion of meropenem. Population PK modeling was conducted from a total of 151 plasma concentrations and 30 ELF concentrations, and Bayesian posterior parameter estimates were used to calculate AUC in plasma and ELF for each patient. The respective median (IQR) AUC from 48 to $72 \mathrm{~h}\left(\mathrm{AUC}_{48-72}\right)$ for the $3 \mathrm{~g} /$ day and $6 \mathrm{~g} /$ day regimens was 322.7 (225.6) $\mu \mathrm{g} \cdot \mathrm{h} /$ $\mathrm{mL}$ and 492.3 (354.1) $\mu \mathrm{g} \cdot \mathrm{h} / \mathrm{mL}$ in plasma, and 101.5 (78.5) $\mu \mathrm{g} \cdot \mathrm{h} / \mathrm{mL}$ and $175.9(258.7) \mu \mathrm{g} \cdot \mathrm{h} / \mathrm{mL}$ in ELF. The median (IQR) penetration ratios $\left(\mathrm{AUC}_{\mathrm{ELF}} / \mathrm{AUC}_{\text {plasma }}\right)$ were $0.32(0.34)$ and $0.36(0.44)$ for the $3 \mathrm{~g} /$ day and $6 \mathrm{~g}$ /day groups, respectively (Table 3). Monte Carlo simulations were performed to estimate the probability of achieving a target of 50\% $f \mathrm{~T}>\mathrm{MIC}$ in ELF for three dosage regimens of meropenem. Target attainment in ELF could be achieved with a $2 \mathrm{~g}$ loading dose followed by $3 \mathrm{~g} /$ day and $6 \mathrm{~g} /$ day continuous infusion dosing strategies when MIC values were $<2 \mu \mathrm{g} / \mathrm{mL}$ and $<4 \mu \mathrm{g} / \mathrm{mL}$, respectively. These target attainment goals were supported by outcome observations among 12 patients, where clinical cures occurred in all patients achieving $>50 \% f \mathrm{~T}>\mathrm{MIC}$ in ELF and treatment failures when $f \mathrm{~T}>\mathrm{MIC}$ was $33 \%$ [57].

\subsubsection{Doripenem}

Plasma and ELF concentrations were compared in 16 mechanically ventilated, intensive care patients receiving doripenem for the treatment of pneumonia [58]. Patients received multiple intravenous doses (i.e., 3-24) of doripenem $500 \mathrm{mg}$ every $8 \mathrm{~h}$ and divided into two groups based on whether administration was a 1-h or 4-h intravenous infusion. Each patient had a serial collection of plasma samples at steady-state, along with a single BAL sample either before or at 2,4 , or $6 \mathrm{~h}$ after the start of the infusion (Table 3 ). The mean total plasma $\mathrm{AUC}_{8}$ of doripenem was $52.98 \mu \mathrm{g} \cdot \mathrm{h} /$ $\mathrm{mL}$ in patients receiving the $1-\mathrm{h}$ infusion and $70.64 \mu \mathrm{g} \cdot \mathrm{h} /$ $\mathrm{mL}$ in patients receiving the $4-\mathrm{h}$ infusion. The doripenem $\mathrm{AUC}_{8}$ based on the mean of two ELF concentrations at each BAL sampling time were $15.3 \mu \mathrm{g} \cdot \mathrm{h} / \mathrm{mL}$ and $14.8 \mu \mathrm{g} \cdot \mathrm{h} / \mathrm{mL}$ 
for patients receiving the 1-h and 4-h infusions, respectively. Neither of the infusion methods for administering a $500 \mathrm{mg}$ dose were able to sustain ELF concentrations of doripenem above $1 \mu \mathrm{g} / \mathrm{mL}$ over the 8 -h dosing interval. These lower and more variable ELF concentrations above the MIC may lend support to the observed lower clinical cure rate and increased risk of death for a 7-day course of doripenem when compared with a 10-day course of imipenem-cilastatin in a randomized clinical trial of patients with ventilatorassociated pneumonia [59].

\subsubsection{Ertapenem}

Single-dose plasma and intrapulmonary concentrations of ertapenem in patients with early-onset ventilator-associated pneumonia or undergoing thoracotomy have been previously reviewed [1]. Bader and colleagues have subsequently reevaluated the PK/PD profile of plasma and ELF concentrations of ertapenem obtained from patients with ventilatorassociated pneumonia $[60,61]$. A population PK model was developed to account for ELF penetration and non-linear plasma protein binding of ertapenem. Monte Carlo simulations were used to calculate the percentage probabilities of target attainment for unbound plasma and ELF at T $>$ MIC target values of $35 \%, 40 \%$, and $45 \%$. Five intermittent dosing strategies of ertapenem were assessed, including $1 \mathrm{~g}$ and 2 g every $24 \mathrm{~h}$ infused intravenously over $30 \mathrm{~min}$ or $3 \mathrm{~h}$, and $1 \mathrm{~g}$ every $12 \mathrm{~h}$ infused intravenously over $30 \mathrm{~min}$. The penetration ratio was 0.34 based on the estimated median AUC ${ }_{24}$ values of $68.2 \mu \mathrm{g} \cdot \mathrm{h} / \mathrm{mL}$ and $200 \mu \mathrm{g} \cdot \mathrm{h} / \mathrm{mL}$ for ELF and unbound plasma, respectively. The probabilities of achieving a target attainment of 35\% T > MIC in ELF was $>90 \%$ for MIC values ranging between 0.008 and $0.12 \mu \mathrm{g} / \mathrm{mL}$ for all five dosage regimens. Ertapenem regimens that included $2 \mathrm{~g} /$ day dosing or a 3-h infusion were able to extend the range of MIC coverage to $0.25 \mu \mathrm{g} / \mathrm{mL}$ and $0.5 \mu \mathrm{g} / \mathrm{mL}$. Similar results were observed at the higher target values in ELF. The probabilities of target attainment of specific Gram-negative pathogens (at $\mathrm{MIC}_{90}$ values) ranged from 99.8 to $100 \%$, 97.9\% to $100 \%, 10.6 \%$ to $74.1 \%$, and 0 to $1.5 \%$ for Escherichia coli $(0.06 \mu \mathrm{g} / \mathrm{mL})$, Serratia marcescens $(0.12 \mu \mathrm{g} / \mathrm{mL})$, Enterobacter spp. $(1 \mu \mathrm{g} / \mathrm{mL})$, and K. pneumoniae (> $2 \mu \mathrm{g} /$ $\mathrm{mL}$ ), respectively. These results provide support for dosing options of ertapenem to be combined with other antibacterial agents for the treatment of patients with hospital-acquired and ventilator-associated bacterial pneumonia.

\section{Macrolides and Ketolides}

Intrapulmonary penetration for many macrolides, azalide, and ketolides has previously been reported [1]. The majority of these studies included clarithromycin, azithromycin, and telithromycin, and demonstrated markedly higher ELF and AM concentrations compared with plasma concentrations. Two novel agents from the ketolide class have subsequently been evaluated.

\subsection{Solithromycin}

Solithromycin is a fluoroketolide antibiotic that has been in clinical development for the treatment of bacterial infections. Solithromycin has demonstrated in vitro activity against organisms that commonly cause communityacquired pneumonia, including Streptococcus pneumoniae, Haemophilus influenzae, Moraxella catarrhalis, and atypical respiratory pathogens. Plasma, ELF, and AM concentrations were compared in 30 healthy adult subjects to determine intrapulmonary penetration following the oral administration of solithromycin $400 \mathrm{mg}$ once daily for 5 days [62]. Compared with the simultaneously collected solithromycin plasma concentrations, ELF concentrations were 2.4 to 28.6 times greater during the 24 -h sampling period. The respective $\mathrm{AUC}_{24}$ values for ELF were $80.3 \mu \mathrm{g} \cdot \mathrm{h} / \mathrm{mL}$ and $63.2 \mu \mathrm{g} \cdot \mathrm{h} / \mathrm{mL}$ based on the mean and median concentrations in ELF at each sampling time. The ELF to plasma concentration ratios were 10.3 and 10.0 based on these $\mathrm{AUC}_{24}$ values, respectively (Table 4). In comparison, steady-state $\mathrm{AUC}_{24}$ of telithromycin in ELF was previously reported as $58.3 \mu \mathrm{g} \cdot \mathrm{h} / \mathrm{mL}$, and the mean ELF to plasma telithromycin ratio based on AUC ${ }_{24}$ was 8.05 [63].

The 30 ELF concentrations were combined with 1966 plasma concentrations to simulate population concentration-time data of solithromycin in ELF and plasma using a physiologically based PK model [64]. The modeling supported a high AUC/MIC target attainment following administration of the oral dosing regimen of solithromycin $800 \mathrm{mg}$ on day 1 and $400 \mathrm{mg}$ once daily on days $2-5$. Okusanya and colleagues performed a PK/PD analysis of solithromycin in a neutropenic murine lung infection model [65]. The observed solithromycin total drug ELF to unbound drug plasma $\mathrm{AUC}_{24}$ ratio in mice was 2.7, which was considerably lower than solithromycin penetration in human lung ELF.

Compared with plasma, AM concentrations of solithromycin were simultaneously 44 to 515 times greater during the 24-h time period after the final solithromycin dose [62]. The ratios of AM to plasma based on mean and median $\mathrm{AUC}_{24}$ values were 193 and 202, respectively. Given that total plasma drug concentrations were evaluated in this study and used for determining ELF and AM ratios, intrapulmonary penetration ratios would be greater when using unbound plasma concentrations. Only the oral formulation of solithromycin has been evaluated in humans. 
Table 4 Plasma and epithelial lining fluid concentrations of ketolides

\begin{tabular}{|c|c|c|c|c|c|c|c|}
\hline Antibacterial agent & Dosage regimen & Subjects $[n]$ & $\begin{array}{l}\text { Sampling } \\
\text { time }[\mathrm{h}]^{\mathrm{a}}\end{array}$ & $\begin{array}{l}\text { ELF to plasma } \\
\text { ratio based on } \\
\text { AUC }\end{array}$ & $\begin{array}{l}\text { Plasma concen- } \\
\text { tration }[\mu \mathrm{g} / \mathrm{mL}]^{\mathrm{b}}\end{array}$ & $\begin{array}{l}\text { ELF concen- } \\
\text { tration } \\
{[\mu \mathrm{g} / \mathrm{mL}]^{\mathrm{b}}}\end{array}$ & References \\
\hline \multirow[t]{5}{*}{ Solithromycin } & \multirow[t]{5}{*}{$400 \mathrm{mg}$ PO q24h $\times 5$ days } & 6 & 3 & \multirow[t]{5}{*}{$10.3^{\mathrm{c}}$} & $0.730 \pm 0.692$ & $7.58 \pm 6.69$ & \multirow[t]{5}{*}[62]{} \\
\hline & & 6 & 6 & & $0.595 \pm 0.325$ & $6.50 \pm 2.73$ & \\
\hline & & 6 & 9 & & $0.301 \pm 0.185$ & $3.78 \pm 4.32$ & \\
\hline & & 6 & 12 & & $0.300 \pm 0.171$ & $2.54 \pm 2.55$ & \\
\hline & & 6 & 24 & & $0.086 \pm 0.070$ & $1.02 \pm 0.83$ & \\
\hline \multirow[t]{6}{*}{ Nafithromycin } & \multirow[t]{6}{*}{$800 \mathrm{mg}$ PO q24h $\times 3$ doses } & 6 & 3 & \multirow[t]{6}{*}{$13.8^{\mathrm{c}}$} & $1.105 \pm 0.140$ & $18.48 \pm 12.31$ & \multirow[t]{6}{*}[66]{} \\
\hline & & 6 & 6 & & $0.966 \pm 0.439$ & $15.29 \pm 14.53$ & \\
\hline & & 6 & 9 & & $0.922 \pm 0.286$ & $8.37 \pm 4.38$ & \\
\hline & & 5 & 12 & & $0.817 \pm 0.261$ & $9.67 \pm 6.20$ & \\
\hline & & 6 & 24 & & $0.239 \pm 0.055$ & $4.13 \pm 1.38$ & \\
\hline & & 6 & 48 & & $0.060 \pm 0.029$ & $1.62 \pm 0.86$ & \\
\hline
\end{tabular}

$E L F$ epithelial lining fluid, $A U C$ area under the concentration-time curve, $P O$ by mouth, $q x h$ every $x$ hours, $S D$ standard deviation

${ }^{\text {a }}$ Sampling time after the last dose

${ }^{\mathrm{b}}$ Total plasma and ELF concentrations expressed as mean $\pm \mathrm{SD}$

${ }^{\mathrm{c}}$ Based on the ratio of $\mathrm{AUC}_{24}$ in $\mathrm{ELF}$ to $\mathrm{AUC}_{24}$ in total plasma

\subsection{Nafithromycin}

Nafithromycin is an oral ketolide being evaluated for the treatment of community-acquired bacterial pneumonia. Compared with the other macrolides and ketolides, higher plasma and ELF concentrations are achieved. Plasma, ELF, and $\mathrm{AM}$ concentrations of nafithromycin were evaluated in healthy adult subjects following $800 \mathrm{mg}$ once-daily oral dosing for 3 days [66]. Nafithromycin concentrations in ELF were 2.5 to 36.3 times higher than plasma concentrations during the 48 -h sampling period. The $\mathrm{AUC}_{24}$ value based on the mean concentrations in ELF at each sampling time was $224.1 \mu \mathrm{g} \cdot \mathrm{h} / \mathrm{mL}$, which resulted in a penetration ratio of ELF to total plasma of 13.8 (Table 4). The $\mathrm{AUC}_{24}$ of nafithromycin in $\mathrm{AM}$ was $8538 \mu \mathrm{g} \cdot \mathrm{h} / \mathrm{mL}$, with a penetration ratio of 527 based on $\mathrm{AUC}_{24}$ values in $\mathrm{AM}$ and plasma. These ratios were based on total plasma drug concentrations as opposed to unbound plasma concentrations. Compared with the other macrolides and ketolides, the AUC values of nafithromycin in both plasma and ELF were substantially higher. Specifically, the mean nafithromycin $\mathrm{AUC}_{24}$ is about three times greater than observed with solithromycin, which could be advantageous for nafithromycin in the treatment of bacterial pneumonia, although the $\mathrm{MIC}_{90}$ is higher for solithromycin $[65,67]$. The pattern of intrapulmonary penetration of the AUC values of ELF and AM being circa 10-fold and 100fold higher, respectively, than total plasma concentrations for these two novel agents are consistent with previously reported findings for azithromycin, clarithromycin, and telithromycin.

\section{Fluoroquinolones}

Fluoroquinolones are used for a wide variety of infectious syndromes, given their antibacterial activity against a broad spectrum of microorganisms. Levofloxacin and moxifloxacin are recommended treatment choices for community-acquired pneumonia, and levofloxacin and ciprofloxacin are treatment options for hospital- and ventilator-acquired pneumonia [68, 69]. Intrapulmonary penetration for moxifloxacin, ciprofloxacin, and levofloxacin has previously been reported and supports the use of these agents for lower respiratory tract infections [1].

\subsection{Levofloxacin}

A wide range of levofloxacin dosages have been evaluated following both oral and intravenous administration. Older studies report ELF to plasma concentration ratios ranging from 1.59 to 2.69 based on AUC [1]. Since then, two studies comparing intrapulmonary concentrations of levofloxacin have been published, one study evaluating patients with idiopathic pulmonary fibrosis and one study evaluating patients with acute exacerbation of chronic bronchitis [70, 71]. Huang and colleagues compared plasma and ELF concentrations of 10 patients with idiopathic pulmonary fibrosis with 10 patients in a control group following a single oral dose of levofloxacin $500 \mathrm{mg}$ [70]. The mean ELF concentration was $10.17 \mu \mathrm{g} / \mathrm{mL}$ in the idiopathic pulmonary fibrosis group and $27.81 \mu \mathrm{g} / \mathrm{mL}$ in the control group. While ELF concentrations were significantly different between groups, the findings are consistent with previously published studies 
on intrapulmonary penetration in both healthy subjects and those who may have impaired pulmonary diffusion. The second study serving as an addition to the levofloxacin intrapulmonary penetration literature is a PK evaluation of levofloxacin $750 \mathrm{mg}$ orally once daily in adults undergoing treatment for acute exacerbation of chronic bronchitis [71]. This study observed an ELF to plasma penetration ratio of 1.13, comparable with previous studies with similar patient populations. The observed AUC to MIC ratios were considered adequate for the treatment of common causative organisms of chronic bronchitis, including S. pneumoniae, H. influenzae, and M. catarrhalis.

A subsequent retrospective analysis used population PK modeling and Monte Carlo simulation to compare the ELF penetration of these 18 infected patients with acute exacerbations of chronic bronchitis and 15 uninfected patients undergoing diagnostic bronchoscopy [72]. The infected patients demonstrated a lower median penetration ratio (1.29 vs. 3.39) compared with uninfected patients based on AUC values of levofloxacin in ELF and unbound plasma. The simulated 24-h AUC values in total plasma of levofloxacin were similar among infected and uninfected patients (mean \pm SD: $140.5 \pm 5.48 \mu \mathrm{g} \bullet \mathrm{h} / \mathrm{mL}$ vs. $133.7 \pm 61.6 \mu \mathrm{g} \bullet \mathrm{h} / \mathrm{mL})$, whereas the AUC in ELF values in infected patients were significantly lower than uninfected patients (mean \pm SD: $189.1 \pm 210.5 \mu \mathrm{g} \bullet \mathrm{h} / \mathrm{mL}$ vs. $461.0 \pm 558.7 \mu \mathrm{g} \bullet \mathrm{h} / \mathrm{mL})$. These results suggest a higher oral dosing regimen (e.g., $750 \mathrm{mg}$ every $24 \mathrm{~h}$ ) may be necessary in infected patients in order provide adequate ELF exposures.

\subsection{Alalevonadifloxacin}

Several new fluoroquinolones are undergoing clinical investigation for their potential use in the treatment of lower respiratory tract bacterial infections. Alalevonadifloxacin is an oral prodrug of levonadifloxacin under investigation as a novel benzoquinolizine quinolone with in vitro activity against other fluoroquinolone-resistant organisms, including MRSA [73]. Plasma, ELF, and AM levonadifloxacin concentrations were compared in 30 healthy adults following oral administration of alalevonadifloxacin $1000 \mathrm{mg}$ administered every $12 \mathrm{~h}$ for nine doses [74]. Levonadifloxacin total drug concentrations in plasma and ELF were similar, with a penetration ratio close to 1 (Table 5). Compared with other fluoroquinolones, levonadifloxacin is highly protein bound $(85 \%)$. The total drug in ELF to unbound drug in plasma penetration ratios were 7.66 and 7.58 based on the mean and median $\mathrm{AUC}_{12}$ values, respectively. AM concentrations of levonadifloxacin in the $12 \mathrm{~h}$ following alalevonadifloxacin administration were lower than total drug plasma and ELF concentrations at all time points evaluated. The penetration ratios of $\mathrm{AM}$ to unbound plasma concentrations of levonadifloxacin based on the respective mean and median $\mathrm{AUC}_{12}$ values were 1.58 and 1.44.

\subsection{Sitafloxacin}

Sitafloxacin is a desfluoroquinolone antibiotic currently available in Thailand and Japan and has a broad spectrum in vitro activity against quinolone-resistant Gram-positive and Gram-negative organisms [75]. No studies have evaluated the intrapulmonary PK of sitafloxacin in healthy subjects; however, Paiboonvong and colleagues evaluated sitafloxacin ELF penetration in 12 critically ill patients with pneumonia (Table 5) [76]. The mean sitafloxacin $\mathrm{AUC}_{8}$ for plasma and ELF were $5.58 \mu \mathrm{g} \cdot \mathrm{h} / \mathrm{mL}$ and $4.77 \mu \mathrm{g} \cdot \mathrm{h} / \mathrm{mL}$, respectively. The resultant ELF to unbound plasma $\mathrm{AUC}_{8}$ penetration ratio was 0.85 , substantially lower than many other fluoroquinolones evaluated in healthy subjects. However, this study had several limitations, including a limited BAL sampling period, technique errors in BAL collection procedures, small sample size, and large variability in the observed ELF concentrations. There are currently no studies evaluating sitafloxacin intrapulmonary penetration after multiple doses or at steady state.

\subsection{Avarofloxacin}

Avarofloxacin (formerly known as JNJ-Q2) is a broadspectrum fluoroquinolone being clinically evaluated for the treatment of community-acquired bacterial infections, including pneumonia. Intrapulmonary penetration was studied in eight healthy subjects following oral administration of avarofloxacin $250 \mathrm{mg}$ every $12 \mathrm{~h}$ for seven doses [77]. The ELF to unbound plasma penetration ratios ranged from approximately 17 to 64 over the 6-h sampling time (Table 5). The AM to plasma penetration ratios for this same time period ranged from approximately 74 to 157 . AUC values for plasma or intrapulmonary concentrations were not reported for this limited dataset since the sponsor discontinued the study after enrollment of only 10 subjects (8 receiving avarofloxacin). Intrapulmonary concentrations following intravenous dosing of avarofloxacin were not evaluated.

\subsection{Lascufloxacin}

Lascufloxacin is a fluoroquinolone in clinical development for the treatment of community-acquired pneumonia and other respiratory tract infections [78]. Plasma, ELF, and AM concentrations were compared in 30 healthy, male adults following a single oral dose of lascufloxacin $75 \mathrm{mg}$ [79]. Plasma and ELF concentrations are shown in Table 5. After accounting for an estimated $26 \%$ plasma protein binding, the total drug ELF to unbound plasma penetration ratio based on lascufloxacin $\mathrm{AUC}_{24}$ was 61.7. Ohya and colleagues 
Table 5 Plasma and epithelial lining fluid concentrations of fluoroquinolones

\begin{tabular}{|c|c|c|c|c|c|c|c|}
\hline Antibacterial agent & Dosage regimen & Subjects $[n]$ & $\begin{array}{l}\text { Sampling } \\
\text { time }[\mathrm{h}]^{\mathrm{a}}\end{array}$ & $\begin{array}{l}\text { ELF to plasma } \\
\text { based on AUC }\end{array}$ & $\begin{array}{l}\text { Plasma con- } \\
\text { centration } \\
{[\mu \mathrm{g} / \mathrm{mL}]^{\mathrm{b}}}\end{array}$ & $\begin{array}{l}\text { ELF concentration } \\
{[\mu \mathrm{g} / \mathrm{mL}]^{\mathrm{b}}}\end{array}$ & References \\
\hline \multirow[t]{5}{*}{ Alalevonadifloxacin ${ }^{c}$} & \multirow{5}{*}{$\begin{array}{l}1000 \mathrm{mg} \text { PO q12h } \times 9 \\
\text { doses }\end{array}$} & 6 & 2 & \multirow[t]{5}{*}{$1.15^{\mathrm{d}}$} & $20.5 \pm 6.3$ & $26.0 \pm 15.9$ & \multirow[t]{5}{*}{ [74] } \\
\hline & & 6 & 4 & & $17.6 \pm 6.1$ & $19.7 \pm 7.2$ & \\
\hline & & 6 & 6 & & $16.4 \pm 4.7$ & $19.9 \pm 11.1$ & \\
\hline & & 6 & 8 & & $9.49 \pm 4.25$ & $10.6 \pm 6.0$ & \\
\hline & & 6 & 12 & & $4.88 \pm 1.09$ & $4.28 \pm 1.40$ & \\
\hline \multirow[t]{4}{*}{ Sitafloxacin } & \multirow[t]{4}{*}{$200 \mathrm{mg} \mathrm{PO} \times 1$ dose } & 12 & $0.5-2$ & \multirow[t]{4}{*}{$0.85^{\mathrm{e}}$} & $0.60 \pm 0.46$ & $0.19 \pm 0.20$ & \multirow[t]{4}{*}{ [76] } \\
\hline & & 12 & $3-4$ & & $1.37 \pm 0.51$ & $0.48 \pm 0.29$ & \\
\hline & & 12 & $5-6$ & & $1.99 \pm 2.34$ & $1.07 \pm 0.93$ & \\
\hline & & 12 & $7-9$ & & $0.85 \pm 0.77$ & $0.61 \pm 0.77$ & \\
\hline \multirow[t]{4}{*}{ JNJ-Q2 } & \multirow{4}{*}{$\begin{array}{l}250 \mathrm{mg} \text { PO q12h } \times 7 \\
\text { doses }\end{array}$} & 2 & 1 & \multirow[t]{4}{*}{ NR } & $0.65(26.7)^{\mathrm{f}}$ & $39.8(35.4,44.2)$ & \multirow[t]{4}{*}{ [77] } \\
\hline & & 2 & 2 & & $0.78(20.2)^{\mathrm{f}}$ & $34.5(31.8,37.2)$ & \\
\hline & & 2 & 4 & & $0.71(11.3)^{\mathrm{f}}$ & $11.4(10.5,12.3)$ & \\
\hline & & 2 & 6 & & $0.64(8.9)^{\mathrm{f}}$ & $35.0(34.9,35.1)$ & \\
\hline \multirow[t]{5}{*}{ Lascufloxacin } & \multirow[t]{5}{*}{$75 \mathrm{mg} \mathrm{PO} \times 1$ dose } & 6 & 1 & \multirow[t]{5}{*}{$61.7^{\mathrm{g}}$} & $0.576 \pm 0.145$ & $12.3 \pm 3.74$ & \multirow[t]{5}{*}{ [79] } \\
\hline & & 6 & 2 & & $0.501 \pm 0.0876$ & $9.22 \pm 3.45$ & \\
\hline & & 6 & 4 & & $0.443 \pm 0.0419$ & $7.15 \pm 3.21$ & \\
\hline & & 6 & 6 & & $0.387 \pm 0.0119$ & $5.84 \pm 1.72$ & \\
\hline & & 6 & 24 & & $0.176 \pm 0.0545$ & $2.65 \pm 0.88$ & \\
\hline
\end{tabular}

$E L F$ epithelial lining fluid, $A U C$ area under the concentration-time curve, $P O$ by mouth, $N R$ not reported, $q x h$ every $x$ hours, $S D$ standard deviation

a Sampling time after the last dose

${ }^{\mathrm{b}}$ Total plasma and ELF concentrations expressed as mean \pm SD or median (minimum, maximum)

${ }^{\mathrm{c}}$ Measured concentrations are levonadifloxacin, the active drug from the alalevonadifloxacin prodrug

${ }^{\mathrm{d}} \mathrm{Based}$ on the ratio of $\mathrm{AUC}_{12}$ in ELF to $\mathrm{AUC}_{12}$ in total plasma

${ }^{\mathrm{e}} \mathrm{Based}$ on the ratio of $\mathrm{AUC}_{8}$ in $\mathrm{ELF}$ to $\mathrm{AUC}_{8}$ in unbound plasma, assuming $63 \%$ protein binding in plasma

${ }^{\mathrm{f}}$ Values expressed as mean (percent coefficient of variation), assuming $65 \%$ protein binding in plasma

${ }^{g}$ Based on the ratio of $\mathrm{AUC}_{24}$ in $\mathrm{ELF}$ to $\mathrm{AUC}_{24}$ in unbound plasma, assuming $74 \%$ protein binding in plasma

explored the in vitro mechanism by which lascufloxacin distributes into the ELF, given the higher penetration ratios observed in the intrapulmonary penetration study [80]. Compared with other fluoroquinolones and phospholipids, lascufloxacin demonstrated greater binding to phosphatidylserine in pulmonary surfactant, indicating a likely mechanism for higher distribution of lascufloxacin into ELF. AM concentrations were also evaluated. The mean $\mathrm{AUC}_{24}$ of lascufloxacin in $\mathrm{AM}$ was $325 \mu \mathrm{g} \cdot \mathrm{h} / \mathrm{L}$ and the mean total drug AM concentration to unbound serum concentration penetration ratio based on $\mathrm{AUC}_{24}$ was 163 . The $\mathrm{MIC}_{90}$ values for common extra- and intracellular respiratory pathogens were well exceeded by the ELF and AM concentrations of lascufloxacin, respectively [79]. No studies evaluating steady-state intrapulmonary concentrations of lascufloxacin have been reported.

\section{Other Antibacterial Agents with Gram-Positive Activity}

\subsection{Vancomycin}

MRSA is an important cause of nosocomial pneumonia. It is imperative that antibiotics with activity against MRSA have reliable lung penetration for the treatment of lower respiratory tract infections. We have previously reviewed the intrapulmonary penetration and ELF concentrations of vancomycin observed in both healthy subjects and critically ill patients [1]. Subsequently, an abstract by Drusano and colleagues describing a population PK modeling study and vancomycin penetration into ELF fluid has been published [81].

Ten healthy adult subjects received vancomycin 1000 mg intravenously every $12 \mathrm{~h}$ and had BAL sampling at 4 and $12 \mathrm{~h}$ after the ninth dose [81]. ELF to plasma penetration ratios, based on individual AUC estimates, ranged from 
0.24 to 4.77 . However, if excluding the outlier of 4.77 , the mean penetration ratio for the remaining nine subjects was 0.41 , similar to the noncompartmental analysis of the same data [82]. A 9999-subject Monte Carlo simulation resulted in mean and median $\mathrm{AUC}_{\mathrm{ELF}} / \mathrm{AUC}_{\text {plasma }}$ penetration ratios of 0.675 and 0.474 , respectively.

\subsection{Linezolid}

Linezolid is an oxazolidinone antibiotic available for both intravenous and oral administration. Linezolid is approved for the treatment of lower respiratory tract infections caused by $S$. pneumoniae or $S$. aureus, including both methicillinsusceptible and methicillin-resistant strains. As previously described, the ELF to plasma concentration ratios of linezolid ranged from 2.3 to 4.2 for $48 \mathrm{~h}$ after the fifth $600 \mathrm{mg}$ oral dose in healthy adults, and approximately 1.04 at 2 and $12 \mathrm{~h}$ after the fourth $600 \mathrm{mg}$ intravenous dose in critically ill patients with ventilator-associated pneumonia $[1,83,84]$.

Boselli and colleagues also conducted an analysis of intrapulmonary penetration of linezolid when administered as a continuous intravenous infusion in patients with ventilatory-associated pneumonia [85]. Twelve critically ill patients received linezolid $600 \mathrm{mg}$ as a $1 \mathrm{~h}$ intravenous infusion loading dose followed by a $1200 \mathrm{mg} /$ day continuous intravenous infusion for 2 days. The median linezolid ELF $\mathrm{AUC}_{24}$ was $164 \mu \mathrm{g} \cdot \mathrm{h} / \mathrm{mL}$ and the median ELF to serum penetration ratio was 0.97 . Despite using two different intravenous dosing strategies, the intrapulmonary penetration ratio of linezolid was similar for every 12-h intermittent intravenous infusions compared with continuous intravenous infusion $[84,85]$.

Intrapulmonary and plasma concentrations of linezolid were also compared when linezolid was administered by intermittent and continuous intravenous infusion to 22 critically ill obese patients with ventilator-associated pneumonia [86]. In this analysis, patients were randomized to receive either linezolid as an intermittent intravenous infusion of $600 \mathrm{mg}$ over $60 \mathrm{~min}$ every $12 \mathrm{~h}$ or a loading dose of $600 \mathrm{mg}$ intravenously over $60 \mathrm{~min}$ followed by $1200 \mathrm{mg} /$ day administered as a continuous intravenous infusion. Linezolid concentrations were collected after 2 days of linezolid therapy, with ELF concentrations determined in 14 patients (e.g., 7 patients in each drug administration group). The median linezolid ELF to plasma ratio was 0.80 for the intermittent intravenous infusion group and 1.06 for the continuous intravenous infusion group $(p=0.46)$. When a 1000-subject Monte Carlo simulation was conducted, a significant difference in the penetration ratio $(0.871$ vs. $0.988, p<0.001)$ was observed between the two dosing regimens. It is unclear if the reduced penetration in the intermittent infusion group can be attributed to PK differences in the obese patient population.

\subsection{Tedizolid}

Tedizolid is also a member of the oxazolidinone class with activity against Gram-positive organisms, including S. pneumoniae and MRSA. The MIC values for these two organisms are approximately eightfold lower for tedizolid compared with linezolid. Tedizolid has high plasma protein binding (89.44\%) and is available as an oral and intravenous formulation. Intrapulmonary penetration was evaluated in 20 healthy adult subjects following three oral doses of tedizolid $200 \mathrm{mg}$ administered every $24 \mathrm{~h}$ [87]. Plasma and ELF concentrations of tedizolid are shown in Table 6 . The mean unbound plasma and total ELF $\mathrm{AUC}_{24}$ estimated by noncompartmental analysis were $2.65 \mu \mathrm{g} \cdot \mathrm{h} / \mathrm{mL}$ and $109.3 \mu \mathrm{g} \cdot \mathrm{h} /$ $\mathrm{mL}$, respectively. The ELF to unbound plasma ratio based on these $\mathrm{AUC}_{24}$ values was 40. Population PK modeling and Monte Carlo simulation resulted in similar estimates of penetration ratio (39.7 and 36.3) based on respective mean and median values of $\mathrm{AUC}_{24}$ in unbound plasma $(2.67 \mu \mathrm{g} \cdot \mathrm{h} /$ $\mathrm{mL}$ and $2.59 \mu \mathrm{g} \cdot \mathrm{h} / \mathrm{mL})$ and $\mathrm{ELF}(106.0 \mu \mathrm{g} \cdot \mathrm{h} / \mathrm{mL}$ and 93.9 $\mu \mathrm{g} \cdot \mathrm{h} / \mathrm{mL}$ ) The antibacterial efficacies of tedizolid, linezolid, and vancomycin were compared in an MRSA murine pneumonia model using ELF exposure similar to those observed in humans (i.e., $109 \mu \mathrm{g} \cdot \mathrm{h} / \mathrm{mL}, 960 \mu \mathrm{g} \cdot \mathrm{h} / \mathrm{mL}$, and $92 \mu \mathrm{g} \cdot \mathrm{h} /$ $\mathrm{mL}$, respectively) [88]. The median MICs for the three stains of MRSA strains used were $0.5 \mu \mathrm{g} / \mathrm{mL}, 4 \mu \mathrm{g} / \mathrm{mL}$, and $1 \mu \mathrm{g} /$ $\mathrm{mL}$ for tedizolid, linezolid, and vancomycin, respectively. Tedizolid and linezolid demonstrated similar efficacy and resulted in higher reduction in bacterial counts and lower mortality compared with vancomycin. These findings lend support to the further exploration of tedizolid for the treatment of lower respiratory tract infections.

\subsection{Dalbavancin}

Dalbavancin is a lipoglycopeptide antibiotic available for intravenous administration in the treatment of acute bacterial skin and skin structure infection. Dalbavancin has a prolonged half-life (i.e., 14.4 days), allowing for either a single- or two-dose dosing regimen $[89,90]$. A study comparing the ELF and plasma concentrations of dalbavancin was conducted in 35 healthy adults using a bronchial microsampling technique (i.e., catheter sponge probes) since dalbavancin is not soluble in the normal saline commonly used with BAL procedures [91]. Subjects received a single dose of dalbavancin $1500 \mathrm{mg}$ administered as an intravenous infusion over $30 \mathrm{~min}$. The total plasma and ELF concentrations collected over a 7-day period are shown in Table 6 . The mean plasma $\mathrm{AUC}_{24}$ and $\mathrm{AUC}_{168}$ were $5255 \mu \mathrm{g} \cdot \mathrm{h} / \mathrm{mL}$ and $21,087 \mu \mathrm{g} \cdot \mathrm{h} / \mathrm{mL}$, respectively. The median ELF AUC ${ }_{168}$ was $527 \mu \mathrm{g} \cdot \mathrm{h} / \mathrm{mL}$. The ratio of ELF to unbound plasma based on $\mathrm{AUC}_{168}$ values was 0.36 , since plasma protein binding of dalbavancin is $93 \%$. Dalbavancin concentrations in ELF 
Table 6 Plasma and epithelial lining fluid concentrations of tedizolid and dalbavancin

\begin{tabular}{|c|c|c|c|c|c|c|c|}
\hline Antibacterial agent & Dosage regimen & Subjects $[n]$ & $\begin{array}{l}\text { Sampling } \\
\text { time }[\mathrm{h}]^{\mathrm{a}}\end{array}$ & $\begin{array}{l}\text { ELF to plasma } \\
\text { ratio based on } \\
\text { AUC }\end{array}$ & $\begin{array}{l}\text { Plasma concen- } \\
\text { tration }[\mu \mathrm{g} / \mathrm{mL}]^{\mathrm{b}}\end{array}$ & $\begin{array}{l}\text { ELF concen- } \\
\text { tration } \\
{[\mu \mathrm{g} / \mathrm{mL}]^{\mathrm{b}}}\end{array}$ & References \\
\hline \multirow[t]{4}{*}{ Tedizolid } & \multirow[t]{4}{*}{$300 \mathrm{mg}$ PO q24h $\times 3$ doses } & 5 & 2 & \multirow[t]{4}{*}{$40^{c}$} & $2.01 \pm 0.55$ & $9.05 \pm 3.83$ & \multirow[t]{4}{*}{ [87] } \\
\hline & & 5 & 6 & & $1.51 \pm 0.33$ & $4.45 \pm 2.18$ & \\
\hline & & 5 & 12 & & $0.946 \pm 0.31$ & $5.62 \pm 1.99$ & \\
\hline & & 5 & 24 & & $0.398 \pm 0.17$ & $1.33 \pm 0.59$ & \\
\hline \multirow[t]{7}{*}{ Dalbavancin } & \multirow{7}{*}{$\begin{array}{l}1500 \mathrm{mg} \text { IV infused over } \\
30 \mathrm{~min} \times 1 \text { dose }\end{array}$} & 5 & 4 & \multirow[t]{7}{*}{$0.36^{\mathrm{d}}$} & $279 \pm 32^{\mathrm{e}}$ & $1.9 \pm 1.0$ & \multirow[t]{7}{*}[91]{} \\
\hline & & 5 & 8 & & $222 \pm 27^{\mathrm{e}}$ & $3.1 \pm 1.9$ & \\
\hline & & 5 & 12 & & $194 \pm 24^{\mathrm{e}}$ & $3.6 \pm 2.1$ & \\
\hline & & 5 & 24 & & $169 \pm 20^{\mathrm{e}}$ & $2.7 \pm 0.5$ & \\
\hline & & 5 & 72 & & $120 \pm 14^{\mathrm{e}}$ & $7.3 \pm 8.2$ & \\
\hline & & 5 & 120 & & $94 \pm 11^{\mathrm{e}}$ & $11.9 \pm 20.1$ & \\
\hline & & 5 & 168 & & $79 \pm 9^{e}$ & $2.0 \pm 0.6$ & \\
\hline
\end{tabular}

$E L F$ epithelial lining fluid, $A U C$ area under the concentration-time curve, $P O$ by mouth, $I V$ intravenously, $q 24 h$ every 24 h, $S D$ standard deviation

${ }^{\text {a }}$ Sampling time after the last dose

${ }^{\mathrm{b}}$ Total plasma and ELF concentrations expressed as mean $\pm \mathrm{SD}$

${ }^{\mathrm{c}} \mathrm{B}$ ased on the ratio of $\mathrm{AUC}_{24}$ in $\mathrm{ELF}$ to $\mathrm{AUC}_{24}$ in unbound plasma, calculated using each participant's derived unbound fraction

${ }^{\mathrm{d}}$ Based on the ratio of $\mathrm{AUC}_{168}$ in ELF to $\mathrm{AUC}_{168}$ in unbound plasma, assuming 93\% protein binding in plasma

${ }^{\mathrm{e}}$ Thirty-seven plasma concentrations were reported at each sampling time; values expressed as median $\pm \mathrm{SD}$

were observed to exceed the $\mathrm{MIC}_{90}$ values for $S$. aureus and S. pneumoniae for up to 7 days after administration. The estimated $f \mathrm{AUC}_{24} / \mathrm{MIC}_{90}$ values in ELF for these pathogens were greater than plasma $f \mathrm{AUC}_{24} / \mathrm{MIC}_{90}$ values needed to achieve stasis, 1-log, and 2-log bactericidal activity in murine infection models. These findings support the further exploration of dalbavancin as a single $1500 \mathrm{mg}$ dosing regimen for the treatment of pneumonia caused by these susceptible Gram-positive organisms.

\section{Tetracyclines}

Tetracycline antibiotics have antibacterial activity against a broad spectrum of microorganisms. Newer analogs have improved potency and retained activity against mechanisms of older tetracycline resistance, including tetracycline efflux pumps and ribosomal protection proteins. Parenteral tigecycline steady-state serum and intrapulmonary concentrations in healthy adults have previously been reported [1]. Tigecycline was found to have mean total serum concentrations ranging from 0.10 to $0.19 \mu \mathrm{g} / \mathrm{mL}$ over a 12-h interval [92]. Given that tigecycline is highly protein bound, unbound concentrations are likely much lower. ELF concentrations ranged from 0.06 to $0.37 \mu \mathrm{g} / \mathrm{mL}$ and the $\mathrm{AUC}_{12}$ was 2.28 $\mu \mathrm{g} \cdot \mathrm{h} / \mathrm{mL}$. Population PK modeling found a median ELF $\mathrm{AUC}_{24}$ of $9.03 \mu \mathrm{g} \cdot \mathrm{h} / \mathrm{mL}$ and a median penetration ratio of 1.15 for tigecycline [93].

\subsection{Omadacycline and Tigecycline}

Omadacycline is an aminomethylcycline antibiotic and a semisynthetic derivative of minocycline available for both intravenous and oral administration [94]. A study comparing the intrapulmonary penetration of tigecycline and omadacycline was conducted in 50 healthy adults [94]. Subjects received either omadacycline $100 \mathrm{mg}$ intravenously every $12 \mathrm{~h}$ for two doses followed by $100 \mathrm{mg}$ every $24 \mathrm{~h}$ for three doses, or tigecycline $100 \mathrm{mg}$ intravenously for one dose followed by $50 \mathrm{mg}$ every $12 \mathrm{~h}$ for six doses. Plasma and ELF concentrations are shown in Table 7. Tigecycline concentrations in both serum and ELF were higher than those previously reported [92, 94]. In comparison, omadacycline concentrations were higher in serum and ELF than tigecycline. The total drug ELF to total drug serum penetration ratios based on AUC values were similar for both agents [94]. Once protein binding estimates were accounted for (approximately $21 \%$ and approximately $80 \%$ for omadacycline and tigecycline, respectively), the total drug ELF to unbound serum penetration ratios were 1.84 for omadacycline and 6.59 for tigecycline [94]. Lakota and colleagues conducted a population PK analysis for omadacycline using the same omadacycline ELF data and plasma concentration-time data from phase I and III clinical research studies [95]. The total drug ELF to unbound plasma penetration ratio based on $\mathrm{AUC}_{24}$ values at day 4 of therapy was calculated to be 2.06 . The ratio of ELF to total or unbound plasma AUC values 
reported in human subjects has tended to be higher than in a murine lung infection model (range 0.72-1.02) since omadacycline concentrations in plasma and ELF are nearly identical and protein binding is slightly lower (approximately $15 \%$ ) in mice [96].

Tigecycline and omadacycline have indications for community-acquired bacterial pneumonia, necessitating utility of these agents against intracellular and atypical pathogens such as Chlamydophila pneumoniae, Legionella pneumophila, and Mycoplasma pneumoniae. For this reason, AM concentrations were evaluated. AM concentrations for both tigecycline and omadacycline were greater than plasma or ELF concentrations at any given time evaluated in this study [94]. The ratio of AM to total plasma concentration based on the mean AUC was 20.8 and 302.46 for tigecycline over $12 \mathrm{~h}$ and omadacycline over $24 \mathrm{~h}$, respectively. These findings provide support for the use of omadacycline in the treatment of community-acquired bacterial pneumonia caused by susceptible organisms. No intrapulmonary studies have been conducted for omadacycline following oral administration.

Plasma and ELF concentrations of tigecycline were evaluated in 32 non-obese critically ill patients receiving a highdose regimen of a $200 \mathrm{mg}$ intravenous loading dose followed by $100 \mathrm{mg}$ every $12 \mathrm{~h}$ infused intravenously over $30 \mathrm{~min}$ [97]. Nineteen patients had a single mini-BAL (i.e., $40 \mathrm{~mL}$ of $0.9 \%$ saline solution) collection on day 4 of therapy and the mean ( \pm standard error $[\mathrm{SE}])$ concentration in ELF at $1 \mathrm{~h}$ and $12 \mathrm{~h}$ was $0.78 \pm 0.2 \mu \mathrm{g} / \mathrm{mL}(n=12)$ and $0.36 \pm 0.1$ $\mu \mathrm{g} / \mathrm{mL}(n=7)$, respectively. The mean $( \pm \mathrm{SE})$ ratio of ELF to total plasma concentrations at these respective sampling times were $2.81 \pm 1.08$ and $2.98 \pm 0.61$. The higher dosage regimen of tigecycline in critically ill patients was associated with similar ELF to total plasma penetration ratios at both the peak and trough sampling times and were higher than observed in healthy adult subjects.

\subsection{Eravacycline}

Eravacycline is a fluorocycline antibiotic that was developed by a synthetic methodology to permit chemical modifications of the tetracycline core D-ring. Eravacycline is currently available only as an intravenous formulation and is indicated for the treatment of adult patients with complicated intra-abdominal infections [98, 99]. A study has assessed plasma and intrapulmonary concentrations in 20 healthy adults after receiving eravacycline $1 \mathrm{mg} / \mathrm{kg}$ intravenously every $12 \mathrm{~h}$ for a total of seven doses [100]. Samples were collected at 2, 4, 6, or $12 \mathrm{~h}$ (Table 7). Protein binding (mean \pm SD: $82.5 \% \pm 1.7 \%$ ) was accounted for and unbound drug plasma concentrations were calculated. The $\mathrm{AUC}_{12}$ of eravacycline in the ELF was more than sixfold greater than the $\mathrm{AUC}_{12}$ of unbound drug concentrations in plasma. This is similar to the protein-adjusted ELF penetration ratio previously estimated for tigecycline [94]. These findings lend support to the further exploration of eravacycline for the treatment of lower respiratory tract infections.

\subsection{Doxycycline and Minocycline}

No human studies currently exist for doxycycline or minocycline, however findings from limited animal studies are worth noting. The minocycline intrapulmonary penetration ratio, based on the ratio of the AUC of ELF to serum, was estimated in mice and ranged from 2.5 to 2.8 [101]. Doxycycline intrapulmonary concentrations have also been evaluated in foals and horses [102, 103]. The ratio of the AUC of ELF to plasma in horses was 0.87 [102]. These findings have not yet been validated in human studies.

\section{Miscellaneous Antibacterial Agents}

\subsection{Hydroxychloroquine}

Hydroxychloroquine has recently been repurposed for the management of patients with coronavirus disease 2019 (COVID-19) for its proposed antiviral activity. A retrospective, observational study of 22 critically ill patients with COVID-19 measured 28 plasma and ELF concentrations of hydroxychloroquine [104]. All patients were intubated and received oral hydroxychloroquine as crushed tablets administered by nasogastric tube at a dose of $400 \mathrm{mg}$ once daily or $200 \mathrm{mg}$ three times daily. Plasma and ELF concentrations were measured 7-12 days after the start of hydroxychloroquine therapy (Table 8). The respective median ratios of ELF to total plasma concentrations of hydroxychloroquine were 39.96 (range 2.1-290.4) and 21.22 (range 13.4-168) for dosage regimens of $400 \mathrm{mg}$ once daily and $200 \mathrm{mg}$ three times daily. Concentrations of hydroxychloroquine in ELF were considerably greater than those in plasma and exhibited wide interpatient variability. Plasma concentrations of hydroxychloroquine were not reflective of ELF concentrations and may not be useful in determining the amount of drug in the ELF of COVID-19 patients.

\subsection{Ivermectin}

Similar to hydroxychloroquine, ivermectin's antiviral properties were being explored for use in the management of COVID-19. Jermain and colleagues developed a minimal physiologically based PK model simulating oral administration of ivermectin and resulting lung penetration following 12,30 , and $120 \mathrm{mg}$ oral doses [105]. Even at a dose of 120 $\mathrm{mg}$, the simulated peak lung concentration of $772 \mathrm{ng} / \mathrm{mL}$ is much lower than the previously reported in vitro $\mathrm{IC}_{50}$ (or half the maximal inhibitory concentration) against severe 
Table 7 Plasma and epithelial lining fluid concentrations of tetracyclines

\begin{tabular}{|c|c|c|c|c|c|c|c|}
\hline Antibacterial agent & Dosage regimen & Subjects $[n]$ & $\begin{array}{l}\text { Sampling } \\
\text { time }[\mathrm{h}]^{\mathrm{a}}\end{array}$ & $\begin{array}{l}\text { ELF to plasma } \\
\text { ratio based on } \\
\text { AUC }\end{array}$ & $\begin{array}{l}\text { Plasma concen- } \\
\text { tration } \\
{[\mu \mathrm{g} / \mathrm{mL}]^{\mathrm{b}}}\end{array}$ & $\begin{array}{l}\text { ELF concen- } \\
\text { tration } \\
{[\mu \mathrm{g} / \mathrm{mL}]^{\mathrm{b}}}\end{array}$ & References \\
\hline \multirow[t]{4}{*}{ Tigecycline } & \multirow{4}{*}{$\begin{array}{l}100 \mathrm{mg} \text { IV } 0.5 \mathrm{~h} \text { infusion } \times 1 \\
\text { dose, then } 50 \mathrm{mg} \text { IV } 0.5 \mathrm{~h} \\
\text { infusion } \mathrm{q} 12 \mathrm{~h} \times 6 \text { doses }\end{array}$} & 4 & 2 & \multirow[t]{4}{*}{$1.71^{\mathrm{c}}$} & $0.217 \pm 0.051$ & $0.553 \pm 0.497$ & \multirow[t]{4}{*}{ [94] } \\
\hline & & 5 & 4 & & $0.159 \pm 0.026$ & $0.233 \pm 0.070$ & \\
\hline & & 4 & 6 & & $0.157 \pm 0.036$ & $0.268 \pm 0.097$ & \\
\hline & & 4 & 12 & & $0.121 \pm 0.036^{\mathrm{d}}$ & $0.149 \pm 0.028^{e}$ & \\
\hline \multirow[t]{7}{*}{ Omadacycline } & \multirow{7}{*}{$\begin{array}{l}100 \mathrm{mg} \text { IV } 0.5 \mathrm{~h} \text { infusion } \mathrm{q} 12 \mathrm{~h} \\
\times 2 \text { doses, then } 100 \mathrm{mg} \text { IV } \\
0.5 \mathrm{~h} \text { infusion } \mathrm{q} 24 \mathrm{~h} \times 3 \text { doses }\end{array}$} & 6 & 0.5 & \multirow[t]{7}{*}{$1.47^{\mathrm{f}}$} & $1.80 \pm 0.13$ & $1.73 \pm 1.01$ & \multirow[t]{7}{*}{ [94] } \\
\hline & & 6 & 1 & & $0.89 \pm 0.19$ & $2.25 \pm 0.72$ & \\
\hline & & 5 & 2 & & $0.93 \pm 0.33$ & $1.51 \pm 0.94$ & \\
\hline & & 6 & 4 & & $0.54 \pm 0.12$ & $0.95 \pm 0.33$ & \\
\hline & & 6 & 8 & & $0.56 \pm 0.12$ & $0.58 \pm 0.19$ & \\
\hline & & 6 & 12 & & $0.42 \pm 0.07$ & $0.61 \pm 0.29$ & \\
\hline & & 6 & 24 & & $0.27 \pm 0.05$ & $0.41 \pm 0.13$ & \\
\hline \multirow[t]{4}{*}{ Eravacycline } & \multirow{4}{*}{$\begin{array}{l}1 \mathrm{mg} / \mathrm{kg} \text { (maximum } 100 \mathrm{mg} \text { ) IV } \\
1 \mathrm{~h} \text { infusion } \mathrm{q} 12 \mathrm{~h} \times 7 \text { doses }\end{array}$} & 5 & 2 & \multirow[t]{4}{*}{$6.44^{\mathrm{g}}$} & $0.083 \pm 0.012^{\mathrm{h}}$ & $0.70 \pm 0.30$ & \multirow[t]{4}{*}{ [100] } \\
\hline & & 5 & 4 & & $0.065 \pm 0.011^{\mathrm{h}}$ & $0.57 \pm 0.20$ & \\
\hline & & 5 & 6 & & $0.054 \pm 0.009^{h}$ & $0.34 \pm 0.16^{\mathrm{i}}$ & \\
\hline & & 5 & 12 & & $0.037 \pm 0.009^{h}$ & $0.25 \pm 0.13^{\mathrm{j}}$ & \\
\hline
\end{tabular}

$E L F$ epithelial lining fluid, $A U C$ area under the concentration-time curve, $I V$ intravenously, $B L Q$ below the lower limit of quantification, $q x h$ every $x$ hours, $S D$ standard deviation

${ }^{\text {a }}$ Sampling time after the last dose

${ }^{\mathrm{b}}$ Total plasma and ELF concentrations expressed as mean $\pm \mathrm{SD}$

${ }^{c}$ Based on the ratio of $\mathrm{AUC}_{12}$ in ELF to $\mathrm{AUC}_{12}$ in total plasma

${ }^{\mathrm{d}}$ Three concentrations were available at this sampling time

${ }^{\mathrm{e}}$ Two of the four subjects had ELF concentrations BLQ $(<1 \mathrm{ng} / \mathrm{mL})$

${ }^{\mathrm{f}}$ Based on the ratio of $\mathrm{AUC}_{24}$ in ELF to $\mathrm{AUC}_{24}$ in total plasma

${ }^{\mathrm{g}} \mathrm{B}$ ased on the ratio of $\mathrm{AUC}_{12}$ in $\mathrm{ELF}$ to $\mathrm{AUC}_{12}$ in unbound plasma, assuming protein binding between 79.3 and $87.1 \%$ in plasma

${ }^{\mathrm{h}}$ Twenty concentrations were available at each sampling time

${ }^{\mathrm{i}}$ Two of the five subjects had ELF concentrations BLQ $(<0.5 \mu \mathrm{g} / \mathrm{mL})$

${ }^{\mathrm{j}}$ Three of the five subjects had ELF concentrations BLQ $(<0.5 \mu \mathrm{g} / \mathrm{mL})$

acute respiratory syndrome coronavirus 2 (SARS-CoV-2) of $1750 \mathrm{ng} / \mathrm{mL}$ [106].

\subsection{Colistin}

Colistin methanesulfonate (CMS) is a prodrug of colistin and is approved for the treatment of multidrug-resistant Gram-negative infections, including those caused by $P$. aeruginosa. Twelve critically ill adults with ventilator-associated pneumonia received CMS 2 million international units (MIU) by nebulization followed by CMS 2 MIU every $8 \mathrm{~h}$ by intravenous infusion over $1 \mathrm{~h}$ [107]. Plasma and BAL samples were collected at steady-state (i.e., after 7-12 doses). Plasma concentrations of the active compound, colistin, ranged from $0.15 \mu \mathrm{g} / \mathrm{mL}$ to $4.7 \mu \mathrm{g} / \mathrm{mL}$, and ELF concentrations ranged from $1.48 \mu \mathrm{g} / \mathrm{mL}$ to $28.9 \mu \mathrm{g} / \mathrm{mL}$. It is possible that ELF concentrations were overestimated due to remaining intrapulmonary colistin following the initial aerosolized loading dose where the observed ELF concentrations (range
9.53-1137 $\mu \mathrm{g} / \mathrm{mL}$ ) were significantly higher than in plasma (range $0.15-0.73 \mu \mathrm{g} / \mathrm{mL}$ ). Population PK/PD modeling and simulations supported the initial addition of aerosol CMS because of the higher antimicrobial activity, lower systemic exposure to CMS ( $9 \%$ of the dose), and because a lower proportion (1.4\%) of CMS was presystemically converted to colistin.

\subsection{Amikacin}

Amikacin is an aminoglycoside often used in combination therapy in the setting of resistant Gram-negative nosocomial infections [108]. Intrapulmonary penetration of amikacin in healthy adults has not been evaluated, however ELF concentrations of amikacin have been studied in eight critically ill patients with ventilator-associated pneumonia [109]. Each patient was administered a single dose of amikacin $20 \mathrm{mg} /$ $\mathrm{kg}$ as an intravenous 30-min infusion. Plasma and ELF concentrations are reported in Table 8 . The mean and median 
Table 8 Plasma and epithelial lining fluid concentrations of antibacterial agents

\begin{tabular}{|c|c|c|c|c|c|c|c|}
\hline Antibacterial agent & Dosage regimen & Subjects $(n)$ & $\begin{array}{l}\text { Sampling time } \\
\text { (h) }\end{array}$ & $\begin{array}{l}\text { ELF to plasma } \\
\text { based on AUC }\end{array}$ & $\begin{array}{l}\text { Plasma concentra- } \\
\text { tion }(\mu \mathrm{g} / \mathrm{mL})^{\mathrm{b}}\end{array}$ & $\begin{array}{l}\text { ELF concentra- } \\
\text { tion }(\mu \mathrm{g} / \mathrm{mL})^{\mathrm{b}}\end{array}$ & References \\
\hline \multirow[t]{2}{*}{ Hydroxychloroquine } & $\begin{array}{l}400 \mathrm{mg} \text { PO once } \\
\text { daily }\end{array}$ & 22 & 7-12 days & ND & $\begin{array}{c}0.09(0.03 \\
0.19)^{\mathrm{c}, \mathrm{d}}\end{array}$ & $\begin{array}{l}3.74(0.13 \\
36.75)^{\mathrm{c}, \mathrm{d}}\end{array}$ & \multirow[t]{2}{*}{ [104] } \\
\hline & $\begin{array}{l}200 \mathrm{mg} \text { PO three } \\
\text { time daily }\end{array}$ & 22 & $7-12$ days & ND & $\begin{array}{l}0.07(0.03 \\
0.09)^{\mathrm{c}, \mathrm{d}}\end{array}$ & $\begin{array}{l}1.81(0.34 \\
10.08)^{\mathrm{c}, \mathrm{d}}\end{array}$ & \\
\hline \multirow[t]{4}{*}{ Amikacin } & \multirow{4}{*}{$\begin{array}{l}20 \mathrm{mg} / \mathrm{kg} \mathrm{IV} \times 1 \\
\text { dose }\end{array}$} & 8 & 1 & \multirow[t]{4}{*}{ NR } & $59.6 \pm 23$ & ND & \multirow[t]{4}{*}{ [109] } \\
\hline & & 8 & 2 & & $34.3 \pm 18$ & $7 \pm 6.3$ & \\
\hline & & 8 & 4 & & $27.4 \pm 21.2$ & ND & \\
\hline & & 8 & 6 & & $19.4 \pm 10$ & ND & \\
\hline \multirow[t]{5}{*}{ Plazomicin } & \multirow{5}{*}{$\begin{array}{l}15 \mathrm{mg} / \mathrm{kg} \mathrm{IV} \times 1 \\
\text { dose }\end{array}$} & 4 & 2 & \multirow[t]{5}{*}{0.13} & \multirow[t]{5}{*}{ NR } & \multirow[t]{5}{*}{ NR } & \multirow[t]{5}{*}{ [112] } \\
\hline & & 4 & 4 & & & & \\
\hline & & 4 & 6 & & & & \\
\hline & & 4 & 8 & & & & \\
\hline & & 4 & 10 & & & & \\
\hline \multirow[t]{6}{*}{ GSK2251052 } & \multirow{3}{*}{$\begin{array}{l}1500 \mathrm{mg} \text { IV } \times 1 \\
\text { dose }\end{array}$} & 5 & 2 & \multirow[t]{3}{*}{$0.54^{\mathrm{f}}$} & \multirow[t]{3}{*}{ NR } & $3.30(31.5)^{\mathrm{e}}$ & \multirow[t]{6}{*}[120]{} \\
\hline & & 5 & 6 & & & $1.05(40.2)^{\mathrm{e}}$ & \\
\hline & & 5 & 12 & & & $0.635(12.9)^{\mathrm{e}}$ & \\
\hline & \multirow{3}{*}{$\begin{array}{l}1500 \mathrm{mg} \mathrm{IV} \\
\mathrm{q} 12 \mathrm{~h} \times 5 \text { doses }\end{array}$} & 5 & 2 & \multirow[t]{3}{*}{$0.53^{\mathrm{f}}$} & \multirow[t]{3}{*}{ NR } & $5.01(25.1)^{\mathrm{e}}$ & \\
\hline & & 5 & 6 & & & $2.17(55.8)^{\mathrm{e}}$ & \\
\hline & & 5 & 12 & & & $1.16(16.5)^{\mathrm{e}}$ & \\
\hline \multirow[t]{3}{*}{ GSK1322322 } & \multirow{3}{*}{$\begin{array}{l}1500 \mathrm{mg} \text { IV } \\
\mathrm{q} 12 \mathrm{~h} \times 7 \text { doses }\end{array}$} & 6 & 2 & \multirow[t]{3}{*}{$1.2^{\mathrm{f}}$} & $13.2 \pm 3.80^{\mathrm{g}}$ & $18.2 \pm 7.55$ & \multirow[t]{3}{*}[123]{} \\
\hline & & 5 & 6 & & $3.19 \pm 1.40^{\mathrm{g}}$ & $6.26 \pm 6.12$ & \\
\hline & & 6 & 12 & & $0.406 \pm 0.178^{\mathrm{g}}$ & $0.703 \pm 0.301$ & \\
\hline
\end{tabular}

$E L F$ epithelial lining fluid; $A U C$ area under the concentration-time curve; $I V$ intravenously; $N D$ not determined; $N R$ not reported, $P O$ by mouth, qxh every x hours, $S D$ standard deviation

${ }^{\text {a }}$ Sampling time after the last dose

${ }^{\mathrm{b}}$ Values expressed as mean $\pm \mathrm{SD}$

${ }^{\mathrm{c}}$ Values expressed as median (range)

${ }^{\mathrm{d}}$ A total of 28 plasma and ELF concentrations from 22 patients

${ }^{\mathrm{e}}$ Values expressed as mean (percent coefficient of variation)

${ }^{\mathrm{f}}$ Based on the ratio of $\mathrm{AUC}_{12}$ in ELF to $\mathrm{AUC}_{12}$ in total plasma

${ }^{\mathrm{g}}$ There were 17 concentrations in plasma at each sampling time

concentrations of amikacin in ELF at $2 \mathrm{~h}$ after the start of infusion were $7 \mu \mathrm{g} / \mathrm{mL}$ and $3.6 \mu \mathrm{g} / \mathrm{mL}$, respectively. The mean $( \pm \mathrm{SD})$ penetration ratio of ELF to plasma concentrations of amikacin was $0.18 \pm 0.17$. These results are comparable with the mean ELF to plasma ratio of tobramycin in critically ill patients previously reported $[1,110]$.

Concentrations of amikacin in ELF have also been evaluated in 17 mechanically ventilated neonates [111]. Dosage regimens for amikacin were administered as 20-min intravenous infusions and were based on guidelines according to postmenstrual age (range 25.1-41 weeks). The median peak (i.e., 1-h after the start of the infusion) and trough plasma concentrations of amikacin were $39.1 \mu \mathrm{g} / \mathrm{mL}$ (range $24.1-73.2 \mu \mathrm{g} / \mathrm{mL}$ ) and $2.1 \mu \mathrm{g} / \mathrm{mL}$ (range $1-7.1 \mu \mathrm{g} / \mathrm{mL}$ ). The median concentration of amikacin in ELF was $6.5 \mu \mathrm{g} / \mathrm{mL}$ (range $1.5-23 \mu \mathrm{g} / \mathrm{mL}$ ), however these observations were obtained over a $24-\mathrm{h}$ time period. The highest concentrations of amikacin in ELF were reported between 6 and $14.5 \mathrm{~h}$ after amikacin administration.

\subsection{Plazomicin}

Plazomicin is a newly FDA-approved aminoglycoside with an indication for complicated urinary tract infection. Plasma and intrapulmonary concentrations were compared in 20 healthy adult subjects after a single dose of plazomicin 15 $\mathrm{mg} / \mathrm{kg}$ as a single dose infused over $10 \mathrm{~min}$ [112]. These investigators used a bronchoscopic microsampling technique, which involves a polyester fiber rod probe to obtain serial ELF concentrations from each subject at the surface of a bronchus (termed 'bronchial ELF'), compared with a single BAL sample obtained from the alveolar space of each 
subject. The respective mean $\mathrm{AUC}_{10}$ values in plasma and ELF were $286 \mu \mathrm{g} \cdot \mathrm{h} / \mathrm{mL}$ and $28.8 \mu \mathrm{g} \cdot \mathrm{h} / \mathrm{mL}$. The ratio of ELF to plasma based on mean $\mathrm{AUC}_{10}$ was 0.13. Although this study was performed in healthy adult subjects, the intrapulmonary penetration ratio is similar to what has been previously described for tobramycin and amikacin in critically ill patients $[1,109,110]$.

\subsection{Arbekacin}

Arbekacin is an investigational aminoglycoside being evaluated as a potential treatment for pneumonia given its activity against Gram-negative pathogens and MRSA. The PK of arbekacin in serum and ELF were evaluated in six healthy adults using the bronchial microsampling technique [113]. Each subject received a single dose of arbekacin $200 \mathrm{mg}$ administered as an intravenous infusion over $1 \mathrm{~h}$. Serial serum and BAL samples were collected over $6 \mathrm{~h}$ after the start of arbekacin infusion. Mean $( \pm \mathrm{SD}) \mathrm{AUC}_{\infty}$ values for plasma and ELF were $51.2 \pm 6.9 \mu \mathrm{g} \cdot \mathrm{h} / \mathrm{mL}$ and $34.6 \pm 15.2$ $\mu \mathrm{g} \cdot \mathrm{h} / \mathrm{mL}$, respectively. The penetration ratio of ELF to serum was 0.67 . In addition, the mean $( \pm \mathrm{SD})$ maximum concentration $\left(C_{\max }\right)$ in ELF was $10.4 \pm 1.9 \mu \mathrm{g} / \mathrm{mL}$, and occurred at $1.7 \pm 0.3 \mathrm{~h}$. While MIC breakpoints for arbekacin have not yet been described, the mean $C_{\max }$ and $\mathrm{AUC}_{\infty}$ values identified in this study suggest that PD targets (e.g., $C_{\mathrm{max}} / \mathrm{MIC}$ and/or AUC/MIC) could be attained for organisms with an MIC of $1 \mu \mathrm{g} / \mathrm{mL}$. Further studies are needed to determine the safety and efficacy of arbekacin for the treatment of hospitalacquired and ventilator-associated bacterial pneumonia.

\subsection{Lefamulin}

Lefamulin (formerly known as BC 3781) is a novel semisynthetic pleuomutilin antibiotic and the first drug of its class available for systemic use in humans. Lefamulin has both an intravenous and oral formulation and is FDAapproved for the treatment of community-acquired bacterial pneumonia $[114,115]$. Pulmonary surfactant has been shown not to inhibit the in vitro activity of lefamulin [116]. Plasma and ELF concentrations have been assessed in 12 healthy adults after receiving a single dose of lefamulin 150 $\mathrm{mg}$ intravenously infused over $1 \mathrm{~h} \mathrm{[117].} \mathrm{The} \mathrm{median} \mathrm{AUC}$ ${ }_{8}$ of lefamulin in total plasma and ELF was $4.99 \mu \mathrm{g} \cdot \mathrm{h} / \mathrm{mL}$ and $3.87 \mu \mathrm{g} \cdot \mathrm{h} / \mathrm{mL}$, with a calculated intrapulmonary penetration ratio of 0.75 . Assuming a plasma protein binding of $87 \%$, ELF concentrations were approximately 5.7 -fold greater than unbound plasma concentrations of lefamulin. In comparison, mice treated with subcutaneous lefamulin doses of $35 \mathrm{mg} / \mathrm{kg}$ or $70 \mathrm{mg} / \mathrm{kg}$ were observed to have higher pulmonary penetration ratios based on AUC (i.e., ELF to total plasma approximately twofold, and ELF to unbound plasma approximately tenfold) [116].
Population PK modeling and Monte Carlo simulations were performed using the data from the previously described 12 subjects, as well as plasma concentrations from 20 subjects receiving either lefamulin $150 \mathrm{mg}$ intravenously or $600 \mathrm{mg}$ orally under both fed and fasted conditions [118]. The median ELF to unbound plasma ratio based on AUC ${ }_{24}$ was approximately 5 , regardless of intravenous or oral administration of lefamulin. PK/PD targets for AUC/MIC ratios were established for ELF and unbound plasma concentration in a neutropenic murine pneumonia model [117]. Both formulations of lefamulin were shown to have $>92 \%$ probability of achieving target attainment associated with a $1-\log _{10}$ reduction in colony-forming units from baseline for S. pneumoniae and S. aureus for $\mathrm{MIC}_{90}$ values of $0.12 \mu \mathrm{g} /$ $\mathrm{mL}$ [119]. These PK/PD target attainment analyses of ELF and unbound plasma concentrations provided support for the dose selection decisions of lefamulin during the clinical drug development program.

\subsection{GSK2251052}

GSK2251052 is a boron-containing leucyl-tRNA synthetase inhibitor that prevents protein synthesis of Gramnegative bacteria. Plasma and intrapulmonary concentrations were compared in 30 healthy adults [120]. Fifteen subjects were evaluated following a single intravenous dose of GSK2251052 $1500 \mathrm{mg}$ and another 15 subjects were assessed after five doses of GSK2251052 1500 mg every $12 \mathrm{~h}$ intravenously infused over $1 \mathrm{~h}$. Sampling times and mean concentrations of GSK2251052 in plasma and ELF are listed in Table 8. The respective $\mathrm{AUC}_{12}$ values in plasma and ELF after a single dose were $30.0 \mu \mathrm{g} \cdot \mathrm{h} / \mathrm{mL}$ and 16.1 $\mu \mathrm{g} \cdot \mathrm{h} / \mathrm{mL}$, whereas $\mathrm{AUC}_{12}$ values after multiple doses were $55.1 \mu \mathrm{g} \cdot \mathrm{h} / \mathrm{mL}$ and $29.4 \mu \mathrm{g} \cdot \mathrm{h} / \mathrm{mL}$. The $\mathrm{AUC}_{12}$ ratios of ELF to total plasma were similar after single and multiple doses (0.54 and 0.53, respectively). Exposure of GSK2251052 in ELF was slightly higher in healthy humans than in a murine infection model (0.54 vs. 0.34) [121].

$\mathrm{AM}$ concentrations were also evaluated and $\mathrm{AUC}_{12}$ ratios of AM to total plasma were 6.21 and 4.98 after single and multiple doses, respectively. Therefore, respective concentrations in ELF and AM were approximately 50\% and 500\% of those in plasma. Unfortunately, further investigations of GSK2251052 were discontinued after bacterial resistance rapidly developed in patients being treated for complicated urinary tract infection during a phase II clinical trial [122].

\subsection{GSK1322322}

GSK1322322 is a potent inhibitor of peptide deformylase and novel hydrazinopyrimidine with in vitro antibacterial activity against common skin and respiratory tract pathogens. An evaluation of the intrapulmonary penetration 
of GSK1322322 into ELF and AM was performed in 17 healthy adults [123]. Subjects received GSK1322322 1500 mg every $12 \mathrm{~h}$ intravenously infused over $1 \mathrm{~h}$ for seven doses. Plasma and ELF concentrations at the three sampling times are listed in Table 8. The mean $\mathrm{AUC}_{12}$ values in total plasma, unbound plasma (assuming protein binding of 66\%), and ELF were $66.7 \mu \mathrm{g} \cdot \mathrm{h} / \mathrm{mL}, 22.7 \mu \mathrm{g} \cdot \mathrm{h} / \mathrm{mL}$, and $78.9 \mu \mathrm{g} \cdot \mathrm{h} /$ $\mathrm{mL}$, respectively. The calculated $\mathrm{AUC}_{12}$ ratios of ELF to total plasma and ELF to unbound plasma were 1.2 and 3.5, respectively. In comparison, the $\mathrm{AUC}_{12}$ ratios of $\mathrm{AM}$ to total plasma and $\mathrm{AM}$ to unbound plasma were 2.5 and 7.4, respectively. Further investigations for the clinical development of GSK1322322 have been discontinued.

\subsection{Fosfomycin}

Fosfomycin is currently FDA-approved as a single-dose oral antibiotic for the treatment of uncomplicated acute cystitis in women. Outside of the US, intravenous fosfomycin is commercially available and is used for a wide variety of infectious syndromes, including systemic multidrug-resistant infections. Although no studies evaluating ELF concentrations of fosfomycin in humans have been published, measurement of interstitial concentrations of fosfomycin from healthy and infected lung tissue of seven patients with sepsis has been described [124]. The mean ( \pm SD) lung to plasma penetration ratio using $\mathrm{AUC}_{\infty}$ values was $0.63 \pm 0.31$ and $0.53 \pm 0.31$ for healthy and infected lung tissues, respectively. A study evaluating ELF concentrations of fosfomycin was performed in six piglets receiving a single intramuscular dose of fosfomycin $15 \mathrm{mg} / \mathrm{kg}$ [125]. The mean fosfomycin $\mathrm{AUC}_{8}$ for plasma and ELF was $98.70 \mu \mathrm{g} \cdot \mathrm{h} / \mathrm{mL}$ and 12.37 $\mu \mathrm{g} \cdot \mathrm{h} / \mathrm{mL}$, respectively. The mean ratio of ELF to plasma concentrations was 0.12 . Additional studies are needed to evaluate ELF concentrations of fosfomycin in humans and to hopefully resolve the observed differences in penetration ratios of various lung matrices.

\section{Conclusions}

The penetration of antibacterial agents into the ELF has continued to be extensively evaluated during the past 10 years. This review provides information since our previous review in 2011 and includes the ELF concentrations and intrapulmonary penetration ratios from more than 40 studies [1]. The antibiotic class with the largest contribution to this review are $\beta$-lactam agents, with or without $\beta$-lactamase inhibitors. This matches the current focus of antibacterial drug development programs seeking regulatory approval of new agents for the treatment of serious infections caused by multidrug-resistant Gram-negative bacteria.
The majority of intrapulmonary penetration studies have been conducted in healthy adult subjects using BAL as a reliable method for measuring antibiotic concentrations in the lungs. Penetration ratios have mainly been determined from AUC values during a single dosing interval following the administration of multiple doses (e.g., steady-state). Protein binding of plasma concentrations has been commonly accounted for so that ratios can represent unbound drugs in the ELF and plasma. These studies in healthy subjects answer the initial question on whether the antibacterial agent can penetrate into the ELF. If penetration does occur, the next questions center on achieving sufficient ELF concentrations with a dosage regimen that is considered to be welltolerated and effective against extracellular bacteria associated with pneumonia.

The past decade has also witnessed an increased number of preclinical studies in the neutropenic murine lung infection model where both plasma and ELF concentrations of antibacterial agents were measured. This model, as well as murine thigh and hollow fiber models, have been useful in identifying which PK/PD parameter(s) best correlates with antibacterial activity and defining drug exposure targets associated with various bacterial reduction endpoints in plasma and ELF [126]. Combining the animal PD target values with human plasma and ELF data from healthy subjects has proven useful as a pharmacological rationale in the dosage selection to treat bacterial pneumonia (Fig. 1) [4].

The number of intrapulmonary penetration studies in critically ill patients remain limited. The observations thus far have suggested noteworthy differences in the time course, magnitude, and variability of ELF concentrations compared with healthy adult subjects $[3,5]$. These alterations can be important considerations for optimizing dosage regimens of antibacterial agents in clinical situations, such as ventilatorassociated bacterial pneumonia, where pathogens may have elevated MIC values. Additional studies are merited in this patient population to further understand the potential impact on concentrations at the sites of pulmonary infection.

This review of the literature and our clinical research experience with these studies has allowed us to further consider the role of intrapulmonary studies during the antibacterial drug development process. We believe the following issues are key steps in developing and evaluating dosage regimens to treat extracellular bacteria in lower respiratory tract infections: (1) assess ELF concentrations in murine infection models to assess both drug penetration and PK/ PD target exposures associated with each organism likely to be treated with the agent; (2) conduct an intrapulmonary penetration study in healthy adult subjects to determine that the agent penetrates into the lung, and document the concentration-time profile in ELF and unbound plasma; (3) consider and incorporate the wide variability and differences in ELF concentrations that may occur in critically ill patients 
as part of the dosage regimen design; (4) use all available PK studies in humans and PD targets from animal and/or in vitro models to conduct population $\mathrm{PK}$ modeling, simulations, and probability of target attainment assessment to select an optimal dosage regimen for clinical trials [4, 127, 128]; (5) collect plasma and ELF concentrations in patients being treated for hospital-acquired and/or ventilator-associated bacterial pneumonia, including adequate number of samples and sampling times to understand the concentrationtime profiles in critically ill patients; and (6) use plasma and ELF data from clinical studies of both healthy subjects and infected patients to develop validated population PK models with covariate effects, and conduct simulations to support target attainment of dosage recommendations in patients with normal and impaired excretion [42, 54, 129].

Penetration ratios determined from AUC values of each matrix remains the most accurate method to describe drug distribution between plasma and the potential site of infection (i.e., ELF). However, absolute drug concentrations in ELF and PK/PD target values are most useful to predict the potential efficacy of antibacterial agents against extracellular pathogens in the lung. A more robust procedure in understanding the therapeutic importance of these concentrations has occurred by linking preclinical PD exposure targets with human population PK analysis and Monte Carlo simulation. These techniques permit co-modeling of both plasma and ELF concentrations from healthy subjects and critically ill patients, and prediction of dose selection of antibacterial agents to treat pneumonia. While these methodologies are currently available, further studies are desperately needed to assess the significance of ELF concentrations in critically ill patients with pulmonary infections and to document what relationships exist between PK/PD parameters and clinical outcomes.

\section{Declarations}

Funding This manuscript was not funded in whole or in part by any research grant or funding body.

Conflict of Interests/Competing Interests Emily Drwiega has no conflicts of interest that are directly relevant to the content of this review. Keith Rodvold has conducted research and/or served as a consultant for intrapulmonary studies discussed in this manuscript for Cempra Pharmaceuticals, Cubist Pharmaceuticals, Durata Therapeutics, Entasis Therapeutics, GlaxoSmithKline, Ortho-McNeil, Paretek Pharmaceuticals, Shionogi \& Co., The Medicine Company/Rempex, and Wockhardt Ltd. He has also served on advisory boards, speaking bureaus, or as a consultant for Merck Inc., Shionogi \& Co., Sinovent, Spero Therapeutics, The Medicine Company/Qpex Biopharma, and Venatorx Pharmaceuticals.

Ethics Approval Not applicable.

Consent to Participate Not applicable.
Consent for Publication Not applicable.

Availability of Data and Material Not applicable.

Code Availability Not applicable.

Author Contributions Both authors made substantial contributions to the conception, drafting, and critical revision of the manuscript for important intellectual content. Both authors approved the final version of the manuscript.

\section{References}

1. Rodvold KA, George JM, Yoo L. Penetration of anti-infective agents into pulmonary epithelial lining fluid: focus on antibacterial agents. Clin Pharmacokinet. 2011;50(10):637-64.

2. Rodvold KA, Yoo L, George JM. Penetration of anti-infective agents into pulmonary epithelial lining fluid: focus on antifungal, antitubercular and miscellaneous anti-infective agents. Clin Pharmacokinet. 2011;50(11):689-704.

3. Rodvold KA, Hope WW, Boyd SE. Considerations for effect site pharmacokinetics to estimate drug exposure: concentrations of antibiotics in the lung. Curr Opin Pharmacol. 2017;36:114-23.

4. Rizk ML, Bhavnani SM, Drusano G, et al. Considerations for dose selection and clinical pharmacokinetics/pharmacodynamics for the development of antibacterial agents. Antimicrob Agents Chemother. 2019;63:e02309-e2318.

5. Heffernan AJ, Sime FB, Lipman J, et al. Intrapulmonary pharmacokinetics of antibiotics used to treat nosocomial pneumonia caused by Gram-negative bacilli: a systematic review. Inter J Antimicrob Agents. 2019;53:234-45.

6. Caro L, Nicolau DP, De Waele JJ, et al. Lung penetration, bronchopulmonary pharmacokinetic/pharmacodynamic profile and safety of $3 \mathrm{~g}$ of ceftolozane/tazobactam administered to ventilated, critically ill patients with pneumonia. J Antimicrob Chemother. 2020;75:1545-53.

7. Katsube T, Nicolau D, Rodvold K, et al. The intrapulmonary pharmacokinetic profile of cefiderocol in mechanically ventilated patients with pneumonia. J Antimicrob Chemother. 2021 (in press).

8. Ambrose PG, Bhavnani SM, Ellis-Grosse EJ, Drusano GL. Pharmacokinetic-pharmacodynamic considerations in the design of hospital-acquired or ventilator-associated bacterial pneumonia studies: look before you leap! Clin Infect Dis. 2010;51(S1):S103-10.

9. Morrissey I, Ge Y, Janes R. Activity of the new cephalosporin ceftaroline against bacteraemia isolates from patients with community-acquired pneumonia. Int $\mathbf{J}$ Antimicrob Agents. 2009;33(6):515-9.

10. Kiang TKL, Wilby KJ, Ensom MHH. A critical review on the clinical pharmacokinetics, pharmacodynamics, and clinical trials of ceftaroline. Clin Pharmacokinet. 2015;54:915-31.

11. Riccobene TA, Pushkin R, Jandourek A, Knebel W, Kharlton T. Penetration of ceftaroline into the epithelial lining fluid of healthy adult subjects. Antimicrob Agents Chemother. 2016;60:5849-57.

12. Bhalodi AA, Crandon JL, Biek D, Nicolau DP. Efficacy of ceftaroline fosamil in a Staphylococcal murine pneumonia model. Antimicrob Agents Chemother. 2012;56(12):6160-5.

13. Portsmouth S, van Veenhuyzen D, Echols R, et al. Cefiderocol versus imipenem-cilastatin for the treatment of complicated urinary tract infections caused by Gram-negative uropathogens: a 
phase 2, randomized, double-blind, non-inferiority. Lancet Infect Dis. 2018;18(12):1319-28.

14. Wunderink RG, Matsunaga Y, Ariyasu M, et al. Cefiderocol versus high-dose, extended-infusion meropenem for the treatment of Gram-negative nosocomial pneumonia (APEKS-NP): a randomized, double-blind, phase 3, non-inferiority trial. Lancet Infect Dis. 2021;21:213-25.

15. Katsube T, Saisho Y, Shijmada J, Furuie H. Intrapulmonary pharmacokinetics of cefiderocol, a novel siderophore cephalosporin, in healthy adult subjects. J Antimicrob Chemo. 2019;74(7):1971-4.

16. Naber KG, Llorens L, Kaniga K, Kotey P, Hedrich D, Redman R. Intravenous doripenem at 500 milligrams versus levofloxacin at 250 milligrams, with an option to switch to oral therapy, for treatment of complicated lower urinary tract infection and pyelonephritis. Antimicrob Agents Chemother. 2019;53(9):3782-92.

17. Lucasti C, Jasovich A, Umeh O, Jiang J, Kaniga K, Friedland I. Efficacy and tolerability of IV doripenem versus meropenem in adults with complicated intra-abdominal infection: a phase III, prospective, multicenter, randomized, double-blind, noninferiority study. Clin Ther. 2008;30(5):868-83.

18. Justo J, Gotfried MH, Deyo K, Fischer P, Danziger LH, Rodvold KA. Doripenem intrapulmonary pharmacokinetics in healthy adult subjects, abstract A1-1748. In: Proceedings of the 51st Interscience Conference on Antimicrobial Agents and Chemotherapy, American Society of Microbiology, Washington, DC. 2011.

19. Chandorkar G, Huntington JA, Gotfried MH, Rodvold KA, Umeh O. Intrapulmonary penetration of ceftolozane/tazobactam and piperacillin-tazobactam in healthy adult subjects. J Antimicrob Chemother. 2012;67:2463-9.

20. Kollef MH, Novacek M, Kivistik U, et al. Ceftolozane-tazobactam versus meropenem for treatment of nosocomial pneumonia (ASPECT-NP): a randomized, controlled, double-blind, phase 3, non-inferiority trial. Lancet Infect Dis. 2019;19(12):1299-311.

21. Melchers MJ, Mavridou E, Seyedmousavi S, van Mil AC, Lagarde C, Mouton JW. Plasma and epithelial lining fluid pharmacokinetics of ceftolozane and tazobactam alone and in combination in mice. Antimicrob Agents Chemother. 2015;59:3373-6.

22. Xiao AJ, Miller BW, Huntington JA, Nicolau DP. Ceftolozane/ tazobactam pharmacokinetic/pharmacodynamic-derived dose justification for Phase 3 studies in patients with nosocomial pneumonia. J Clin Pharmacol. 2016;56(1):56-66.

23. Dallow J, Otterson LG, Huband MD, Krause KM, Nichols WW. Microbiological interactions studies between ceftazidime-avibactam and pulmonary surfactant and between ceftazidime-avibactam and antibacterial agents of other classes. Int J Antimicrob Agents. 2014;44:552-6.

24. Nicolau DP, Siew L, Armstrong J, et al. Phase 1 study assessing the steady-state concentration of ceftazidime and avibactam in plasma and epithelial lining fluid following two dosing regimens. J Antimicrob Chemother. 2015;70:2862-9.

25. Berkhout J, Melchers MJ, Van Mil AC, et al. Pharmacokinetics and penetration of ceftazidime and avibactam into epithelial lining fluid in thigh- and lung-infected mice. Antimicrob Agents Chemother. 2015;59:2299-304.

26. Torres A, Zhong N, Pachl J, et al. Ceftazidime-avibactam versus meropenem in nosocomial pneumonia, including ventilator-associated pneumonia (REPROVE): a randomized, double-blind, phase 3 non-inferiority trial. Lancet Infect Dis. 2018;18(3):285-95.

27. Dimelow R, Wright JG, MacPherson M, Newell, Das S. Population pharmacokinetic modelling of ceftazidime and avibactam in the plasma and epithelial lining fluid of healthy volunteers. Drugs R D. 2018;18:221-30.
28. Livermore DM, Mushtaq S, Warner M, Vickers A, Woodford N. In vitro activity of cefepime/zidebactam (WCK 5222) against Gram-negative bacteria. J Antimicrob Chemother. 2017;72(5):1373-85.

29. Sader HS, Rhomberg PR, Flamm RK, Jones RN, Castanheira M. WCK 5222 (cefepime/zidebactam) antimicrobial activity tested against Gram-negative organisms producing clinically relevant B-lactamases. J Antimicrob Chemother. 2017;72(6):1696-703.

30. Rodvold KA, Gotfried MH, Chugh R, et al. Plasma and intrapulmonary concentrations of cefepime and zidebactam following intravenous administration of WCK5222 to healthy adult subjects. Antimicrob Agents Chemother. 2018;62(8):e00682-e718.

31. Boselli E, Breilh D, Duflo F, et al. Steady-state plasma and intrapulmonary concentrations of cefepime administered in continuous infusion in critically ill patients with severe nosocomial pneumonia. Crit Care Med. 2003;31:2102-6.

32. Lepak AJ, Zhao M, Andes DR. WCK 5222 (Cefepime/Zidebactam) pharmacodynamic target analysis against Metallo-Blactamase producing Enterobacteriaceae in the neutropenic mouse pneumonia model. Antimicrob Agents Chemother. 2019;63(12):e01648-e1719.

33. Kidd JM, Abdelraouf K, Nicolau DP. Efficacy of human-simulated bronchopulmonary exposures of cefepime, zidebactam and the combination (WCK 5222) against MDR Pseudomonas aeruginosa in neutropenic murine pneumonia model. J Antimicrob Chemother. 2020;75(1):149-55.

34. Morrissey I, Magnet S, Hawser S, Shapiro S, Knechtle P. In vitro activity of cefepime-enmetazobactam against Gram-negative isolates collected from US and European Hospitals during 20142015. Antimicrob Agents Chemother. 2019;63(7):e00514-9.

35. Das S, Fitzgerald R, Ullah A, et al. Intrapulmonary pharmacokinetics of cefepime and enmetazobactam in healthy volunteers: towards new treatments for nosocomial pneumonia. Antimicrob Agents Chemother. 2020;65(1):e01468-e1520.

36. Johnson A, McEntee L, Farrington N, et al. Pharmacodynamics of cefepime combined with novel extended-spectrum-B-lactamase (ESBL) inhibitor enmetazobactam for murine pneumonia caused by ESBL-producing Klebsiella pneumoniae. Antimicrob Agents Chemother. 2020;64(6):e00180-e220.

37. Zhanel GG, Lawrence CK, Adam H, et al. Imipenem-relebactam and meropenem-vaborbactam: two novel carbapenem-B-lactamase inhibitor combinations. Drugs. 2018;78(1):65-98.

38. Rubio-Aparicio D, Loutit J, Dudley M, Lomovskaya O. Potency of meropenem-vaborbactam in lung surfactant. Antimicrob Agents Chemother. 2017;62(1):e01702-e1717.

39. Wenzler E, Gotfried MH, Loutit JS, et al. Meropenem-RPX7009 concentrations in plasma, epithelial lining fluid, and alveolar macrophages of healthy adult subjects. Antimicrob Agents Chemother. 2015;59:7232-9.

40. Rizk ML, Rhee EG, Jumes PA, et al. Intrapulmonary pharmacokinetics of relebactam, a novel $\beta$-lactamase inhibitor, dosed in combination with imipenem-cilastatin in healthy subjects. Antimicrob Agents Chemother. 2018;62(3):e01411-e1417.

41. Van Hasselt JG, Rizk ML, Lala M, et al. Pooled population pharmacokinetic model of imipenem in plasma and the lung epithelial lining fluid. Br J Clin Pharmacol. 2016;81:1113-23.

42. Bhagunde P, Patel P, Lala M, et al. Population pharmacokinetic analysis for imipenem-relebactam in healthy volunteers and patients with bacterial infections. CPT Pharmacometrics Syst Pharmacol. 2019;8(10):748-58.

43. Titov I, Wunderink RG, Roquilly A, et al. A randomized, double-blind, multicenter trial comparing efficacy and safety of imipenem/cilastatin/relebactam versus piperacillin-tazobactam in adults with hospital-acquired or ventilator-associated bacterial pneumonia (RESTORE-IMI 2 Study). Clin Infect Dis. 2020. https://doi.org/10.1093/cid/ciaa803. (Epub 12 Aug 2020). 
44. McLeod SM, Shapiro AB, Moussa SH, et al. Frequency and mechanism of spontaneous resistance to sulbactam combined with the novel B-lactamase inhibitor ETX2514 in clinical isolates of Acinetobacter baumannii. Antimicrob Agents Chemother. 2018;62(2):e01576-e1617.

45. Barnes MD, Kumar V, Bethel CR, et al. Targeting multidrugresistant Acinetobacter spp.: sulbactam and diazabicyclooctenone B-lactamase inhibitor ETX2514 as a novel therapeutic agent. mBio. 2019;10(2):e00159-19.

46. Rodvold KA, Gotfried MH, Isaacs RD, O'Donnell JP, Stone E. Plasma and intrapulmonary concentrations of ETX2514 and sulbactam following intravenous administration of ETX2514SUL to healthy adult subjects. Antimicrob Agents Chemother. 2018;62(11):e01089-e1118.

47. Felton TW, McCalman K, Malagon I, et al. Pulmonary penetration of piperacillin and tazobactam in critically ill patients. Clin Pharmacol Ther. 2014;96(4):438-48.

48. Felton TW, Ogungbenro K, Boselli E, Hope WW, Rodvold KA. Comparison of piperacillin exposure in the lungs of critically ill patients and healthy volunteers. J Antimicrob Chemother. 2018;73(5):1340-7.

49. Wenzler E, Bunnell KL, Bleasdale SC, Benken S, Danziger LH, Rodvold KA. Pharmacokinetics and dialytic clearance of ceftazidime-avibactam in a critically ill patient on continuous venovenous hemofiltration. Antimicrob Agents Chemother. 2017;61(7):e00464-e517.

50. Cousson J, Floch T, Guillard T, et al. Lung concentrations of ceftazidime administered by continuous versus intermittent infusion in patients with ventilator-associated pneumonia. Antimicrob Agents Chemother. 2015;59(4):1905-9.

51. Boselli E, Breilh D, Rimmele T, et al. Plasma and lung concentrations of ceftazidime administered in continuous infusion to critically ill patients with severe nosocomial pneumonia. Intensive Care Med. 2004;30(5):989-91.

52. Katsube T, Kawaguchi N, Echols R, Wajima T, Nicolau DP. Cefiderocol population pharmacokinetics and probability of target attainment in plasma and epithelial lining fluid in patients with pneumonia, bloodstream infection/sepsis, or complicated urinary tract infections. Open Forum Infect Dis. 2020;7(Suppl 1):S665.

53. Caro L, Nicolau DP, De Waele JJ, et al. Lung penetration, bronchopulmonary pharmacokinetic/pharmacodynamic profile and safety of $3 \mathrm{~g}$ ceftolozane/tazobactam administered to ventilated, critically ill patients with pneumonia. J Antimicrob Chemother. 2020;75(6): 1546-53.

54. Zhang Z, Patel YT, Fiedler-Kelly J, Feng H, Bruno CJ, Gao W. Population pharmacokinetic analysis for plasma and epithelial lining fluid ceftolozane/tazobactam concentrations in patients with ventilated nosocomial pneumonia. J Clin Pharmcol. 2021;61(2):254-68.

55. Lodise TP, Sorgel F, Melnick D, et al. Penetration of meropenem into epithelial lining fluid of patients with ventilator-associated pneumonia. Antimicrob Agents Chemother. 2011;55(4):1606-10.

56. Frippiat F, Musuamba FT, Seidel L, et al. Modelled target attainment after meropenem infusion in patients with severe nosocomial pneumonia: the PROMESSE study. J Antimicrob Chemother. 2015;70(1):207-16.

57. Benitez-Cano A, Luque S, Sorli L, et al. Intrapulmonary concentrations of meropenem administered by continuous infusion in critically ill patients with nosocomial pneumonia: a randomized pharmacokinetic trial. Crit Care. 2020;24(1):55.

58. Oesterreicher Z, Minichmayr I, Sauermann R, et al. Pharmacokinetics of doripenem in plasma and epithelial lining fluid (ELF): comparison of two dosage regimens. Eur J Clin Pharmacol. 2017;73(12):1609-13.
59. Kollef MH, Chastre J, Clavel M, et al. A randomized trial of 7-day doripenem versus 10-day imipenem-cilastatin for ventilator-associated pneumonia. Crit Care. 2012;16(6):R218.

60. Bader JC, Lakota EA, Dale GE, et al. Pharmacokinetic-pharmacodynamic evaluation of ertapenem for patients with hospitalacquired or ventilator-associated bacterial pneumonia. Antimicrob Agents Chemother. 2019;63(6):e00318-e319.

61. Boselli E, Breilh D, Saux M, Gordien J, Allaouchiche B. Pharmacokinetics and lung concentrations of ertapenem in patients with ventilator-associated pneumonia. Intensive Care Med. 2006;32(12):2059-62.

62. Rodvold KA, Gotfried MH, Still JG, Clark K, Fernandes P. Comparison of plasma, epithelial lining fluid, and alveolar macrophage concentrations of solithromycin (CEM-101) in healthy adult subjects. Antimicrob Agents Chemother. 2012;56(10):5076-81.

63. Ikawa K, Kikuchi E, Kikuchi J, Nishimura M, Derendorf H, Morikawa N. Pharmacokinetic modelling of serum and bronchial concentrations for clarithromycin and telithromycin, and site-specific pharmacodynamic simulation for their dosages. $\mathbf{J}$ Clin Pharm Ther. 2014;39:411-7.

64. Salerno SN, Edginton A, Cohen-Wolkowiez M, Hornik CP, Watt $\mathrm{KM}$, Jamieson BD, et al. Development of an adult physiologically based pharmacokinetic model of solithromycin in plasma and epithelial lining fluid. CPT Pharmacometrics Syst Pharmacol. 2017;6:814-22.

65. Okusanya OO, Forrest A, Bhavnani SM, Fernandes P, Ambrose PG, Andes DR. Pharmacokinetic/pharmacodynamic evaluation of solithromycin again Streptococcus pneumoniae using data from a neutropenic murine lung infection model. Antimicrob Agents Chemother. 2019;63(8):e02606-e2618.

66. Rodvold KA, Gotfried MH, Chugh R, Gupta M, Friedland HD, Bhatia A. Comparison of plasma and intrapulmonary concentrations of nafithromycin (WCK 4873) in healthy adult subjects. Antimicrob Agents Chemother. 2017;61(9):e01096-e1117.

67. Flamm RK, Rhomberg PR, Sader HS. In vitro activity of the novel lactone ketolide nafithromycin (WCK 4873) against contemporary clinical bacteria from a global surveillance program. Antimicrob Agents Chemother. 2017;61(12):e01230-e1317.

68. Metlay JP, Waterer GW, Long AC, Anzueto A, Brozek J, Crothers K, et al. Diagnosis and treatment of adults with communityacquired pneumonia. An official clinical practice guideline of the American Thoracic Society and Infectious Diseases Society of America. Am J Respir Crit Care Med. 2019;200(7):e45-e67.

69. Kalil AC, Metersky ML, Klompas M, Muscedere J, Sweeney DA, Palmer LB, et al. Management of adults with hospital-acquired and ventilator-associated pneumonia: 2016 clinical practice guidelines by the Infectious Diseases Society of America and the American Thoracic Society. Clin Infect Dis. 2016;63(5):e61-111.

70. Huang H, Wang Y, Jiang C, Lang L, Wang H, Chen Y, et al. Intrapulmonary concentration of levofloxacin in patients with idiopathic pulmonary fibrosis. Pulm Pharmacol Ther. 2014;28:49-52.

71. Nicolau DP, Sutherland C, Winget D, Baughman RP. Bronchopulmonary pharmacokinetic and pharmacodynamic profiles of levofloxacin $750 \mathrm{mg}$ once daily in adults undergoing treatment for acute exacerbation of chronic bronchitis. Pulm Pharmacol Ther. 2012;25:94-8.

72. Kuti JL, Nicolau DP. Presence of infection influences the epithelial lining fluid penetration of oral levofloxacin in adult patients. Int J Antimicrob Agents. 2015;45:512-8.

73. Bhagwat SS, Nandanwar M, Kansagara A, Patel A, Takalkar S, Chavan R, et al. Levonadifloxacin, a novel broad-spectrum anti-MRSA benzoquinolizine quinolone agent: review of current evidence. Drug Des Devel Ther. 2019;13:4351-65. 
74. Rodvold KA, Gotfried MH, Chugh R, Gupta M, Yeole R, Patel A, et al. Intrapulmonary pharmacokinetics of levonadifloxacin following oral administration of alalevonadifloxacin to healthy adult subjects. Antimicrob Agents Chemother. 2018;62(3):e02297-e2317.

75. Tiengrim S, Phiboonbankit D, Thunyaharn S, Tantisiriqat W, Santiwatanakul S, Susaengrat W, et al. Comparative in vitro activity of sitafloxacin against bacteria isolated from Thai patients with urinary tract infections and lower respiratory tract infections. J Med Assoc Thai. 2012;95(Supp 2):S6-17.

76. Paiboonvong T, Nosoongnoen W, Sathirakul K, Tangsujaritvijit V, Kaemapairoj J, Tragulpiankit P, et al. Pharmaokinetics and penetration of sitafloxacin into alveolar epithelial lining fluid in critically ill Thai patients with pneumonia. Antimicrob Agents Chemother. 2019;63(10):e00800-e819.

77. Davenport JM, Covington P, Gotfried M, Medlock M, Watanalumlerd P, McIntyre G, et al. Summary of pharmacokinetics and tissue distribution of a broad-spectrum fluoroquinolone, JNJ-Q2. Clin Pharmacol Drug Dev. 2012;1(4):121-30.

78. Kishii R, Yamaguchi Y, Takei M. In vitro activities and spectrum of the novel fluoroquinolone lascufloxacin (KRP-AM1977). Antimicrob Agents Chemother. 2017;61(6):e00120-e217.

79. Furuie H, Tanioka S, Shimizu K, Manita S, Nishimura M, Yoshida H. Intrapulmonary pharmacokinetics of lascufloxacin in healthy adult volunteers. Antimicrob Agents Chemother. 2018;62(4):e02169-e2217.

80. Ohya K, Tankano J, Manita S. In vitro mechanistic study of the distribution of lascufloxacin into epithelial lining fluid. Antimicrob Agents Chemother. 2019;63(4):e02208-e2218.

81. Lodise TP, Drusano GL, Butterfield JM, Scoville J, Gotfried M, Rodvold KA. Penetration of vancomycin into epithelial lining fluid in healthy volunteers. Antimicrob Agents Chemother. 2011;55(12):5507-11.

82. Rodvold KA, Gotfried MH, Loutit JS, Porter SB. Plasma and intrapulmonary concentrations of oritavancin and vancomycin in normal healthy adults, abstract O-254. Clin Microbiol Infect. 2004;10(Suppl 3):44.

83. Conte JE, Golden JA, Kipps J, Zurlinden E. Intrapulmonary pharmacokinetics of linezolid. Antimicrob Agents Chemother. 2002;46(5):1475-80.

84. Boselli E, Breilh D, Rimmele T, Djabarouti S, Toutain J, Chassard D, et al. Pharmacokinetics and intrapulmonary concentrations of linezolid administered to critically ill patients with ventilator-associated pneumonia. Crit Care Med. 2005;33(7):1529-33.

85. Boselli E, Breilh D, Caillault-Sergent A, Djabarouti S, Guillaume C, Xuereb F, et al. Alveolar diffusion and pharmacokinetics of linezolid administered in continuous infusion to critically ill patients with ventilator-associated pneumonia. J Antimicrob Chemother. 2012;67:1207-10.

86. De Pascale G, Fortuna S, Tumbarello M, Cutuli SL, Vallecoccia M, Spanu T, et al. Linezolid plasma and intrapulmonary concentrations in critically ill obese patients with ventilator-associated pneumonia: intermittent vs continuous administration. Intensive Care Med. 2015;41:103-10.

87. Housman ST, Pope JS, Russomanno J, Salerno E, Shore E, Kuti $\mathrm{JL}$, et al. Pulmonary disposition of tedizolid following administration of once-daily oral 200-milligram tedizolid phosphate in healthy adult volunteers. Antimicrob Agents Chemother. 2012;56(5):2627-34.

88. Tessier PR, Keel RA, Hagihara M, Crandon JL, Nicolau DP. Comparative in vivo efficacies of epithelial lining fluid exposures of tedizolid, linezolid, and vancomycin for methicillin-resistant Staphylococcus aureus in a mouse pneumonia model. Antimicrob Agents Chemother. 2012;56(5):2342-6.

89. Dunne MW, Puttagunta S, Giordano P, Krievins D, Zelasky M, Baldassarre J. A randomized clinical trial of single-dose versus weekly dalbavancin for treatment of acute bacterial skin and skin structure infection. Clin Infect Dis. 2016;62(5):545-51.

90. Boucher HW, Wilcox M, Talbot GH, Puttagunta S, Das AF, Dunne MW. Once-weekly dalbavancin versus daily conventional therapy for skin infection. N Engl J Med. 2014;370:2169-79.

91. Rappo U, Dunne MW, Puttagunta S, Baldassarre JS, Su S, Desai-Krieger D, et al. Epithelial lining fluid and plasma concentrations of dalbavancin in healthy adults after a single 1,500-milligram infusion. Antimicrob Agents Chemother. 2019;63(11):e01024-e1119.

92. Conte JE, Golden JA, Kelly MG, Zurlinden E. Steady-state serum and intrapulmonary pharmacokinetics and pharmacodynamics of tigecycline. Int J Antimicrob Agents. 2005;25(6):523-9.

93. Rubino CM, Ma L, Bhavnani SM, Korth-Bradley J, Speth J, Ellis-Grosse E, et al. Evaluation of tigecycline penetration into colon wall tissue and epithelial lining fluid using a population pharmacokinetic model and Monte Carlo simulation. Antimicrob Agents Chemother. 2007;51(11):4085-9.

94. Gotfried MH, Horn K, Garrity-Ryan L, Villano S, Tzanis E, Chitra $\mathrm{S}$, et al. Comparison of omadacycline and tigecycline pharmacokinetics in the plasma, epithelial lining fluid, and alveolar cells of healthy adult subjects. Antimicrob Agents Chemother. 2017;61(9):e01135-e1217.

95. Lakota EA, Van Wart SA, Trang M, Tzanis E, Bhavani SM, Safir MC, et al. Population pharmacokinetic analyses for omadacycline using phase 1 and 3 data. Antimicrob Agents Chemother. 2020;64(7):e02263-e2319.

96. Lepak AJ, Zhao M, Marchillo K, VanHecker J, Andes DR. In vivo pharmacodynamic evaluation of omadacycline (PTK 0796) against Streptococcus pneumoniae in the murine pneumonia model. Antimicrob Agents Chemother. 2017;61(5):e02368-e2416.

97. De Pascale G, Lisi L, Pia Ciotti GM, Vallecoccia MS, Cutuli SL, Cascarano L, et al. Pharmacokinetics of high-dose tigecycline in critically ill patients with severe infections. Ann Intensive Care. 2020;10(1):94.

98. Solomkin J, Evans D, Slepavicius A, Lee P, Marsh A, Tsai $\mathrm{L}$, et al. Assessing the efficacy and safety of eravacycline vs ertapenem in complicated intra-abdominal infections in the investigating gram-negative infections treated with eracycline (IGNITE 1) trial: a randomized clinical trial. JAMA Surg. 2017;152(3):224-32.

99. Solomkin JS, Gardovskis J, Lawrence K, Montravers P, Sway A, Evans D, et al. IGNITE4: results of a phase 3, randomized, multicenter, prospective trial of eravacycline vs meropenem in the treatment of complicated intraabdominal infections. Clin Infect Dis. 2019;69(6):921-9.

100. Connors KP, Housman ST, Pope JS, Russomanno J, Salerno E, Shore E, et al. Phase 1, open-label, safety and pharmacokinetic study to assess bronchopulmonary disposition of intravenous eravacycline in healthy men and women. Antimicrob Agents Chemother. 214;58(4):2113-8.

101. Zhou J, Ledesma KR, Chang K, Abodakpi H, Gao S, Tam VH. Pharmacokinetics and pharmacodynamics of minocycline against Acinetobacter baumannii in a neutropenic murine pneumonia model. Antimicrob Agents Chemother. 2017;61(5):e02371-e2416.

102. Winther L, Hansen SH, Baptiste KE, Friis C. Antimicrobial disposition in pulmonary epithelial lining fluid of horses, part II. Doxycyline. J Vet Pharmacol Ther. 2010;34:285-9.

103. Womble A, Giguere S, Lee EA. Pharmacokinetics of oral doxycycline and concentrations in body fluid and bronchoalveolar cells of foals. J Vet Pharmacol Ther. 2007;30:187-93.

104. Ruiz S, Concordet D, Lanot T, et al. Hydroxychloroquine lung pharmacokinetics in critically ill patients with COVID-19. Int J Antimicrob Agents. 2021;57(2):106247. 
105. Jermain B, Hanafin PO, Cao Y, et al. Development of a minimal physiologically-based pharmacokinetic model to simulate lung exposure in humans following oral administration of ivermectin for COVID-19 drug repurposing. J Pharm Sci. 2020;109:3564-8.

106. Caly L, Druce JF, Catton MG, et al. The FDA-approved drug ivermectin inhibits the replication of SARS-CoV-2 in vitro. Antiviral Res. 2020;178:104787.

107. Boisson M, Jacobs M, Gregoire N, et al. Comparison of intrapulmonary and systemic pharmacokinetics of colistin methanesulfonate (CMS) and colistin after aerosol delivery and intravenous administration of CMS in critically ill patients. Antimicrob Agents Chemother. 2014;58(12):7331-9.

108. Niederman MS, Alder J, Bassetti M, et al. Inhaled amikacin adjunctive to intravenous standard-of-care antibiotics in mechanically ventilated patients with Gram-negative pneumonia (INHALE): a double-blind, randomized, placebo-controlled, phase 3, superiority trial. Lancet Infect Dis. 2020;20(3):330-40.

109. Najmeddin F, Shahrami B, Azabakht S, et al. Evaluation of epithelial lining fluid concentration of amikacin in critically ill patients with ventilator-associated pneumonia. J Intensive Care Med. 2020;35(4):400-4.

110. Bosselli E, Breilh D, Djabarouti S, et al. Reliability of mini-bronchoalveolar lavage for the measurement of epithelial lining fluid concentrations of tobramycin in critically ill patients. Intensive Care Med. 2007;33(9):1519-23.

111. Tayman C, El-Attug MN, Adams E, et al. Quantification of amikacin in bronchial epithelial lining fluid in neonates. Antimicrob Agents Chemother. 2011;55(9):3990-3.

112. Cass R, Kostrub CF, Gotfried M, et al. A double-blind, randomized, placebo-controlled study to assess the safety, tolerability, plasma pharmacokinetics and lung penetration of intravenous plazomicin in healthy subjects [poster 1637]. Abstracts from the European Congress of Clinical Microbiology and Infectious Diseases, Berlin, Germany; 2013.

113. Funatsu Y, Hasegawa N, Fujiwara H, et al. Pharmacokinetics of arbekacin in bronchial epithelial lining fluid of healthy volunteers. J Infect Chemother. 2014;20(10):607-11.

114. File TM, Goldberg L, Das A, et al. Efficacy and Safety of intravenous-to-oral lefamulin, a pleuromutilin antibiotic, for the treatment of community-acquired bacterial pneumonia: the phase III lefamulin evaluation against pneumonia (LEAP 1) Trial. Clin Infect Dis. 2019;69(11):1856-67.

115. Alexander E, Goldberg L, Das A, et al. Oral lefamulin vs moxifloxacin for early clinical response among adults with community-acquired bacterial pneumonia. JAMA. 2019;322(17):1661-71.

116. Wicha WW, Strickmann DB, Paukner S. Pharmacokinetics/pharmacodynamics of lefamulin in a neutropenic murine pneumonia model with Staphylococcus aureus and Streptococcus pneumoniae. J Antimicrob Chemother. 2019;74:11-8.

117. Zeitlinger M, Schwameis R, Burian A, et al. Simultaneous assessment of the pharmacokinetics of pleuromutilin, lefamulin, in plasma, soft tissues and pulmonary epithelial lining fluid. $\mathrm{J}$ Antimicrob Chemother. 2016;71:1022-6.

118. Zhang L, Wicha WW, Bhavnani SM, Rubino CM. Prediction of lefamulin epithelial lining fluid penetration after intravenous and oral administration using Phase 1 data and population pharmacokinetics methods. J Antimicrob Chemother. 2019;74:27-34.

119. Bhavnani SM, Zhang L, Hammel JP, et al. Pharmacokinetic/pharmacodynamic target attainment analyses to support intravenous and oral lefamulin dose selection for the treatment of patients with community-acquired bacterial pneumonia. J Antimicrob Chemother. 2019;74:35-41.

120. Tenero D, Bowers G, Rodvold KA, et al. Intrapulmonary pharmacokinetics of GSK2251052 in healthy volunteers. Antimicrob Agents Chemother. 2013;57(7):334-9.

121. Andes DR, Okusanya OO, Bulik CC, et al. Evaluation pharmacokinetics-pharmacodynamics of GSK2251052 against gramnegative bacilli using data from a neutropenic murine-pneumonia infection model, abstract A-1271. In: Proceedings of the 52nd Interscience Conference on Antimicrobial Agents and Chemotherapy, American Society for Microbiology, Washington, DC; 2012.

122. O’Dwyer K, Spivak AT, Ingraham K, et al. Bacterial resistance to leucyl-tRNA synthetase inhibitor GSK2251052 develops during treatment of complicated urinary tract infections. Antimicrob Agents Chemother. 2015;59(1):289-98.

123. Naderer OJ, Rodvold KA, Jones LS, et al. Penetration of GSK1322322 into epithelial lining fluid and alveolar macrophages as determined by bronchoalveolar lavage. Antimicrob Agents Chemother. 2014;58(1):419-23.

124. Matzi V, Lindenmann J, Porubsky C, et al. Extracellular concentrations of fosfomycin in lung tissue of septic patients. J Antimicrob Chemother. 2010;65(5):995-8.

125. Soraci AL, Perez DS, Martinez G, et al. Fosfomycin concentrations in epithelial lining fluid in weaning piglets. J Vet Pharmacol Therap. 2011;35:406-9.

126. Andes DR, Lepak AJ. In vivo infection models in the pre-clinical pharmacokinetic/pharmacodynamic evaluation of antimicrobial agents. Curr Opin Pharmacol. 2017;36:94-9.

127. Trang M, Dudley MN, Bhavnani SM. Use of Monte Carlo simulation and considerations for PK-PD targets to support antibacterial dose selection. Curr Opin Pharmacol. 2017;36:107-13.

128. Jorda A, Zeitlinger M. Preclinical pharmacokinetic/pharmacodynamic studies and clinical trials in the drug development process of EMA-approved antibacterial agents: a review. Clin Pharmacokinet. 2020;59:1071-84.

129. Bhavnani SM, Hammel JP. Clinical pharmacokinetic-pharmacodynamic analyses: a critical element for developing for antibacterial agents. Curr Opin Pharmacol. 2017;36:94-9. 